\title{
ANALYTICAL AND EXPERIMENTAL EVALUATION OF JOINING SILICON NITRIDE TO METAL AND SILICON CARBIDE TO METAL FOR ADVANCED HEAT ENGINE APPLICATIONS
}

S. Kang, J. H. Selverian, H. Kim D. O'Niel, and K. Kim

Date Published - April 1990

FINAL REPORT - PHASE I

Prepared by

GTE Laboratories Incorporated 40 Sylvan Road

Waltham, Massachusetts 02254

Subcontract No. 86X-SB047C

Prepared for the

U.S. Department of Energy

Assistant Secretary for Conservation and Renewable Energy

Office of Transportation Systems

Advanced Materials Development Program

EE 0400000

\author{
for \\ Oak Ridge National Laboratory \\ Oak Ridge, Tennessee 37831-6285 \\ operated by \\ MARTIN MARIETTA ENERGY SYSTEMS, INC. \\ for the \\ U.S. DEPARTMENT OF ENERGY \\ under contract DE-AC05-84OR21400
}




\section{Table of Contents}

ABSTRACT

1 INTRODUCTION

2 DESIGN AND ANALYSIS FOR CERAMIC-METAL JOINTS

2.1 IAILURE CRITERIA

Analysis of Brazc Rupture - $\beta$ Criterion

Analysis of Ceramic Fracture - $\gamma$ Criterion

2.2 CONSTITUTIVE MODELING OF JOINT MATERIALS 12

Strain Response of Joints 12

Basic Assumptions for Constitutive Equations 13

Physical Propertics for Joint Materials 14

Molybdenum.

PY6 Silicon Nitride 15

$\begin{array}{ll}2.3 \text { OPTIMIZATION OF JOINT GEOMETRY } & 16\end{array}$

Flat Joint 20

Parabolic Joint 22

Conical Joint $\quad 23$

Cylindrical Joint $\quad 26$

Selection of Joint Geometry 26

2.4 EFFECT OF INTERLAYER MATERIAL . 29

2.5 ANALYSIS OF FINAL BRAZE JOINT MODEL

3 JOINT MATERIAL DEVELOPMENT

3.1 INTRINSIC PROPERTIES OF JOINING MATERIALS 43

Structural Alloys $\quad 43$

$\begin{array}{ll}\text { Structural Ceramics } & 45\end{array}$

Braze Alloys $\quad 46$

3.2 COATING MATERIALS DEVELOPMENT $\quad 47$

Screcning of Candidate Coating Materials 49

Wetting Behavior $\quad 54$

Effect of Coatings on the Mechanical Properties of the
Ceramic

$\mathrm{Si}_{3} \mathrm{~N}_{4}$ System $\quad 56$

SiC System 60

Mechanical Strength and Microstructure 61

$\mathrm{Si}_{3} \mathrm{~N}_{4}$ System $\quad 62$

SiC System 63

Effects of Brazing Processes $\quad 64$

3.3 INTERLAYER MATERIALS DEVELOPMENT

Interlayer for $\mathrm{Si}_{3} \mathrm{~N}_{4}$ System $\quad 70$

Interlayer for SiC System $\quad 71$

3.4 BRAZING ALLOY DEVELOPMENT $\quad 72$

Experimental Alloys $\quad 72$

Commercial Alloys $\quad 74$

4 FINAL JOINT SELECTION

4.1 HIGH-TEMPERATURE STRENGTHS OF THE SYSTEMS

$\mathrm{Si}_{3} \mathrm{~N}_{4}$ System $\quad 77$

SiC System $\quad 78$

$\begin{array}{ll}4.2 \text { SYSTEMS COMPATIBILITY } & 81\end{array}$

$\begin{array}{ll}\text { 4.3 FINAL JOINT SYSTEMS } & 81\end{array}$

Matcrial System $\quad 81$

$\begin{array}{lr}\text { Joint Geometry } & 84\end{array}$ 


\section{Table of Contents}

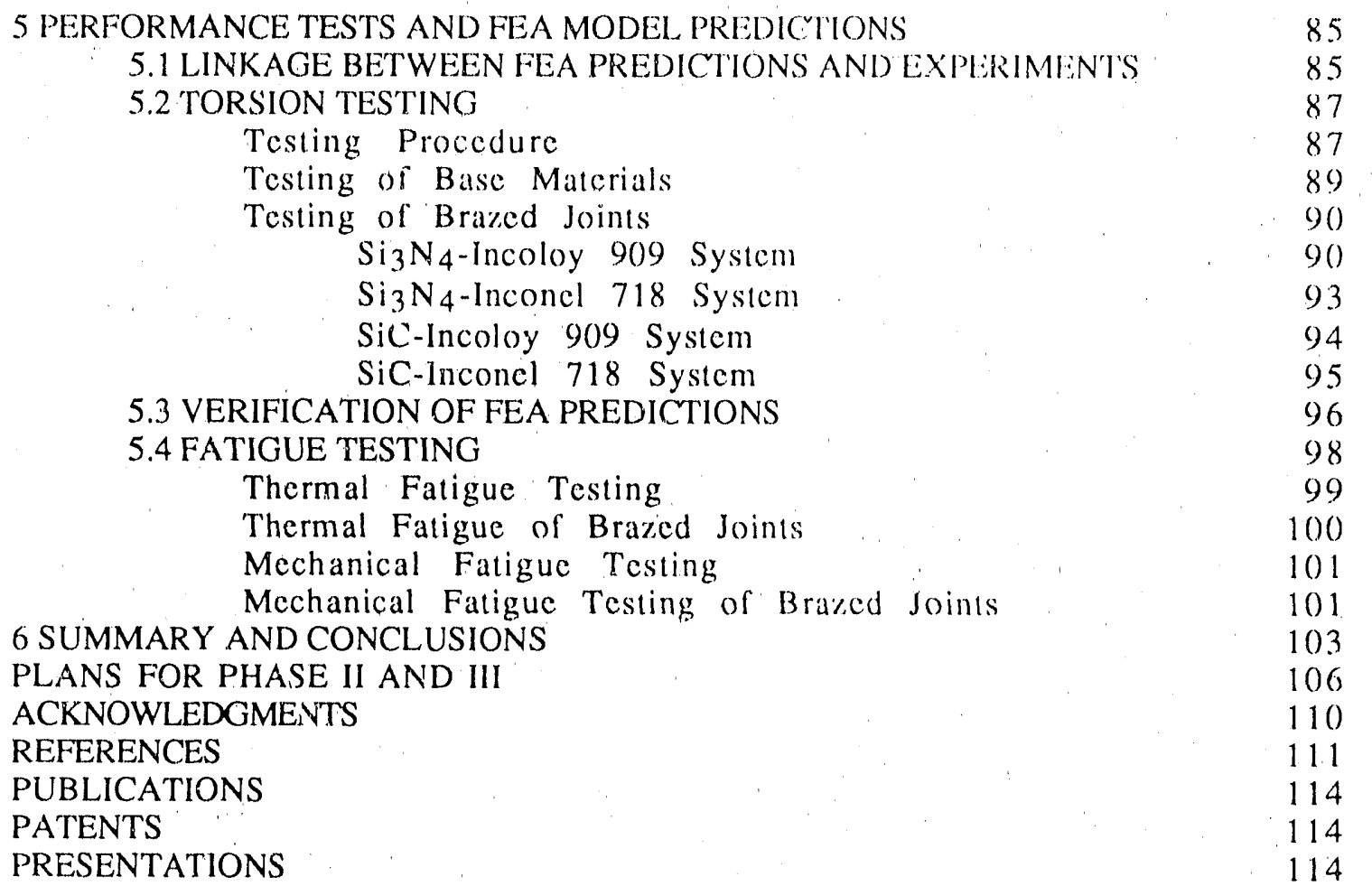




\section{List of Tables}

Table 2.1. Material properties for materials used in the joint. 14

Table 2.2. Material propertics for Mo. 15

Table 2.3. Material constants for the ABAQUS finite element model. 16

Table 2.4. Material properties of material system A. 17

Table 2.5. Temperature dependence of the elastic modulus, E(T'), strain hardening exponent, $\mathrm{n}$, and strength cocfficient, $\mathrm{f}(\mathrm{T})$. $\quad 30$

Table 3.1. Compositions of the structural alloys used in this study. 44

Table 3.2. Properties of the structural alloys used in this study. 44

Table 3.3. Compositions of the different ceramics used in this study. $\quad 46$

'Table 3.4. Properties of Hexaloy SA SiC and PY6 $\mathrm{Si}_{3} \mathrm{~N}_{4}$. 46

Table 3.5. Room-temperature properties of the braze alloys. 47

Table 3.6. Free-cnergy change for various reactions and $x$-ray diffraction results ovtained from heat-treated powder mixtures.

Table 3.7. Reactions considered in selection of coating materials for $\mathrm{SiC}$. 51

Table 3.8. $\mathrm{Si}_{3} \mathrm{~N}_{4}$ shcar coupon test data. $\quad 62$

Table 3.9. SiC shear coupon test results. 63

Table 3.10. The effect of processing parameters on bond strength of Mo-SNW 1000 joints.

Table 3.11. Effect of interlayer material and thickness on shear strength.

Table 3.12. Effect of interlayer material and thickness on shear strength.

Table 3.13. Alloys studied for the $650^{\circ} \mathrm{C}$ application. 73

Table 3.14. Alloys studied for the $950^{\circ} \mathrm{C}$ application. 74

Table 3.15. Composition and melting points of commercial brazc alloys.

Table 3.16. Mass spectroscopy results for brazc, coating, ccramic interactions at $1300^{\circ} \mathrm{C}$. $\quad 76$

Table 4.1. Results of hot shear tests. 78

Table 4.2. Shear tests with Au-34Pd-36Ni, Au-5Pd-2Ni, and Pd-40Ni brazes in the $\mathrm{Si}_{3} \mathrm{~N}_{4}$ system. 79

Table 4.3. Shear tests with Au-34Pd-36Ni and Au-5Pd-2Ni in the SiC system. 80

Table 4.4. Final material systems for the brazed joints. 82

Table 5.1. Torsional strength of the PY6 material. 89

Tabie 5.2. Torsional strength of Incoloy 909 and Inconel 718 matcrials. $\quad 89$

Table 5.3. Results of the room-tempcrature torsion tests of the $650{ }^{\circ} \mathrm{C} \mathrm{Si}_{3} \mathrm{~N}_{4}$ brazed joints. 90

Table 5.4. Results of the $650^{\circ} \mathrm{C}$ torsion tests of the $650^{\circ} \mathrm{C} \mathrm{Si} \mathrm{SN}_{4}$ brazed joints. $\quad 92$

Table 5.5. Results of the room-temperature torsion tests of the $950{ }^{\circ} \mathrm{C} \mathrm{Si}{ }_{3} \mathrm{~N}_{4}$ brazcd joints. 93

Table 5.6. Results of the $9500^{\circ} \mathrm{C}$ torsion tests of the $9500^{\circ} \mathrm{C} \mathrm{Si}{ }_{3} \mathrm{~N}_{4}$ brazed joints. 


\section{List of Tables}

Page.

Table 5.7. Results of the room-temperature torsion tests of the $650^{\circ} \mathrm{C} \mathrm{SiC} \mathrm{brazed} \mathrm{joints.}$

Table 5.8. Results of the $650^{\circ} \mathrm{C}$ torsion tests of the $650^{\circ} \mathrm{C}$ SiC brazed joints.

Table 5.9. Comparison between FEA predictions and experimental joint strengths.

Table 5.10. Comparison between FEA predictions and cxperimental joint failure strains. At $20^{\circ} \mathrm{C}$ the constant $\mathrm{k}$ in Equation 2.24 was 13,694 in-lbs/rad.

Table 5.11. Room-temperature fatigue tests of the $\mathrm{Si}_{3} \mathrm{~N}_{4}$ brazed joints. 


\section{List of Figures}

Page

Figure 2.1. Slip line solution for direct shear. Cross-hatched regions are rigid bodies subjected to the direct shear loading. D indicates shear dead zones. The shaded region represents deformed bulk braze matcrial.

Figure 2.2. Position through the braze versus plastic shear strain for the model shown in Figure 2.1. $y=0$ is the center line, and $y=15$ is the outer surface.

Figure 2.3. Joint geometries investigated for the optimization study.

Figure 2.4. Meshes used in FEA of ceramic-metal joints. (a) Flat joint, (b) Parabolic joint - small convex ceramic, (c) Parabolic joint - large convex ceramic, (d) Parabolic joint - small concave ceramic, (c) Parabolic joint large concave ceramic.

Figure 2.5. Fine meshes used in FEA of ceramic-metal joints. (a) Flat butt joint, (b) Thick conical joint, (c) Thin conical joint, (d) Square ended cylindrical joint, and (c) Tapered cylindrical joint.

Figure 2.6. $\sigma_{y}$ versus $y$ at the ceramic surface for different butt joints. (a-top) $\diamond$ and + are convex ceramics, $x$ and $\Delta$ are concave ceramics, and $\square$ is a flat joint. (b-bottom) Enlarged figure of part a. $\sigma_{y}$ is the residual stress along the $y$-axis.

Figure $2.7 \quad \sigma_{y}$ versus, $y$ for the flat butt joint at various temperatures during cooling of the braze joint.

Figurc 2.8. $\sigma$ y versus $y$ for the conical joints at various temperatures during cooling of the braze joint. (a-top) Thick wall, $(a / b)=0.5$. (b-bottom) Thin wall, $(a / b)=$ 0.8 .

Figure 2.9. $\sigma_{y}$ versus $y$ for the cylindrical joints at various temperatures during cooling of the brazed joint. (atop) Square-cnded joint, (b-bottom) Tapered joint.

Figure 2.10. (a-top) $\sigma_{y}$ versus $y$ for several joints at $x=6.951 \mathrm{~mm}$. (b-bottom) Close-up of (a). $\diamond$ and + are for cylindrical joints with tapered and squared ends, respectively, while $\Delta$ and $\square$ are for conical and flat joints.

Figure 2.11. Finite element mesh used for interlayer study.

Figure 2.12. Contours of maximum principal stress in ceramic-metal brazing joint with $\mathrm{Ni}$ as the interlayer:

Figure 2.13. Contours of maximum principal stress in ceramic-metal brazing joint with Mo as the interlayer.

Figure 2.14. Contours of Mises equivalent stress in ccramic-metal braze joint with $\mathrm{Ni}$ as the interlayer.

Figure 2.15. Contours of Mises equivalent stress in ceramic-metal braze joint with Mo as the interlayer.

Figure 2.16. The FEA mesh, used for detailed thermal X-Y-Z coordinate system shown, maps to r-z-q of the cylindrical coordinate system used in the analysis. 


\section{List of Figures}

Page

Figure 2.17. (a-right) Mesh at $1180^{\circ} \mathrm{C}$ shows the initial condition without residual stress. (b-left) Mesh at $20^{\circ} \mathrm{C}$ demonstrates the deformation associated with residual stress.

Figure 2.18. Contour plot of maximum principal stress $\left(\sigma_{1}\right.$ in Pa) at $20^{\circ} \mathrm{C}$ in the vicinity of the joint.

Figure 2.19. Contour plot of von Mises stress (Pa) at $20^{\circ} \mathrm{C}$ in the vicinity of the joint.

Figure 2.20. (a-right) Mcsh at $1180^{\circ} \mathrm{C}$. (b-left) At $650^{\circ} \mathrm{C}$ after reheating from $20^{\circ} \mathrm{C}$.

Figure 2.21. Contour plot of maximum principal stress $\left(\sigma_{1}\right.$ in $\left.\mathrm{Pa}\right)$ at $650^{\circ} \mathrm{C}$ in the vicinity of the joint.

Figure 2.22. Contour plot of von Mises stress (Pa) at $650^{\circ} \mathrm{C}$ in the vicinity of the joint.

Figure 3.1. Generalized matcrials system.

Figure 3.2. Coefficient of thermal expansion (CTE) of Incoloy 909 and Inconel 718 as a function of temperature.

Figure 3.3. TEM image of the interface in a brazed joint between Au-18Ni brazc and $\mathrm{Ti}$ coated $\mathrm{Si}_{3} \mathrm{~N}_{4}$.

Figure 3.4. TEM image of the interface in a brazed joint between Au-18Ni brazc and Ti coated SiC.

Figure 3.5. Wetting of Au-18Ni braze on $\mathrm{Ti}, \mathrm{Zr}, \mathrm{Hf}$, and $\mathrm{Ta}$ coated SNW 1000.

Figure 3.6. Wetting of Au-18 Ni braze on $\mathrm{Ti}, \mathrm{Zr}$, Hf, and Ta coated SiC.

Figure 3.7. Procedure to evaluate the effect of coating on the mechanical propertics of ceramic materials.

Figure 3.8. Effects of $\mathrm{Ti}, \mathrm{Zr}, \mathrm{Hr}$, and $\mathrm{Ta}$ coatings on the MOR strength of SNW1000.

Figure 3.9. Effects of Ti-Ni coating on the MOR strength of SNW1000.

Figure 3.10. Effects of Ni coating on the MOR strength of SNW1000.

Figure 3.11. SEM micrographs of (a) Ni coated and (b) Ti coatcd MOR bars, after heat-treatment.

Figure 3.12. Effects of $\mathrm{Ti}, \mathrm{Zr}, \mathrm{Hf}$, and $\mathrm{Ta}$ coatings on the MOR strength of AY6.

Figure 3.13. Effects of Ti coatings on the MOR strength of PY6.

Figure 3.14. Effects of $\mathrm{Ti}, \mathrm{Zr}, \mathrm{Hf}$, and $\mathrm{Ta}$ coatings on the MOR strength of Hexaloy SA SiC.

Figure 3.15. Schematic of the shear test samples.

Figure 3.16. Microprobe result showing the extent of Mo diffusion in the SNW100()-Zr-(Au-18Ni)-Mo-Incoloy 909 system.

Figure 3.17. Backscattered clectron image (BSE) and $x$-ray maps of a brazed joint between Ti coated SNW1000 and Mo. Sample was vacuum brazed with the $\mathrm{Au}-18 \mathrm{Ni}$ alloy for 10 minutes at $980^{\circ} \mathrm{C}$.

Figure 3.18. Backscatlered electron image (BSE) and $x$-ray maps of a brazed joint between $\mathrm{Zr}$ cuated SNW1000 and Mo. Sample was vacuum brazed with the $\mathrm{Au}-18 \mathrm{Ni}$ alloy for 10 minutes at $980^{\circ} \mathrm{C}$. 


\section{List of Figures}

Page

Figure 3.19. Schematic of the shear test samples containing an interlayer.

Figure 3.20. Wetting angle of $950^{\circ} \mathrm{C}$ brazes (Palni and Palniro 1, 4, and 7) on Ti coated PY6.

Figure 4.1. SEM micrograph of a brazed joint between Inconel 718 and $\mathrm{Ti}$ coated PY6 $\mathrm{Si}_{3} \mathrm{~N}_{4}$ with a $\mathrm{Ni}$ interlayer and the Au$5 \mathrm{Pd}-2 \mathrm{Ni}$ braze.

Figure 4.2. SEM micrograph of a brazed joint between Inconel 718 and $\mathrm{Ti}$ coated PY6 with a Mo interlayer and 30Au-34Pd$36 \mathrm{Ni}$ braze. The top part of the PY6 was removed. Note

Figure 4.3. Details of metal-ceramic joint geometry.

Figure 5.1. Brazed joint from the $650^{\circ} \mathrm{C} \mathrm{Si}_{3} \mathrm{~N}_{4}$ system, Incoloy 909. (Au-5Pd-2Ni)-Ni-Ti-PY6

Figure 5.2. Fracture surface of the $650^{\circ} \mathrm{C} \mathrm{Si}_{3} \mathrm{~N}_{4}$ system fractured in a room-temperature torsion test.

Figure 5.3. Schematic of the fracture path for the $650^{\circ} \mathrm{C} \mathrm{Si} \mathrm{N}_{4}$ brazed joints tested at $650^{\circ} \mathrm{C}$. Crack passed through all 3 regions at the interface

Figure 5.4. Fracture surface of the $950^{\circ} \mathrm{C} \mathrm{Si}_{3} \mathrm{~N}_{4}$ system fractured in a room-temperature torsion test.

Figure 5.5. Fracture surface of the $650^{\circ} \mathrm{C} \mathrm{SiC} \mathrm{system} \mathrm{fractured} \mathrm{in} \mathrm{a}$ room-temperature torsion test.

Figure 5.6. Thermal cycle used in thermal fatigue tests of brazed joints for a $650^{\circ} \mathrm{C}$ use temperature.

Figure 5.7. Thermal cycle used in thermal fatigue tests of brazed joints for a $950^{\circ} \mathrm{C}$ use temperature.

Figure 5.8. Microfocus $x$-ray image of $650^{\circ} \mathrm{C}$ SiC brazed joint immediately after brazing. Lateral cracks extend from the ceramic-metal interface into the SiC. Structural alloy (1). Lateral cracks (2). Uncracked SiC (3). Taken at $90 \mathrm{kV}, 0.35 \mathrm{~mA}$.

Figure 5.9. Mechanical cycle used for fatigue testing the brazed joints. 


\title{
ANALYTICAL AND EXPERIMENTAL EVALUATION OF JOINING SILICON NITRIDE, TO METAL AIND SILICON CARBIDE 'TO METAL FOR ADVANCED HEA'T ENGINE APPLICA'TIONS'
}

\author{
S. Kang, J.H. Sclverian, H. Kim, D. O'Neil, and K. Kim
}

\begin{abstract}
This report summarizes the results of Phase $I$ of Analytical and Experimental Evaluation of Joining Silicon Nitride to Metal and Silicon Carbide to Metal for Advanced Heat Engine Applications ${ }^{\dagger}$. A general methodology was developed to optimize the joint geometry and material systems for 650 and 95()$^{\circ} \mathrm{C}$ applications. Failure criteria were derived to predict the fracture of the braze and ceramic. Extensive finite element analyses (FEA), using ABAQUS code, were performed to examine various joint geometries and to evaluate the affect of different interlayers on the residual stress state. Also, material systems composed of coating materials, interlaycrs, and brazc alloys were developed for the program based on the chemical stability and strength of the joints during processing and service. Finally, the FEA results were compared with experiments using an idealized strength relationship. The results showed that the measured strength of the joint reached $30-90 \%$ of the strength predicted by FEA. Overall results demonstrated that FEA is an effective tool for designing the geometrics of ceramic-metal joints and that joining by brazing is a relevant method for advanced heat engine applications.
\end{abstract}

$\dagger$ Research sponsored by the U.S. Department of Encrgy, Assistant Secretary for Conservation and Renewable Encrgy, Office of Transportation Systems, as part of the Ceramic Technology for Advaried Heat Engines Project of the Advanced Materials Development Program under contract DE-AC(05-840R21400) with Martin Marictta Energy Systems, Inc., Work Breakdown Structure Subelement 1.4.1.2. 


\section{INTRODUCTION}

In order to broaden the application area of advanced ceramic materials, it is necessary to have the technology 10 join ceramic and metallic components: The current ceramic heat engine program is an example of this type of effort. Perfection in ccramic forming and perfection in the production of reliable ccramic components are two of the key issucs in the development of advanced heat engines. An additional key issue which will surface in the later stages of the engine development is the problem of joining a ceramic rotor to a metal shaft to transmit power. Besides the applicalions in advanced heat cngines, which impose the most severe environments on ceramic-metal joints, there are many other application arcas, such as culting tools, electronic devices, and light bulbs, which require ceramic-metal joining technology.

The major problem in joining two dissimilar matcrials is the thermal mismatch, which causes a significant residual stress at the interface. !oining methods using a mechanical fit, diffusion bonding, glass frit scaling, or brazing generatc complicated stress states in the ceramic parts, leading 10 catastrophic failure of the ceramic during processing or service. There were many studies to quantify the residual stress associated with joining dissimilamaterials using finite element analysis (FEA). However, the studies reported were most often limited to two dimensions and clastic deformations. Also, no methodology to design the joint geometry using FEA has been reported.

In this program, brazing was chosen to join $\mathrm{Si}_{3} \mathrm{~N}_{4}$ or $\mathrm{SiC}$ 10) structural alloys since this method provides supcrb tolerance for processing and excellent capability in stress accommodation. Brazed joints also perform well when subjected to dynamic motion with high loads. In order to handle the plastic deformation occurring in the joint, a general-purpose finite element program, ABAQUS, was used to guide the design of the joint geometry. ABAQUS is especially well suited for solid mechanics problems involving large clastoplastic deformations in three dimensions.

A general methodology was developed for the systemalic and comprehensive study of ceramic-metal joints. The goal of Phase I of this work was to demonstrate analytical tools for use in designing ccramic-melal joints. This required the expression of the stress response of joints as a function of the mechanical and mysical propertics of the ceramic, metal, and other matcrials used in the joint. Various constitutive equations were derived for the joint materials as a function of temperature. Several joint geometries and interlayer materials were serecned using the constitutive equations with llie FEA technique.

The application temperatures of interest for $\mathrm{Si}_{3} \mathrm{~N}_{4}$ to metal and $\mathrm{SiC}$ 10 metal joints were 650 and $950^{\circ} \mathrm{C}$. Significant efforts were made 10 develop material systems which could perform at these temperatures. The efforts in material systems development were divided into three parts: (1) coating materials development, (2) interlayer development, and (3) brazing alloy development. Based on the screcning study of coating matcrials, interlayer materials, and brazc alloys, promising materials were lested as systems in terms of high-temperature performance and chemical stability during 
processing and service. The final screening was done using the final joint geometry suggested by the FEA study.

Performance tests of the brazed joints were done with the final geometry and material systems using room-temperature and $650^{\circ} \mathrm{C}$ lorsion tests. These testing results were compared to the FEA predictions of the residual stress. Attempts were made to link the experimental results with the FEA predictions based on several simplifying assumptions. Thermal and mechanical fatigue testing was also done with the final joint systems. 


\section{DESIGN AND ANALYSIS FOR CERAMIC-METAL JOINTS}

\subsection{FAILURE CRITERIA}

The deformation mechanics for the brazing process of dissimilar materials is complex. It is a temperature dependent process; the braze alloy changes its state from liquid to solid at the beginning of the process, and experiences severe plastic deformation during the subsequent cooling stage.

Ceramics are brittle materials in comparison to metals. In addition, metals and ceramics have quite different thermal expansion cocfficients. The differences in mechanical and thermal properties of these materials result in large thermal mismatch strains and, consequently, thermal residual stresses. In most cases, flaws in the ceramic near the interface and flaws in the braze due to imperfect bonding are believed to determine the strength of the joint.

Thermal stresses arising in ceramic-metal joints cause residual stress weakening of the joint structure. The thermal stresses are' in equilibrium along the joining area; therefore, the global stress state decays exponentially away from the joint (St. Venant's principle). Fracture occurs within the distance of the characteristic dimension of the joint.

To date, investigations have not treated filler materials or special layers between two materials. In practice, there is a filler material for a brazc joint. For this study, the influence of the filler material was considered. If the strength of the joint is bound by the flow stress of the filler matcrial, the global tensile strength of various butt joints can be analyzed by using bound theorems ${ }^{1}$. Shear failure of a ductile interface filler material can be understood with the aid of Green's slip line solution of direct shear2. Therefore, the slip line solution was recxamined and compared with results from finite element analyses.

The most important part of the failure analysis and strength prediction of the braze joint is that of ceramic component failure. The strength of a ceramic is very sensitive to the distribution, orientations, and locations of initial flaws. Therefore, deterministic analysis of the ccramic's strength seems unrealistic.

In this study, four different approaches of predicting joint strength were investigated. The first was the application of the maximum principal stress criteria. This may be the most primitive and inaccurate approach. The second was the crack growth criteria for a particular mechanism of crack growth. However, there is great uncertainty concerning which crack growth mechanism to use. The third was the application of the J-integral near the edge of the braze. Lastly, a probabilistic fracture mechanics approach" can be applied to the joint problem. However, there is difficulty in the probabilistic approach in that it is difficult to select an acceptable uncertainty level. In this report, the second and third approaches, were used to make a strength criteria for ceramic failure.

\section{Analysis of Braze Rupture - $\beta$ Criterion}

In the ceramic-metal joint, fracture of the braze alloy is one of the limiting factors to joint strength. Therefore, the mechanical propertics of the braze have to be fully exploited by using a strength critcrion of the joint in 
the neighborhood of the braze. A simple $\beta$ criterion was derived to determine the critical area and thickness of the braze joint for a butt joint geometry. This critcrion has been established considering the state of strain in the braze during the thermal cycle of the brazing process and during loading. The strain components (z-direction is the thickness direction of the braze) can be approximated by

$$
\begin{gathered}
\gamma_{\mathrm{zr}}=\left[\left(\alpha_{\mathrm{m}}-\alpha_{\mathrm{c}}\right)\left(\mathrm{T}_{\mathrm{S}}-\mathrm{T}\right)-\varepsilon^{\mathrm{EA}}\right]\left(\frac{\mathrm{r}}{\mathrm{t}}\right) \\
\varepsilon_{\mathrm{rr}} \cong \varepsilon_{\theta \theta} \cong-\frac{\varepsilon_{\mathrm{zz}}}{2} \cong\left(\frac{\alpha_{\mathrm{m}}+\alpha_{\mathrm{c}}}{2}-\alpha_{\mathrm{b}}\right)\left(\mathrm{T}_{\mathrm{S}}-\mathrm{T}\right)
\end{gathered}
$$

where $\alpha_{m}, \alpha_{b}$, and $\alpha_{c}$ are the thermal expansion coefficients of metal, braze, and ceramic. $T_{S}$ is the solidification temperature of the braze alloy, and $T$ is the operation temperature of the joint. ' $r$ ' is the distance from the centroid of the braze area, ' $t$ ' is the $t^{\text {: }}{ }^{\prime}$ ness of the braze, and $\varepsilon E A$ is the elastic accommodation strain of the inctal and ceramic. $\varepsilon^{\mathrm{EA}}$ can be approximated by

$$
\varepsilon^{E A}=\frac{4 \tau_{y}^{B} J_{1}}{2 A r_{0}}\left(\frac{1-v_{m}}{E_{m}}+\frac{1-v_{c}}{E_{c}}\right)
$$

where $\tau_{y}^{B}$ is the shear yield stress of the braze, $J_{1}$ is the first polar moment of inertia of the braze area, $A, U$ is Poisson's ratio, and $r_{0}$ is the average radius of the braze area. The radius is measured from the centroid of the braze area. The subscript; $m, c$ and $b$ (or superscript $B$ ), indicate metal, ceramic and braze, respectively.

We can define a dimensionless number, $\beta$, which is an effective plastic strain normalized by the rupture strain, $\varepsilon_{\mathrm{e}}$ (ductility):

$$
\beta=\frac{T_{S}-T}{\sqrt{3} \varepsilon_{c}} \sqrt{\left(\alpha_{m}-\alpha_{c}-\frac{\varepsilon^{E A}}{T S}\right)^{2}\left(\frac{r}{t}\right)^{2}+3\left(\alpha_{m}+\alpha_{c}-2 \alpha_{b}\right)^{2}} \quad \text { Eq. } 2.4
$$

This equation indicates that when $\beta$ becomes unity, the braze will rupture. Therefore, if $r$ exceeds the critical value for which $\beta$ becomes unity, the braze arca beyond the critical valuc would behave as a crack. The total joint strength, in consequence, will be reduced for $r$ greater than this value. For cyclical thermal loading, this equation has to be modified to account for damage accumulation.

As an example, for a butt joint between Inconel 600 and $\mathrm{Si}_{3} \mathrm{~N}_{4}$ with a $0.004 "$ thick braze layer $(\mathrm{Ag}-28 \mathrm{Cu})$ and a $820^{\circ} \mathrm{C}$ brazing temperature, the 
mismatch strain between the metal and ceramic, $\left(\alpha_{\mathrm{m}}-\alpha_{\mathrm{c}}\right)\left(\mathrm{T}_{\mathrm{S}}-\mathrm{T}\right)$, is $0.8 \%$ and the elastic accommodation strain, $\varepsilon^{\mathrm{EA}}$, is $0.1 \%$. With $\varepsilon_{\mathfrak{c}}=0.5$ and $\beta=1$, the maximum braze diameter should not exceed $8 \mathrm{~mm}$. The size of the braze can be increased if a compressive stress is induced in the braze during the cooling process.

The $\beta$ criterion, Equation 2.4, was based on the braze surviving one brazing process thermal cycle. It was formulated assuming that the brazc deforms in simple uniform shear throughout the thickness. The magnitude of the shear strain was assumed to vary along the lateral direction of the brazc. However, if the braze terminates at the edge with a traction-free side surface, then the local deformation near the edge is under the condition of 'direct shear'. A study on the slip line field of direct shear in plain strain was reported previously ${ }^{2}$. The slip line solution is shown in Figure 2.1, and the actual simple shear yield zone is surrounded by rigid dead zones (D). The shear yield zone is approximately three-quarters of the total braze thickness.

FEA has shown that the shear strain is localized along the boundarics of the dead zones, while the central region undergoes moderate simple shear. Results of the FEA are shown in Figure 2.2. This analysis indicates that shear rupture of the braze is more likely than predicted by the $\beta$ criterion because of strain localization. Shear rupture along double localized layers has been observed experimentally. Another interesting feature of the finite element solution is that a normal stress concentration is induced near the edge of the braze by plastic deformation of the braze. However, the normal stress concentration is limited to a distance of approximately onc-third of the braze thickness. One-half of the normal stress at the edge is applied as a compressive stress to the metal component, and the other half is applied as a tensile stress to the ceramic component. 


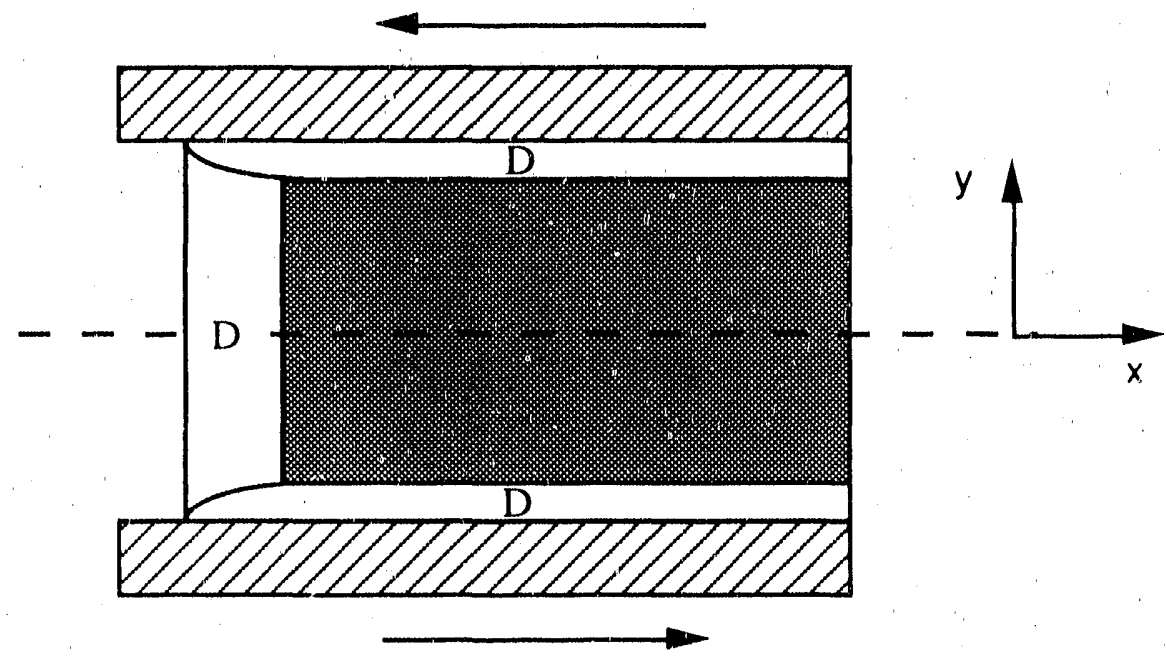

Figure 2.1. Slip line solution for direct shear. Cross-hatched regions are rigid bodies subjected to the direct shear loading. $D$ indicates shear dead zones. The shaded region represents deformed bulk braze matcrial.

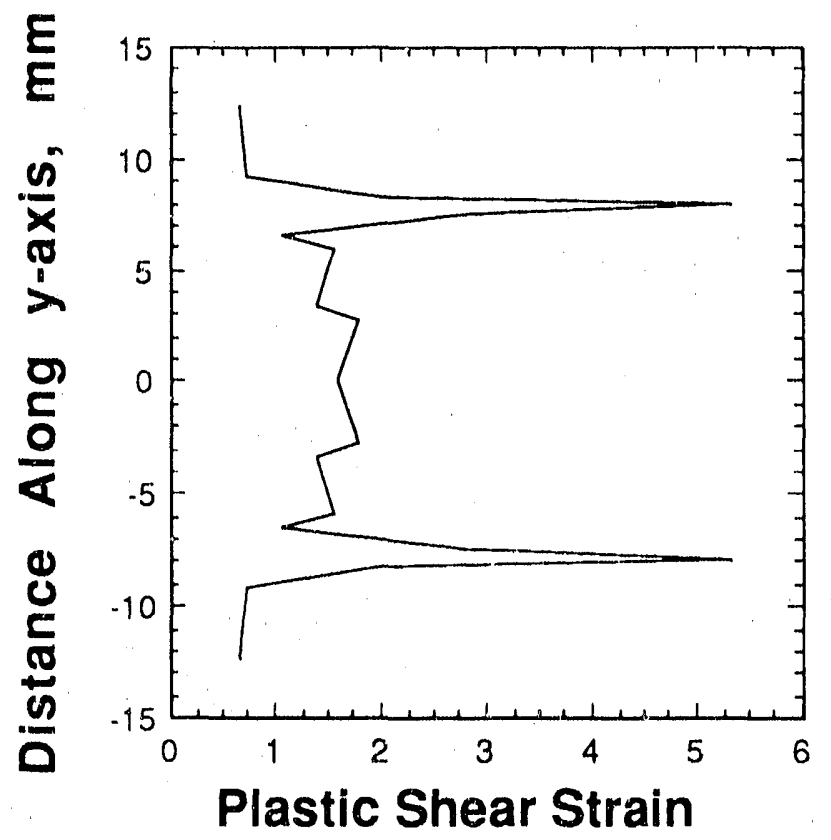

Figure 2.2. Position through the braze versus plastic shear strain for the model shown in Figure 2.1. $y=0$ is the center line, and $y=15$ is the outer surface. 


\section{Analysis of Ceramic Fracture - $y$ Criterion}

As mentioned previously, strength prediction of a coramic with insufficient information on the micro-flaw distribution is a difficult task. Four phenomenological failure criteria are used for ceramic fracture.

The first criterion is that of maximum principal stress. This is not an accurate criterion, because the crack growth mechanisms and the energy balance are not considered. Accurate estimation of maximum principal stress is impractical because preexisting flaws in the ceramic cause sharp stress concentrations. Therefore, this criteria has not been adapted here. However, for qualitative comparisons of stress states of different joint configurations, the distribution of maximum principal stress has been used.

The second criteria considered was a crack growth critcria with a particular choice of the most probable crack growth configurations. This assumes that a microcrack grows from the edge of the ceramic-brazc interface. The energy release rate, or crack driving force, decreases initially as the crack grows, then increases after the crack has grown beyond a critical length. The initial decrease in the stress intensity factor is due to the local nurmal stress concentration near the edge caused by plastic shear deformation of the braze. The subsequent increase in the stress intensity factor is caused by long-range, compared to the braze thickness, shear stresses. These longrange shear stresses are caused by the thermal mismatch strain between the ceramic and metal and are transferred from the metal to the ceramic by the braze. This changing stress intensity factor implies that the fracture toughness of the ceramic should be greater than the minimum stress intensity factor of the critical crack length and that all of the initial flaw sizes should be smaller than the critical length.

Therefore, the critcrion for safe brazing was derived as

$$
\gamma_{1}<\gamma_{\mathrm{t}}<1
$$

where

$$
\gamma_{1} \equiv \frac{\left.4 l \tau_{o g}^{2} g\right) f(\theta)}{K_{I C}^{2}}
$$

and

$$
\gamma_{t} \equiv \frac{41 \tau_{0}^{2} g(\theta)^{2}}{K_{I C}^{2}}
$$

where $\mathrm{K}_{\mathrm{IC}}$ is the ceramic fracture toughness, ' $t$ ' the braze thickness, $\tau_{0}$ is the braze yield stress, and $g(\theta)$ and $f(\theta)$ are crack-angle dependent geometric factors. 
Derivation of this result was obtained by examining the contribution of shear and normal point loading stresses to the stress intensity at the tip of the flaw:

$$
\begin{aligned}
& K_{i}^{p}=\left(\frac{P}{\sqrt{1}}\right) f_{i}(\theta), \quad \text { for point loading, and } \\
& K_{i}^{\tau}=\left(\tau_{0} \sqrt{1}\right) g_{i}(\theta), \text { for distributed shear } 2.8 \\
&
\end{aligned}
$$

where 1 is the crack length and $\mathrm{i}=\mathrm{I}$ or 11 , indicating the mode of the stress intensity factor. Then the total stress intensity factor can be written

$$
K_{i}=\frac{P}{\sqrt{1}} f_{i}(\theta)+\left(\tau_{0} \sqrt{1}\right) g_{i}(\theta)
$$

Provided that the crack initiates at a particular angle $\theta_{0}$, for which $\mathrm{K}_{I I}=0$ and $\mathrm{P}=\tau_{0} \mathrm{t} / 2$ for equilibrium, the total stress intensity factor becomes

$$
K_{I}=\tau_{0} \sqrt{1}\left(\sqrt{1 / 1} f\left(\theta_{0}\right)+\sqrt{1 / t} g\left(\theta_{0}\right)\right),
$$

where $f\left(\theta_{0}\right)=f_{l}\left(\theta_{0}\right) / 2$ and $g\left(\theta_{0}\right)=g_{l}\left(\theta_{0}\right)$.

For initial flaws, $\partial \mathrm{K}_{\mathrm{I}} / \partial \overline{\mathrm{I}} \leq 0$ prevents unstable crack growth and $\partial \mathrm{K}_{\mathrm{I}} / \partial \overline{\mathrm{I}}=$ 0 provides the minimum intensity factor, where $i=1 / t$. This condition gives

$$
i \leq \mathrm{f}\left(\theta_{0}\right) / \mathrm{g}\left(\theta_{0}\right)
$$

and

$$
\mathrm{K}_{\mathrm{I}}^{\mathrm{min}}=2 \tau_{0} \sqrt{\mathrm{tf}\left(\theta_{0}\right) \mathrm{g}\left(\theta_{0}\right)}
$$

The requirement that $\mathrm{K}_{\mathrm{I}}^{\mathrm{min}}<\mathrm{K}_{\mathrm{IC}}$ together with Equations 2.12 and 2.13 provide input for the criterion in Equation 2.5 .

This criterion can also be written in a dimensional form as

$$
\frac{\lg I}{f_{I}}<t<\frac{K_{I C}^{2}}{4 \tau_{0}^{2} g_{I} f_{I}}
$$


As shown in this incquality, an acceptablo braze thickness is bound by the flaw size and ceramic toughness. Therefore, if $\mathrm{K}_{\mathrm{Id}}^{2}\left(4 \tau_{0}^{2} g_{l} f_{l}\right)<\mathrm{g}_{\mathrm{I}} / \mathrm{f}_{\mathrm{l}}$, the brazing process will cause fracture of the ceramic componenl for any thickness. An asymptotic geometric function for $f_{l}(\theta)$ can be obtained in the closed form, using a conservation integral (M-integral), as

$$
\mathrm{f}_{\mathrm{I}}(\theta)=\cos \psi \sqrt{\frac{\sin ^{2} \phi}{\phi+\sin \phi}+\frac{\cos ^{2} \phi}{\phi-\cos \phi}-\frac{\sin ^{2} \theta}{\theta+\sin \theta}-\frac{\cos ^{2} \theta}{\theta-\cos \theta}} \quad \text { Eq. } 2.15
$$

where $\phi$ is the ceramic corner angle and $\tan \psi=K_{11}^{p} / K_{I}^{p}$. In general, $f_{1}(\theta)$ and $\mathrm{g}_{\mathrm{I}}(\theta)$ have to be determiried for finite geometry specimens, by FEA or other numerical methods, such as the boundary integral method. Closed form geometric functions for $f_{l}(\theta)$ and $g_{l}(\theta)$ are not known.

The above criterion is applicable if a failure begins from the edge of the interface. However, experiments show that in many cases failure starts from some distance away from the edge. As mentioned previously, tractions induced on the ceramic surface by a thermal strain mismatch are in equilibrium. Therefore, the global stress state decays exponentially with distance from the joint. If the structure is elastic cverywhere, then a stress singularity occurs at the interface edge for certain ranges of interface corner angles. If the interface is able to slide with flow stress $\tau_{0}$, the stress concentration near the interface is reduced and the peak stress is pushed away from the interface.

If the braze does not flow plastically, but flows by purcly clastic deformation, the stress concentration near the critical area, in $10 \mathrm{rms}$ of the principal shear stress, is approximatcly

$$
\tau \cong \frac{2 \mu_{1} \mu_{2}}{\mu_{1}+\mu_{2}}\left(\alpha_{1}-\alpha_{2}\right) \Delta \mathrm{T}\left(\frac{\mathrm{L}}{\mathrm{r}}\right)^{\mathrm{m}} \mathrm{F}^{*}\left(\alpha^{*}, \beta^{*}\right), \quad \operatorname{Rc}(\mathrm{m})>0, \quad \text { Eq. } 2.16
$$

where $\mu_{1}, \mu_{2}$ and $\alpha_{1}, \alpha_{2}$ are the shear modulus and thermal expansion coefficient for material 1 and 2 , respectively, $F^{*}$ is a dimensionless function of Dundurs parameters ${ }^{3}\left(\alpha^{*}, \beta^{*}\right)$, and $L$ is a characteristic length for the brate interface. As $r$ approaches 0 , the stress concentration increases rapidly. This may cause the initiation of crack growth in the ceramic part.

If we introduce a braze layer that has the flow shear stress $\tau_{0}$, the Jintegral around the stress concentration area may be expressed as

$$
J=\tau_{0} L\left(\alpha_{1}-\alpha_{2}\right) \Delta T h^{*}\left(\alpha^{*}, \beta *, \text { geometry }\right),
$$


where $h^{*}$ is a function of sample geometry and material properties, is bounded by unity, and is calculated by numerical techniques.

The $J$ integral can be regarded as a measure of the strength of a stress concentration. Therefore, one design strategy is to keep $J$ as small as possible. That means $\tau_{0}, \mathrm{~L},\left(\alpha_{1}-\alpha_{2}\right), \Delta \mathrm{T}$, and $\mathrm{h}^{*}$ have to be small. Therefore, the following incquality should be valid to prevent cracking:

$$
\frac{K_{I C}^{2}\left(1-v^{2}\right)}{E J}>1
$$

or replacing $J$ with Equation 2.17:

$$
\frac{K_{1 C}^{2}\left(1-v^{2}\right)}{E \tau_{0} L\left(\alpha_{1}-\alpha_{2}\right) \Delta T}>h^{*}\left(\alpha^{*}, \beta^{*}, \text { geometry }\right)
$$

for $\gamma_{0} l \leq L\left(\alpha_{1}-\alpha_{2}\right) \Delta T \leq \gamma_{f} t$, where $\gamma_{0}=\tau_{0} / 2$, and $\gamma_{f}$ and $t$ are the shear failure strain and braze thickness, respectively. $\mathrm{K}_{I C}, v$, and $\mathrm{E}$ are toughness, Poisson's ratio, and Young's modulus of ceramic, respectively. In general, we must satisfy

$$
\frac{K_{I C}^{2}\left(1-v^{2}\right)}{E \tau_{0} L\left(\alpha_{1}-\alpha_{2}\right) \Delta T}>\frac{K_{I C}^{2}\left(1-v^{2}\right)}{E \tau_{0} \gamma_{f} l}>h^{*}\left(\alpha^{*}, \beta^{*}, \text { geometry }\right) \text { Eq. } 2.20
$$

To cnsure that the ceramic will not fracture upon cooling and in order to have a large effective torque transmitting area of the braze joint, the following is suggested based on the $\gamma$ criteria:

- $\gamma_{\mathrm{f}}$ and 1 should be optimized for the $\beta$ and $\gamma$ criteria.

- E and $\tau_{0}$ should be minimized.

- KIC should be maximized.

- $h^{*}(\alpha *, \beta *$, geometry $)$ should be minimized.

The major geometry variables are $(t / L)$, curvature, and shape factors. It is clear that numerical optimization schemes to reduce $h^{*}\left(\alpha^{*}, \beta^{*}\right.$, geometry) should be examined, and these are discussed in the following sections.

A fourth approach to ceramic failure involves the implementation of probabilistic fracture mechanics. The probability of failure of the ceramic component cvolves from the nonuniform distribution of flaws or siress concentrations, their size, and their orientation within the coramic structure. 
This approach has not beun studied in Phase 1 , but will be investigated in Phase II.

\subsection{CONSTITUTIVE MODELING OF JOINT MATERIALS}

In order to express the response of the joint as a function of inaterials properties and temperature, constitutive equations were devoloped for the joint materials with the assumptions discussed below. Based on these constitutive equations, various joint geometries and material systems were examined using FEA.

\section{Strain Besponse of Joints}

The rotational strain, $\gamma$, of a member loaded in torsion is given by:

$$
\gamma=\frac{\tau}{\mathrm{G}}
$$

and the shear stress, $\tau$, is given by:

$$
\tau=\frac{\mathrm{Tc}}{\mathrm{J}}
$$

Eq. 2,22

where $G$ is the shear modulus (a proportionality constant between $\tau$ and $\gamma$ ), $T$ is the torque, $c$ is the distance from the center of the member to the point of interest, and $\mathrm{J}$ is the polar moment of inertia, $1 / 2 \pi \mathrm{r}^{4}$. $c$ is usually set equal to the radius $r$.

The angle of twist of one end of the joint, with respect to the other end, $\phi$, is given in radians by:

$$
\phi=\frac{T L}{J G}=\frac{\gamma L}{c}
$$

where $L$ is the length of the member.

Once the failure stress of the joint, $\tau$, has been predicted by FEA the failure strain of the joint can also be predicted. The mechanical tests of the brazed joints resulted in linear plots of $\mathrm{T}$ versus $\phi$ :

$$
\mathrm{T}=\mathrm{k} \phi
$$

where $k$ is a constant of proportionality. Solving Equation 2.23 for $\mathrm{T}$ we get: 


$$
T=\frac{J G}{L} \frac{\gamma L}{c}
$$

Comparing Equation 2.24 and 2.25 we sec that:

$$
\mathrm{k}=\frac{\mathrm{JG}}{\mathrm{L}}
$$

Since the FEA predicts the failure stress of the joints, Equation 2.25 was rearranged into a relationship between failure stress, $\tau_{f}$, and failure strain, $\gamma_{f}$ :

$$
\gamma_{f}=\tau_{\mathrm{f}} \frac{\mathrm{J}}{\mathrm{kL}}
$$

\section{Basic Assumptions for Constitutixe Equations}

The materials used in the ceramic-metal braze joint are the following:

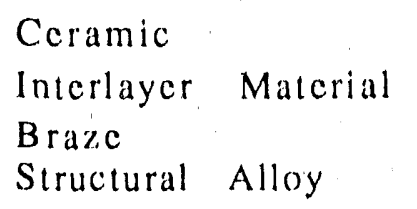

The uniaxial stress and strain relations of all the materials were considered to be temperature-dependent, but rate-independent, with power law hardening constitutive relations. Therefore, the stress can be described as follows:

in the clastic range

$$
\sigma=\mathrm{E}(\mathrm{T}) \varepsilon
$$

in the plastic range

$$
\sigma=\left\{(T) e^{n}\right.
$$

Mo (low $\alpha$ ) or $\mathrm{Ni}$ (low yicld stress, $\sigma_{y}$ ) Au- $18 \mathrm{Ni}$ or $\mathrm{Au}-5 \mathrm{Pd}-2 \mathrm{Ni}$ Incoloy 909

where $\sigma$ is true stress, $\varepsilon$ is true strain, $E(T)$ is Young's modulus as a function of temperature, $n$ is strain hardening cocfficient, and $f(T)$ is a strength coefficient as a function of temperature.

The assumptions made on the temperature dependence were

- Strain hardening coefficient, $\mathrm{n}$, is temperature independent. 
- Young's modulus, $\mathrm{E}(\mathrm{T})$, is a linear function of temperi ure.

$$
E(T)=E_{l} T+E_{0}
$$

- $f(T)$ is a linear function, or piccewise lincar function of temperature,

$$
f(T)=A T+B
$$

- Ultimate tensile strength and yicld strength are linear functions of temperature and are equal io zero at the melting iemperature.

The hardening coefficient ' $n$ ' can be calculated as

$$
n=\frac{\ln \left(\sigma_{\mathrm{TS}} / \sigma_{\mathrm{y}}\right)}{\ln \left(\varepsilon_{\mathrm{TS}} / \varepsilon_{\mathrm{o}}\right)}
$$

where $\sigma_{T S}$ and $\varepsilon_{T S}$ are ultimate strength and corresponding strain, and yicld strain, $\varepsilon_{0}$, equals $\sigma_{y} / E$.

\section{Physical Properties for Joint Materials.}

The properties of the structural alloys, $\mathrm{Ni}$, and the $\mathrm{Au}-18 \mathrm{Ni}$ braze are listed in Table 2.1. The properties of other joint materials were discussed

\begin{tabular}{|c|c|c|c|c|c|c|c|}
\hline Material & $\begin{array}{c}\mathrm{T} \\
\left({ }^{\circ} \mathrm{C}\right)\end{array}$ & $\begin{array}{c}\sigma_{y} \\
(\mathrm{MPa})\end{array}$ & $\begin{array}{c}E \\
(\mathrm{GPa})\end{array}$ & $\begin{array}{c}\sigma_{\mathrm{TS}} \\
(\mathrm{MPa})\end{array}$ & $\varepsilon_{\mathrm{f}}$ & $\begin{array}{c}\text { Poisson's } \\
\text { Ratio }\end{array}$ & $\begin{array}{c}\text { CIE } \\
\left(\times 10^{-6} /{ }^{\circ} \mathrm{C}\right)\end{array}$ \\
\hline Incoloy 909 & $\begin{array}{r}20 \\
650\end{array}$ & $\begin{array}{l}1034 \\
862\end{array}$ & $\begin{array}{l}158.585 \\
155.174\end{array}$ & $\begin{array}{l}1276 \\
1034\end{array}$ & $\begin{array}{l}0.15 \\
0.25\end{array}$ & & $\begin{array}{r}6.5 \\
10.0\end{array}$ \\
\hline Inconel 718 & 20 & 1033 & 179 & & & 0.27 & 14.1 \\
\hline $\mathrm{Ni}$ & $\begin{array}{r}20 \\
800\end{array}$ & $\begin{array}{c}58.607 .5 \\
26.43\end{array}$ & $\begin{array}{l}214 \\
173.46\end{array}$ & 400 & 0.65 & & $\begin{array}{l}13.4 \\
16.5\end{array}$ \\
\hline $\mathrm{Au}-18 \mathrm{Ni}$ & 20 & 582 & 38.98 & 715 & 0.048 & & 17.5 \\
\hline
\end{tabular}
separately.

Table 2.1. Matcrial properties for matcrials used in the joint. 
Molebdenum. The material data for Mo are listed in Table 2.2. Because of the strong nonlinearlty of the yicld stress whth respect to temperature, $\mathrm{C}(\mathrm{T})$ was taken as piecewise linear function of temperature in four different sections, The sections were from $20^{\circ} \mathrm{C}$ to $200^{\circ} \mathrm{C}$, from $200^{\circ} \mathrm{C}$ to $300^{\circ} \mathrm{C}$, from 30()$^{\circ} \mathrm{C}$ $10800^{\circ} \mathrm{C}$, and from $8(0)^{\circ} \mathrm{C}$ to $1000^{\circ} \mathrm{C}$. $\mathrm{f}(\mathrm{T})$ was expressed as the following:

$$
\begin{array}{ll}
f^{\prime}(T)=A_{1} T+B_{1} & \text { for } 20^{\circ} \mathrm{C} \geq T \geq 200^{\circ} \mathrm{C} \\
f^{\prime}(T)=A_{2} T+B_{2} & \text { for } 200^{\circ} \mathrm{C} \geq T \geq 300^{\circ} \mathrm{C} \\
f^{\prime}(T)=A_{3} T+B_{3} T & \text { for } 300^{\circ} \mathrm{C} \geq T \geq 800^{\circ} \mathrm{C} \\
f^{\prime}(T)=A_{4} T+B_{4} & \text { for } 800^{\circ} \mathrm{C} \geq T \geq 1000^{\circ} \mathrm{C}
\end{array}
$$

Table 2.2. Matcrial properties for Mo.

\begin{tabular}{r|rrrr}
\hline $\mathrm{T}\left({ }^{\circ} \mathrm{C}\right)$ & $\sigma_{y}(\mathrm{MPa})$ & $\mathrm{E}(\mathrm{GPa})$ & $\sigma_{\mathrm{TS}}(\mathrm{MPa})$ & $\varepsilon_{\Upsilon}$ \\
\hline \hline 20 & 560.60 & 328.17 & 665.00 & 0.01 \\
20() & 124.11 & 319.48 & & \\
300 & 206.85 & 309.68 & & \\
800 & 68.95 & 294.00 & & \\
1000 & 55.16 & 269.50 & & \\
\hline
\end{tabular}

EY6 Silicen Nitride. The ceramic was regarded as an clastic matcrial. Young's modulus as a function of temperature was obtained using general rules of temperature dependence. Unless there is a phase transformation in the temperature range of interest, the temperature dependent Young's modulus can be represented as

$$
E(T)=E^{*}\left(1-a \frac{T+273}{T_{m}+273}\right)
$$

where $E^{*}$ is the 'extrapolated' Young's modulus at absolute zero degrec Kolvin and $T_{m}$ is the melting temperature of the matcrial in degrees Celsius. The cmpirical constant "a" is 0.3 .3 for covalent bonding coramics and 0.47 for melals.

Table 2.3 lists Young's modulii and strength cocfficients as a function of temperature for the joint materials. For PY6 $\mathrm{Si}_{3} \mathrm{~N}_{4}$, the matcrial constants were derived using $\mathrm{T} m=190\left(0^{\circ} \mathrm{C}\right.$ and $\mathrm{E}=296.5 \mathrm{GPa}$ at $20^{\circ} \mathrm{C}$." The matcrial property data shown in the lable was expressed in a form suitable for the ABAQUS finite element program. These constitutive data were implemented 
with the ABAQUS finite clement program. $\mathrm{J}_{2}$ flow theory (Pranor-Reuss equations) with an isotrople hardening law was used. The matcrials were assumed to be rate-independent. Because of the heating process during manufacturing of the joint, it was assumed that the effect of heat generation due to plastic work on constitutive models was negligible.

Table 2.3. Material constants for the ABAQUS finite element model.

\begin{tabular}{|c|c|c|c|c|c|c|}
\hline Constant & $\begin{array}{c}\text { Incoloy } \\
909\end{array}$ & $\begin{array}{c}\mathrm{Ni} \\
\text { interlayer }\end{array}$ & $\begin{array}{c}\text { Mo } \\
\text { interlayer }\end{array}$ & $\begin{array}{c}\text { Au-18Ni } \\
\text { braze }\end{array}$ & $\begin{array}{c}A u-5 P d-2 N i \\
\text { braze }\end{array}$ & $\begin{array}{c}\mathrm{PY}_{6} \\
\mathrm{Si}_{3} \mathrm{~N}_{4}\end{array}$ \\
\hline $\begin{array}{l}\mathrm{E}_{\mathrm{t}}\left(\mathrm{GPa} /{ }^{\circ} \mathrm{C}\right) \\
\mathrm{E}_{0}(\mathrm{GPa}) \\
\mathrm{n} \\
\mathrm{A}_{1}\left(\mathrm{MPa} /{ }^{\circ} \mathrm{C}\right) \\
\mathrm{B}_{1}(\mathrm{MPa}) \\
\mathrm{A}_{2}\left(\mathrm{MPa} /{ }^{\circ} \mathrm{C}\right) \\
\mathrm{B}_{2}(\mathrm{MPa}) \\
\mathrm{A}_{3}\left(\mathrm{GPa} /{ }^{\circ} \mathrm{C}\right) \\
\mathrm{B}_{3}(\mathrm{MPa}) \\
\mathrm{A}_{4}\left(\mathrm{GPa} /{ }^{\circ} \mathrm{C}\right) \\
\mathrm{B}_{4}(\mathrm{MPa})\end{array}$ & $\begin{array}{c}-0.005415 \\
158.7 \\
0.0575 \\
0.3478 \\
1338.0\end{array}$ & $\begin{array}{c}-0.05197 \\
215.0 \\
0.235 \\
-0.2282 \\
391.0\end{array}$ & $\begin{array}{c}0.05987 \\
329.4 \\
0.099 \\
-4.333 \\
1137.0 \\
1.571 \\
238.5 \\
-0.5387 \\
588.7 \\
-0.1472 \\
277.5\end{array}$ & $\begin{array}{c}-0.02433 \\
56.68 \\
0.129 \\
-1.256 \\
1236.0\end{array}$ & $\begin{array}{c}-0.001008- \\
28.41 \\
0.1304 \\
-0.2093 \\
241.2\end{array}$ & $\begin{array}{l}0.04712 \\
297.4\end{array}$ \\
\hline
\end{tabular}

\subsection{OPTIMIZATION OF JOINT GEOMETRY}

Several studics have concentrated on elther measuring 4 or predicting $5-7$ the thermal stresses generated during cooling of the joint from the brazing temperature as a function of joint matcrials and geometry. The purpose of this study was to determine the optimum geometry of the braze layer to minimize the residual tensile stresses in the ceramic shaft. The initial geometry of the joint is shown in Figure 2.3a. The ccramic shaft had a diameter of $14 \mathrm{~mm}$. The metal shaft was either solid or hollow. The braze was $0.05 \mathrm{~mm}$ thick and had an area of $154 \mathrm{~mm}^{2}$. The length of each component was taken to be $30 \mathrm{~mm}$ to allow for interface effects to sufficiently decay.

The joining process was nerformed by heating the components until the braze melted, then cooling the joint $1020^{\circ} \mathrm{C}$. Relevant mechanical propertics of the matcrials used were described in the previous section. The coramic was assumed to be linearly clastic. Metal and braze materials were assumed to be elastic-perfectly plastic, and to obey a von Mises yicld condition.

Several joint geometries were studied; these are shown in Figure 2.3 and consist of flat, parabolic, conical, and cylindrical geometrics. Each of the joint geometries was investigated with material system A, shown in Table 2.4. 
Table 2.4. Material properties of material system A.

\begin{tabular}{lccc}
\hline Property & $\begin{array}{c}\text { Ceramic } \\
\text { (Sintered AY6) }\end{array}$ & $\begin{array}{c}\text { Braze } \\
\text { (Cusil ABA) }\end{array}$ & $\begin{array}{c}\text { Metal } \\
\text { (Inconcl 718) }\end{array}$ \\
\hline Young's Modulus (GPa) & 296 & 83 & 179 \\
Poisson's Ratio & 0.0 & 0.36 & 0.27 \\
Yicld Stress (MPa) & $\ldots .7$ & 271 & 1033 \\
CTE $\left(10^{-6} /{ }^{\circ} \mathrm{C}\right)$ & 3.7 & 18.5 & 14.1 \\
Brazing tcmpcrature $\left({ }^{\circ} \mathrm{C}\right)$ & $\ldots$ & 780 & $\ldots$ \\
\hline
\end{tabular}

Since the joints are axisymmetric, only half of the model is shown. The dimensions of the metal shaft and the braze were chosen so that the braze area was $154 \mathrm{~mm}^{2}$ and the limit torque of the metal shaft was not less than what the brazc layer could support.

The numerical analysis was done using ABAQUS with 8-node, parametric axisymmetric finite elements with reduced integration. Element 'CAx8R' was used for the ccramic, and the hybrid element 'CAx8RH' was used for the metal and brazc materials. 

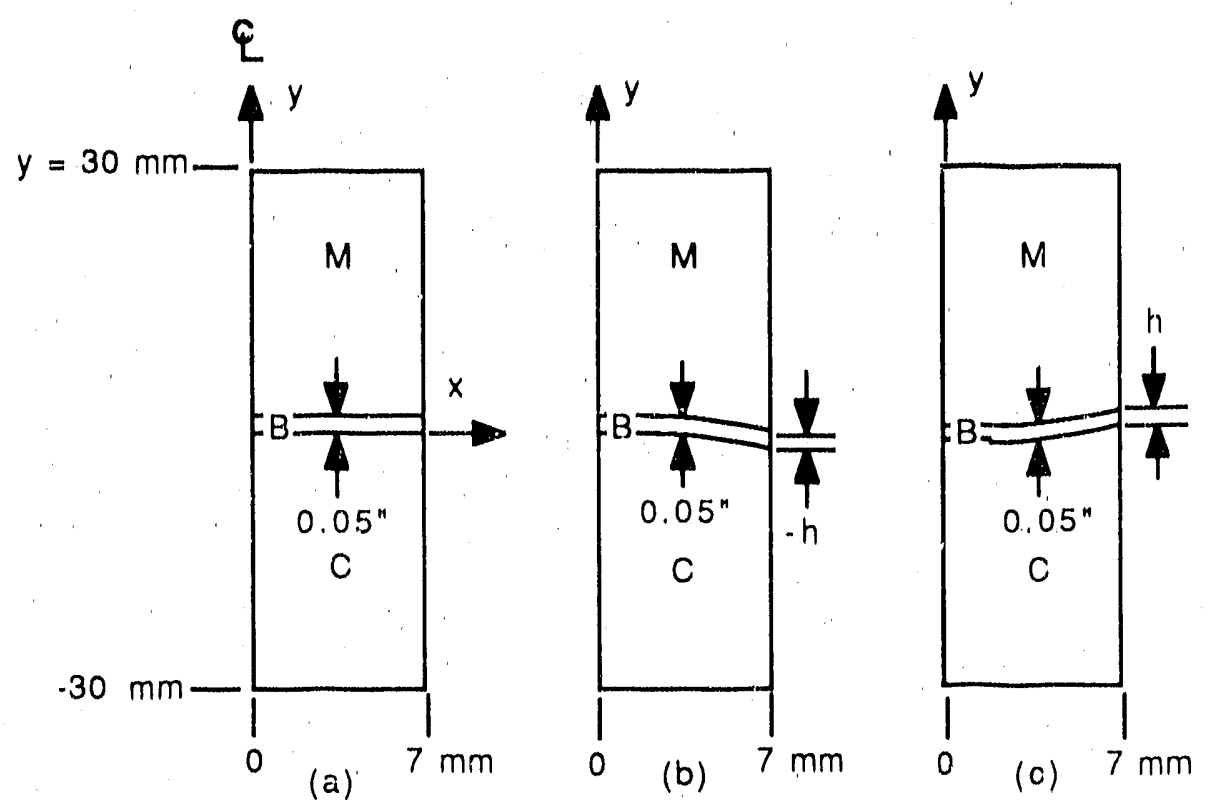

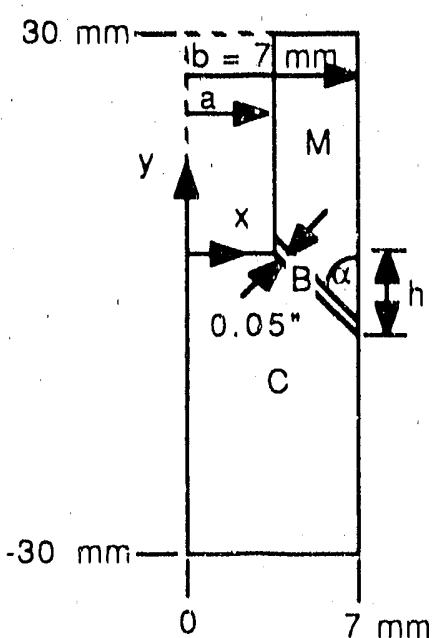

(d)

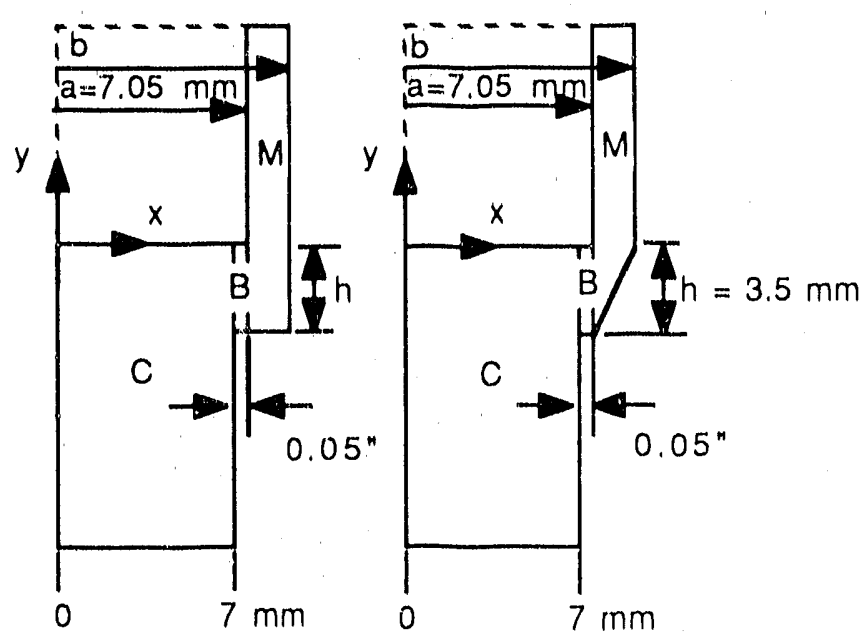

(e)

(f)

Figure 2.3. Joint geometries investigated for the optimization study. 
The fintic element modeling was performed to ensure that the differences in stress states among different models were due to their geometry differences and not to modeling differences. This implies that finite element modeling errors should be approximately the same for all models. An $\mathrm{h}$ convergence study was performed to ensure that acceptable results were generated by each of the finite element models used in this study. The analysis scheme was to start the analysis at the solidus temperature of the braze, then to cool the structure down slowly to $20^{\circ} \mathrm{C}$. Output from ABAQUS analyses consisted of element stresses and strains at integration points within the elements and the displacements at the nodes. Nodal stresses were also obtained, but were not as accurate as those at element integration points. Therefore, comparisons were done using integration point stresses. The results are presented for the critical tensile regions in the ceramic since the primary concern was the magnitude and location of tensile stresses in the ceramic.

A description of the models used for each of the joint geometries, followed by pertinent results from these analyses, will now be discussed. Schematics of each of the joint geometries are illustrated in Figures 2.3 a-c. In Figure 2.3 a-c, solid metals were joined to the ceramic by a butt joint, while hollow metals were joined to the edges of the ceramic in Figure 2.3 d-c. All parts are round and the points, $x=0$, denote the center of the bars. Figure 2.4 shows the finite element meshes used for flat and parabolic geometries in this analysis. Reiatively fine meshes were used for the joint area and the outer surface of the joint components, where maximum residual stresses were expected. For conical and cylindrical geometries, finer meshes were used, as shown in Figure 2.5. These fine meshes was also utilized for the flat butt joint geometry to study the effect of temperature on the the residual stress.
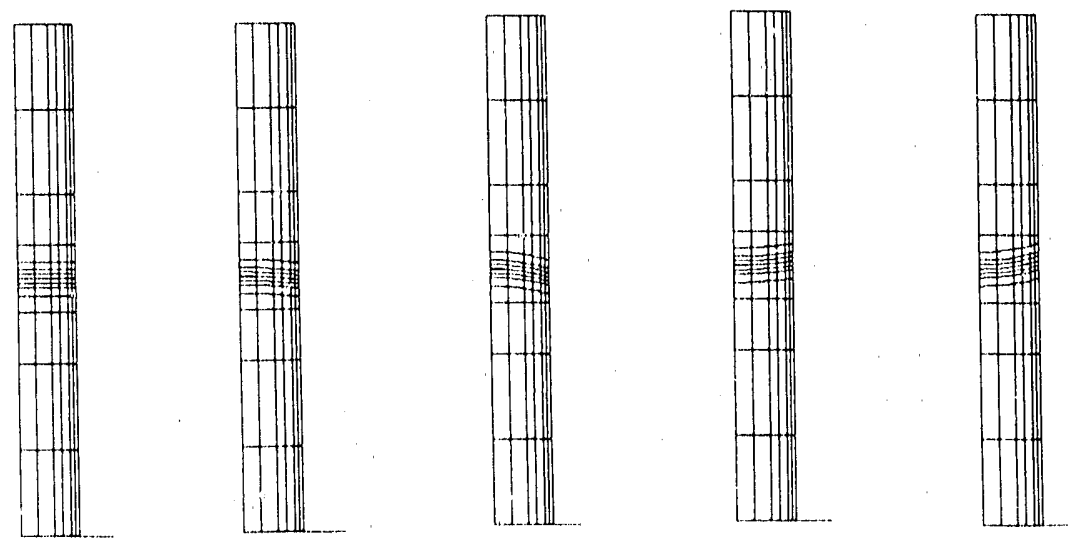

Figure 2.4 Meshes used in FEA of ceramic-metal joints. (a) Flat joint, (b) Parabolic joint - small convex ceramic, (c) Parabolic joint large convex ceramic, (d) Parabolic joint - small concave ccramic, (c) Parabolic joint - large concave ceramic. 

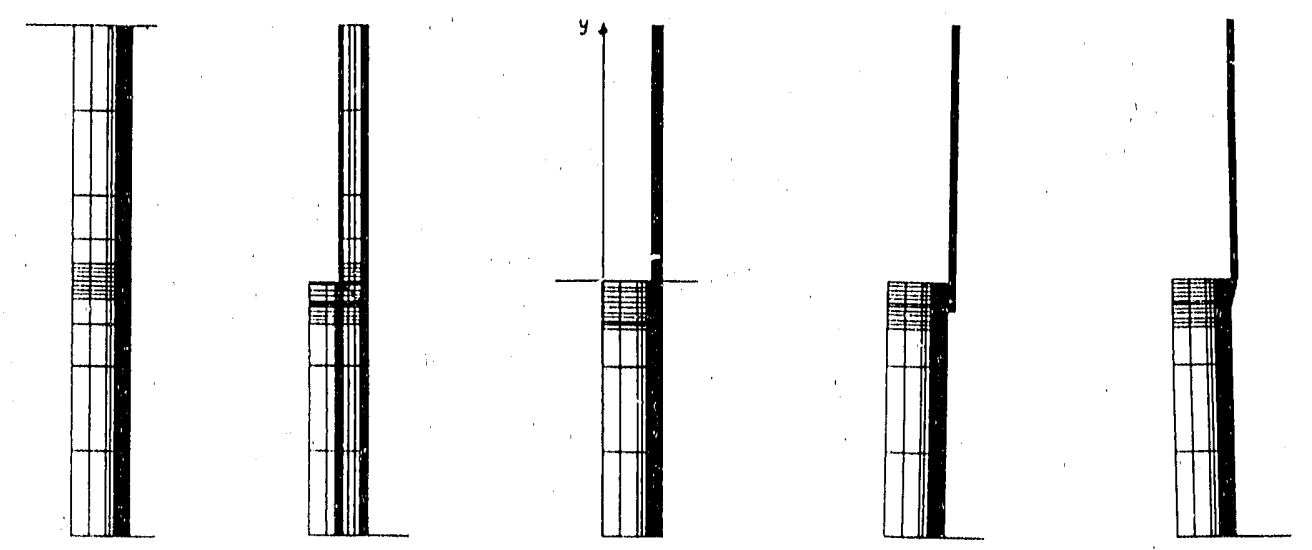

Figure 2.5. Fine meshes used in FEA of ceramic-metal joints. (a) Flat butt joint, (b) Thick conical joint, (c) Thin conical joint, (d) Square ended cylindrical joint, and (c) Tapered cylindrical joint.

Elat Joint. This is the simplest butt joint geometry. The braze had an area of $154 \mathrm{~mm}^{2}$ and a thickness of $0.05 \mathrm{~mm}$. Figure 2.6 is a plot of $\sigma_{y}$ versus $y$ position at $x \approx 7$, i.e., the outer edge of the ceramic at $20^{\circ} \mathrm{C}$ for material system A. $\sigma_{y}$ denotes the residual stress "along the $y$-axis" and the edge of the ceramic part was at the left side of the $x$-axis, $x<0$. Large tensile stresses occur in the ceramic near the joint area, $y=0$. The maximum principal stress is nearly equal to $\sigma_{y}$, and hence $\sigma_{y}$ was used to represent the level of the residual stress. The results from various parabolic joints are shown in the same plot. Figure $2.6 \mathrm{~b}$ shows an enlarged view of Figure 2.6a. The peak stresses of all these geometries occurred in the ceramic some distance away from the joint. The flat butt joint had the lowest maximum residual stress compared to levels in the parabolic butt joints.

Figure 2.7 shows a plot of $\sigma_{y}$ versus $y$ position at $x \approx 7$ at different cooling stages using the fine mesh in Figure $2.5 \mathrm{a}$. These results show that $\sigma_{y}$ continues to increase until the temperature reached $400^{\circ} \mathrm{C}$, after which there was little reduction in $\sigma_{y}$. Jramatic changes in the residual stress occurred between 600 and $700^{\circ} \mathrm{C}$. Below $400^{\circ} \mathrm{C}$, large plastic strains in the braze relaxed some of the differential contraction and, therefore, did not increase the level of residual stress. 

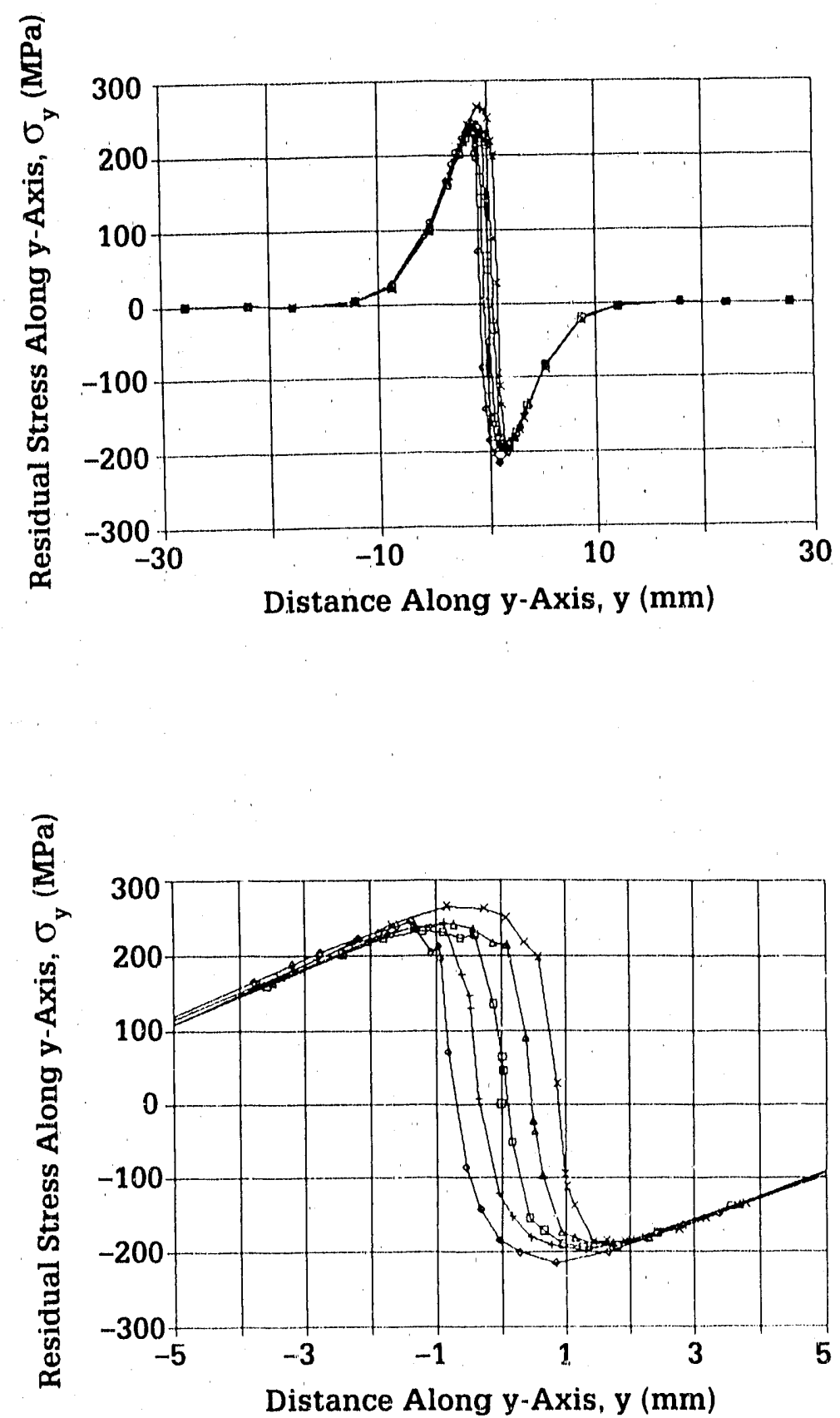

Figure 2.6. $\quad \sigma_{y}$ versus $y$ at the ceramic surface for different butt joints. (a-top) $\diamond$ and + are convex ceramics, $X$ and $\Delta$ are concave ceramics, and $\square$ is a flat joint. (b-bottom) Enlarged figure of part a. $\sigma_{y}$ is the residual stress along the y-axis. 


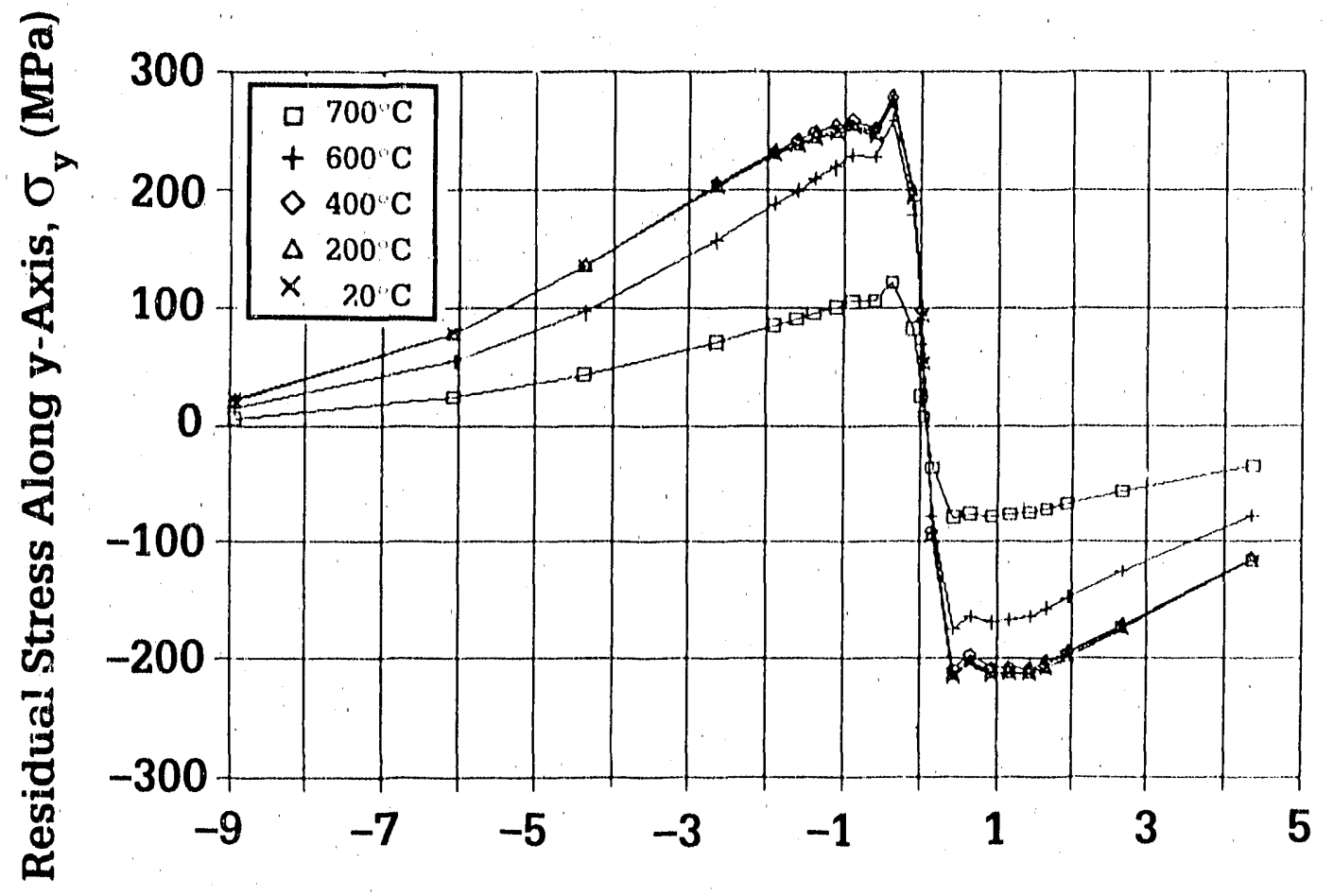

Distance Along y-Axis, y (mm)

Figure $2.7 \quad \sigma_{y}$ versus $y$ for the flat butt joint at various icmperatures during cooling of the braze joint.

Parabolic Joint. Two different geometries were considered for the parabolic joint, one with a downward contour, and the other with an upward contour. The $y$ location of the braze is given by

$$
y=h\left(\frac{2 x}{d}\right)^{2} \quad \text { and } d=14 \mathrm{~mm}
$$

where $h$ is the dip at the outer surface. The distance between the lower and upper surface of the braze was kept constant at $0.05 \mathrm{~mm}$. The meshes for the parabolic joints are shown in Figures 2.4 b-e. In order to have a regular mesh near the joint area, all the element edge lines between $y= \pm 4.0$ were downward parabolic curves.

A plot of $\sigma_{y}$ versus $y$ position at $x \approx 7$ for the parabolic joint are shown in Figure 2.6 along with the results from the flat joint. As discussed carlier, the flat joint resulted in the lowest value for the maximum tensile stress in the ceramic. The shift of the maximum stress points for the parabolic joints was attributed to the changes in the location of the joints with parabolic geometry. 
Conical Loint. For the conical joint, the metal shaft had a hollow cross-section with an inner radius, $a$, and an outer radius, $b=7 \mathrm{~mm}$. Since the braze area was held constant at $\pi b^{2}$; the parameters shown in Figure $2.3 \mathrm{~d}$ were relaicd geometrically by

$$
\begin{gathered}
a^{2}=b^{2}(1-\sin \alpha) \\
\text { and } \\
h=\frac{b-a}{\tan \alpha} .
\end{gathered}
$$

If $\tau_{0}^{M}$ and $\tau_{O}^{B}$ are the shear yicld stresses for the metal and the braze, respectively, the fully plastic torque, neglecting residual stresses, is

$$
\mathrm{T}_{0}^{\mathrm{M}}=\frac{2 \pi}{3}\left(\mathrm{~b}^{3}-\mathrm{a}^{3}\right) \tau_{0}^{\mathrm{M}}
$$

for the metal, and

$$
\mathrm{T}_{o}^{\mathrm{B}}=\frac{2 \pi}{3 \sin \alpha}\left(\mathrm{b}^{3}-\mathrm{a}^{3}\right) \tau_{o}^{\mathrm{B}}
$$

for the brazc. Hence,

$$
\frac{\mathrm{T}_{0}^{\mathrm{M}}}{\mathrm{T}_{\mathrm{O}}^{\mathrm{B}}}=\left(\frac{\tau_{0}^{\mathrm{M}}}{\tau_{0}^{\mathrm{B}}}\right) \sin \alpha \geq 1
$$

gives limiting values for $\alpha$ and $(\mathrm{a} / \mathrm{b})$. For the joint geometry and material system A considered in this study,

$$
\begin{gathered}
\sin \alpha \geq \frac{\tau_{0}^{\mathrm{B}}}{\tau_{\mathrm{o}}^{\mathrm{M}}}=\frac{271}{1033}=0.26 \\
\alpha \geq 15.2^{\circ} \quad \text { and } \quad \frac{\mathrm{a}}{\mathrm{b}} \leq 0.86 .
\end{gathered}
$$


Two relevant values of ( $a / b)$ were chosen to study the effect of thickness of the conical geometry, Figure $2.3 \mathrm{~d}$, on the residual stress within boundary conditions imposed by the material system:

i) $(a / b)=0.5, a=3.5 \mathrm{~mm}, b=7.0 \mathrm{~mm}, \alpha=49^{\circ}$ and $\mathrm{h}=3.09 \mathrm{~mm}$ : thick conical joint, and

ii) $(a / b)=0.8, a=5.6 \mathrm{~mm}, b=7.0 \mathrm{~mm}, \alpha=21^{\circ}$ and $\mathrm{h}=3.63 \mathrm{~mm}$ : thin conical joint.

The mesh for the thick and thin conical joints are shown in Figure 2.56 and $2.5 \mathrm{c}$, respectively. The bottom edge of the braze lies between the levels $\mathrm{y}=$ 0 and $y=-3.63$. The mesh refinement in the critical region of the interface, close to the point $x=7.0, y=-3.63$, was done similarly to that of the previous case.

Plots of $\sigma_{y}$ versus $y$ position at $x=6.951$ for the conical joints are shown in Figure 2.8. When $(\mathrm{a} / \mathrm{b})=0.5$, as in Figure $2.8 \mathrm{a}$, convergence problems with ABAQUS were encountered for temperatures lower than 20()$^{\circ} \mathrm{C}$, and henee the final result at $20^{\circ} \mathrm{C}$ was not obtained for the thick conical joint mesh. These results showed thai $\sigma_{y}$ continued to increase as the temperature was reduced, and that the peak stresses occurred adjacent to the braze. Lower tensile stresses were observed for $(a / b)=0.8$ than for $(a / b)=0.5$, Figure 2.8b. Hence, the geometry with $(\mathrm{a} / \mathrm{b})=0.5$ was not considered for further analysis. 

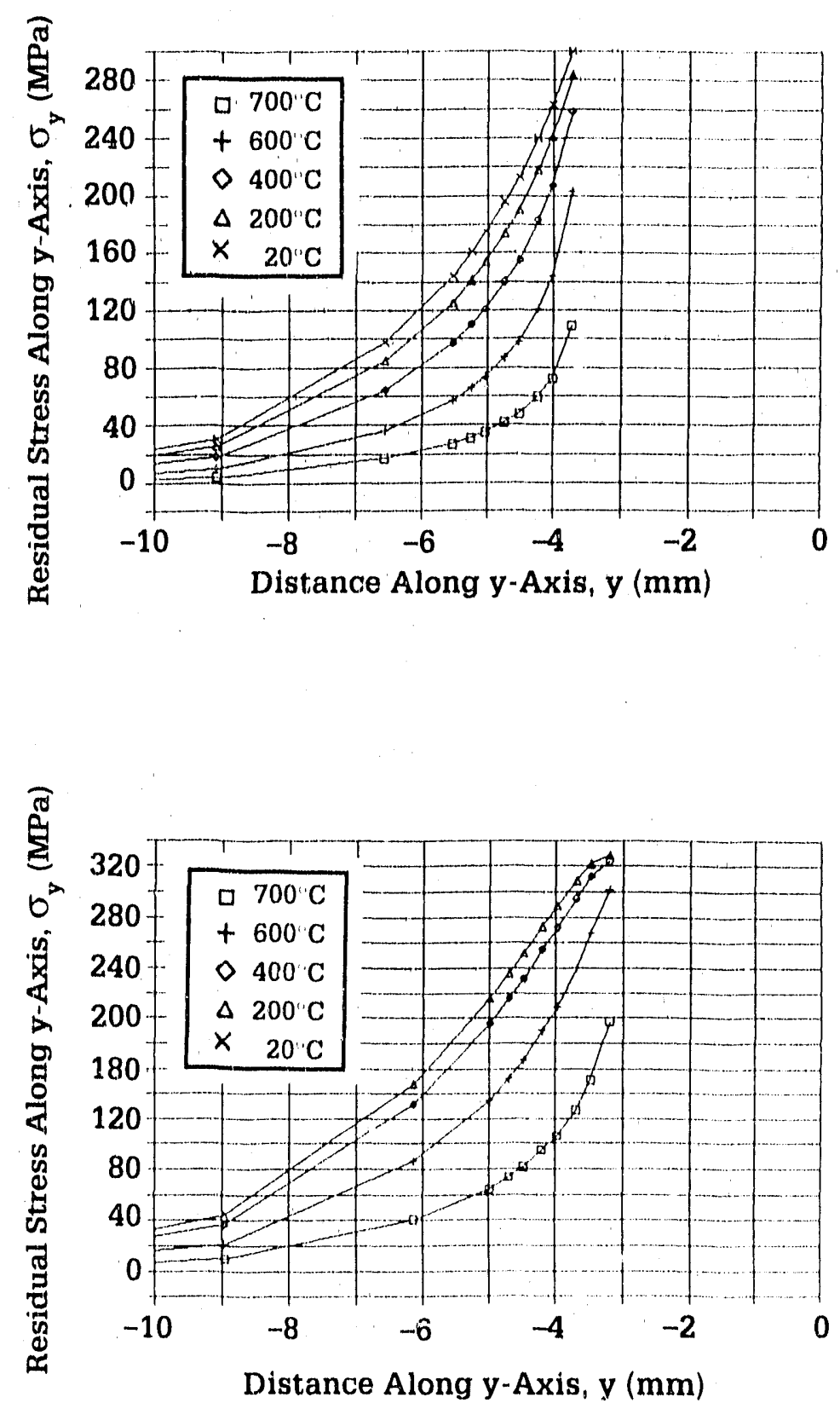

Figure 2.8. $\sigma_{y}$ versus $y$ for the conical joints at various temperatures during cooling of the braze joint. (a-top) Thick wall, $(a / b)=0.5$. (b-bottom) Thin wall, $(a / b)=0.8$. 
Culindrical doint. The metal shaft (outer radius b and inner radlus $7.05 \mathrm{~mm}$ ) fits outside the ceramic shaft. For a constant braze angle, lhe lenglh of the joint, $h$, must be half of the radius of the inner shaft, $i . c ., h=3.5 \mathrm{~mm}$, Two detalled geometries were considered for the lower edge of the metal shafi, a square edge geometry (Figure 2.3e), and a tapered edge geometry (Figure 2.3f). The meshes for the cylindrical joints with the square-edge and the tapered-edge are shown in Figure $2.5 \mathrm{~d}$ and $\mathrm{c}$.

Figures 2.9 shows Plots of $\sigma_{y}$ versus $y$ as a function of temperalure at $x=6.951$ for the cylindrical joints. Tue results showed that the maximum tensile stress occurred near the ends of the braze $(y=-3.5$ and $y=0.0)$ with compressive stress in the middle. This is equivalent to the stress observed along the $x$-axis in butt joints. It was noted that the tapered edge resulted in slightly lower ory at $y=-3.5$ than did the square end whereas the opposite is true at $y=0$.

The stress values in the ceramic at $x=6.951$ were compared in Figure 2,10 for different joint geometries. The results showed that ofher joint geometries provided little improvement in minimum $\sigma_{y}$ over the llat butt joint.

Selection of Joint Geometry. Figure 2.10b shows that the cylindrical joint with the tapered end had a higher residual stress near the joint than did the flat butt joint (320 MPa versus $200 \mathrm{MPa}$ at $y=-(1.2 \mathrm{~mm})$. The the maximum residual stress would be the detcrmining factor in the selection of a joint design if the coramic in use could not survive that level of stress during cooled down to room temperature. If, however, the fracture strength of the ceramic excecds the level of the residual stress, comparison of different geometries should to be made using a probabilistic approach to fracture.

The probabllity of ccramic survival can be expressed as:

$$
P_{s}=\exp \left(-\int_{v}\left(\frac{\sigma}{\sigma_{0}}\right)^{m} d v\right)
$$

where $\sigma_{0}$ is a normalization parameter with no physical significance, $m$ is lice Weibull modulus $(m>1)$, and " $v$ " is the volume of material exposed 10 stress $\sigma$. In the case of a ceramic-metal joint, where stress $\sigma$ is strongly dependent on the location, qualitative comparison of $P_{S}$ is only possible with FEA based on finalized dimensions of the joint geometry and on materials properties.

While the cylindrical joint has the highest residual stress level, its $P_{s}$ is much smaller than that of the flat butt joint. The cylindrical joint has a lower $P_{s}$ because the volume exposed 10 the stress is significantly smaller than in the flat butt joint. Therefore, failure associated with the residual stress will be less for the cylindrical joint than for the flat joint. Based on this information, cylindrical joint was selected over flat joint. 

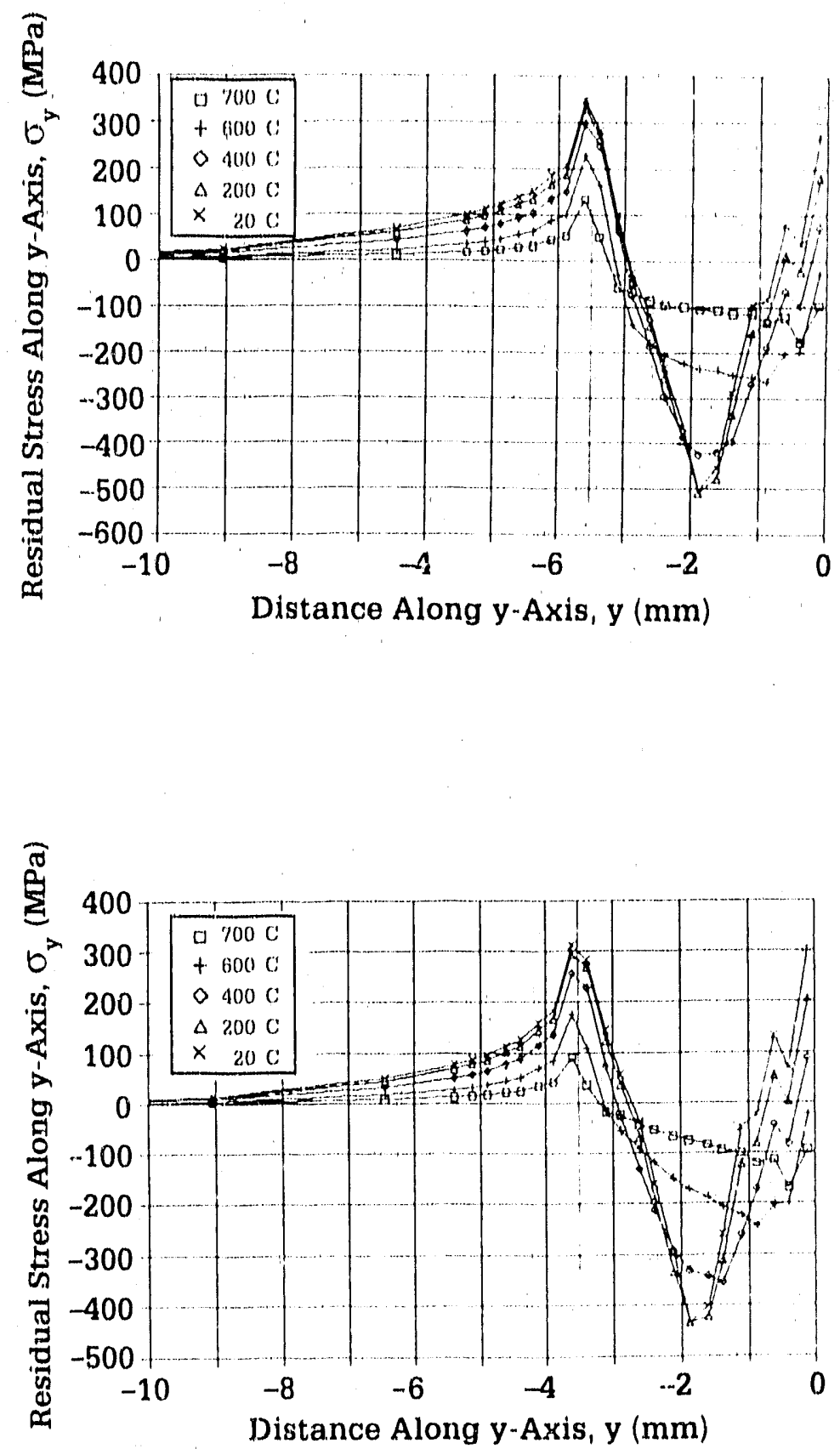

Figure 2.9. $\sigma_{y}$ versus $y$ for the cylindrical joints at various temperatures during cooling of the brazed joint. (a-1op) Square-ended joint, (b-bollom) Tapered joint. 

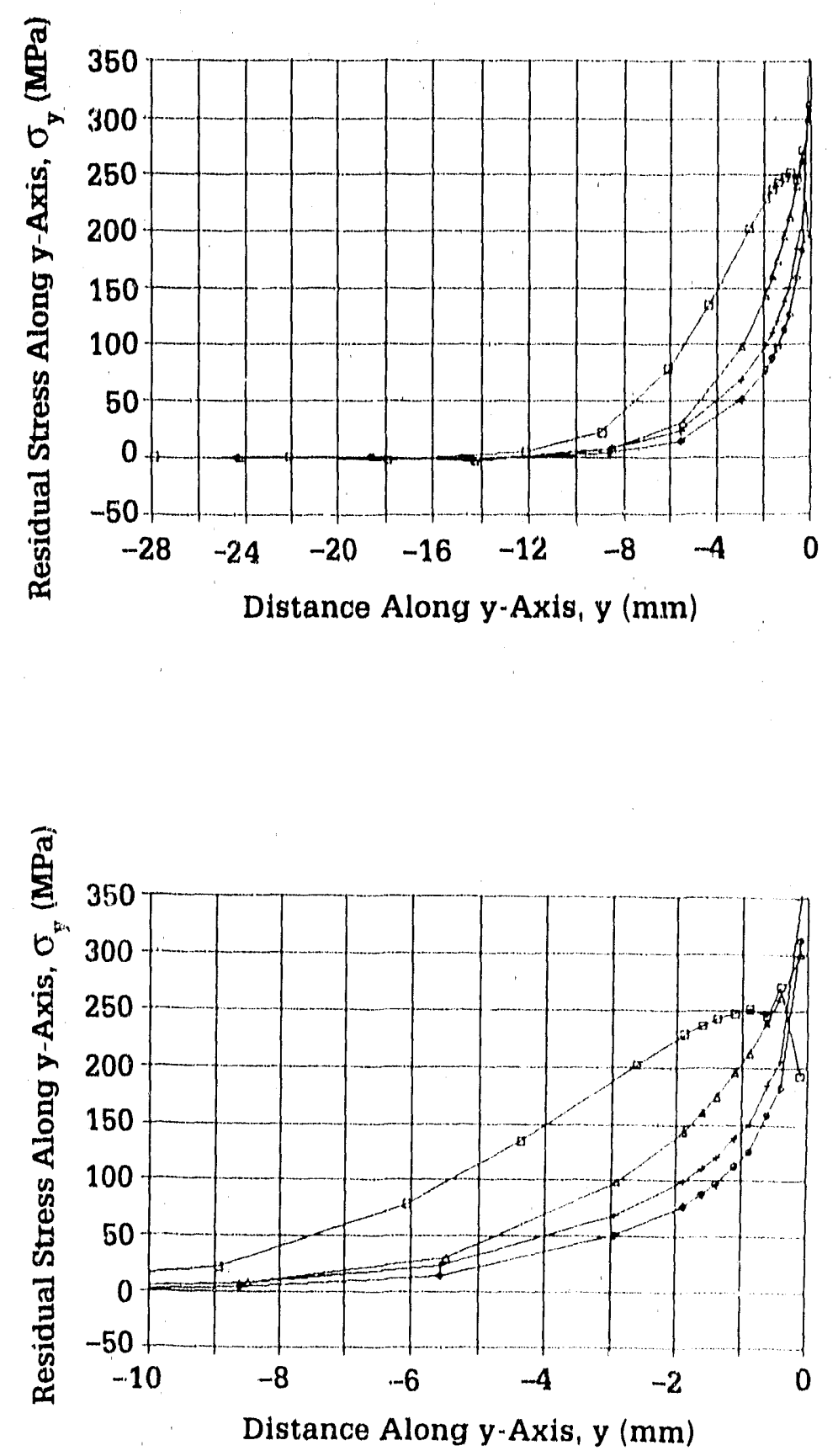

Figure 2.10. (a-top) $\sigma_{y}$ versus $y$ for several joints at $x=6.951 \mathrm{~mm}$. (b-bottom) Close-up of (a). $\diamond$ and + are for cylindrical joints with lapered and squared cnds, respectively, while $\Delta$ and $\square$ are for conical and flat joints. 


\subsection{EFFEC'T OF IN'TERLAYER MA'TERIAL}

On the basis of the fallure criteria, Equation 2.20, it was suggested that low yicld strength and low cocfliclent of thermal expanston (CTE) propertios should reduce the tendency of ecramic fallure. Since both properties are not found in one material, a FEA study was done to investigate the relative effectivencss of these properties in controlling residual stress. For this study, Ni was solected for lis low shear strength, while Mo was selected for lis low C'TE. Results showed that low yleld stress $\mathrm{Ni}$ was more effective than low expansion coefficient Mo in reducing the residual stress in the coramic at roomiemperature after brazing.

Additional FEA of the joint was conducted with modified constilutive equations derived as a function of temperature: the mechanleal properties of the braze were assumed to be temporature-independent. Also, the number of clements was increased to highlight the stress distribution around critical crack initiation sites. The number of elements used was $166,56,140$, and 192 for the ceranic, braze, interlayer, and structural alloy, respectively. While the predictions of the model were unchanged from those reported carlier, the accuracy of those predictions was improved.

Temperalure-dependent power law equations were used for the plastic deformation of the metal joint components with the following assumptions:

- The strain hardening exponent, $n$, is independent of temperature.

- The strength cocflicient, $f(T)$, is a linear function of temperature.

- The young's modulus, E(T), is a linear function of temperature

$$
\begin{array}{ll}
\sigma=\mathrm{E}(\mathrm{T}) \mathrm{e} & \text { in clastic range } \\
\sigma=\mathrm{T}(\mathrm{T}) \varepsilon^{n} & \text { in plastic range } \\
\mathrm{E}(\mathrm{T})=\mathrm{E}_{\mathrm{O}}\left(1-\mathrm{a} \frac{\mathrm{T}}{\mathrm{T}_{\mathrm{m}}}\right), &
\end{array}
$$

where $\sigma, \varepsilon, \mathrm{E}(\mathrm{T}), \mathrm{n}$, and $\mathrm{l}(\mathrm{T})$, are truc stress, true strain, Young's modulus, strain hardening exponent, and "a" is a strength cocfficient, respectively. The coramic was treated as a perfect clastic material, while the brazc alloy was treated as an clastic-perfect plastic material.

The materials' proportics as a function of temperature were used 10 calculatc $E\left({ }^{\prime}\right), n$, and $\mathrm{I}^{\prime}\left(\mathrm{T}^{\prime}\right)$ for the matcrials in the ceramic-metal joint system, Table 2.5. An improved FEA of the joint was performed using these modified constitutive equations, Section 2.2 . 
Table 2.5. Temperature dependence of the clastle modulus, E(T), strain hardening exponent, $n$, and strength cocffletent, $\left.\mathrm{I}^{(T)} \mathrm{T}\right)$.

\begin{tabular}{|c|c|c|c|}
\hline Matcrial & $\begin{array}{l}\mathrm{E}(\mathrm{T}) \\
(\mathrm{GPa})\end{array}$ & $n$ & $\begin{array}{l}l^{\prime}(T) \\
(k s i)\end{array}$ \\
\hline $\mathrm{Ni}$ & $-0.052 T+215.04$ & 0.235 & $0.23 \mathrm{~T}+390.96$ \\
\hline \multirow[t]{4}{*}{ Mu } & $-0.060 T+329.37$ & 0.099 & $\begin{array}{c}-4.33 \mathrm{~T}+1136.51 \\
\left(20^{\circ} \mathrm{C} \leq \mathrm{T}<20()^{\circ} \mathrm{C}\right)\end{array}$ \\
\hline & & & $\begin{array}{c}1.57 \mathrm{~T}+2.38 .53 \\
\left(200^{\circ} \mathrm{C} \leq \mathrm{T} 3(0)^{\circ}\right)\end{array}$ \\
\hline & & & $\begin{array}{c}-0.54 \mathrm{~T}+588.71 \\
(30) 0^{\circ} \mathrm{C} \leq \mathrm{T}<8\left(0\left(0^{\circ}\right)\right.\end{array}$ \\
\hline & & & $\begin{array}{c}-0.15 \mathrm{~T}+277.53 \\
\left(8(0) 0^{\circ} \mathrm{C} \leq \mathrm{T}<1(0)(0)^{\circ}\right)\end{array}$ \\
\hline Incoloy 909 & $-0.0054 T+158.69$ & 0.0575 & $-0.35 \mathrm{~T}+1387.98$ \\
\hline $\mathrm{PY}_{6} \mathrm{Si}_{3} \mathrm{~N}_{4}$ & $-0.049 \mathrm{~T}+279.52$ & 1.00 & $\mathrm{~N} / \mathrm{A}$ \\
\hline Au-18 Ni Brazc & $-0.035 \mathrm{~T}+58.88$ & 0.00 & 99.5 \\
\hline
\end{tabular}

Mises equivalent stress determines the deformation of the metal components, while the maximum principal stress will determine cracking of the ceramic components. Therefore, contours of Mises equivalent stress in the melal and of the maximum principal stress in the ceramic were used to judge the joint's materials and design. Figure 2.11 shows the finite clement mesh for the analysis. For all of the analyses, 8-node biquadratic elements were used for the metal components. A fine mesh spacing was used for the interlayer 10 show the nonlinear plastic behavior of that layer.

Figures 2.12 - 2.15 show the results of FEA where 20 contours were drawn 10 a $2.00 \times 10^{8}$ Pa maximum stress. As shown in Figures 2.12 and 2.13 , the $\mathrm{Ni}$ interlayer resulted in a lower principal stress in the ceramic compared to the Mo interlayer. The tensile stress in the ceramic with a $\mathrm{Ni}$ intelayer was about one-fifth of the stress in the ceramic with a Mo interlayer. Comparing contour \#14 in Figure 2.12 and 2.13 gives $1.05 \times 10^{7}$ versus $5.26 \times 10^{7}$ Pa for the maximum tensile stress in the coramic with a $\mathrm{Ni}$ and $\mathrm{Mo}$ interlayer, respectively. Therefore, a $\mathrm{Ni}$ interlayer will reduce the chance of cracking in the ceramic. Figures 2.14 and 2.15 show the similar advantage of a $\mathrm{Ni}$ irterlayer over a Mo interlayer. Mises equivalent stress in the Mo interlayer exceeds $2.00 \times 10^{8} \mathrm{~Pa}$, whereas the $\mathrm{Ni}$ interlayer sees this level of stress only in the vicinity of the interface between the $\mathrm{Ni}$ and Incoloy 909. 
In conclusion, at room-temperature, even for the tomperaturedependent constitutive models used in this study, the low yicld strength $\mathrm{Ni}$ interlayer resulted in lower residual stress levels in the joint than did the Mo interlayer. Shear lesting of coupon lap joints, discussed in Section 3.3, supported this conclusion.

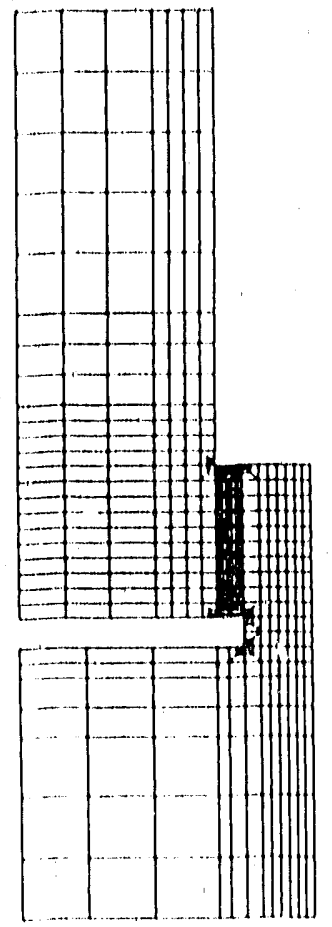

Figure 2.11. Finite element mesh used for interlayer study. 


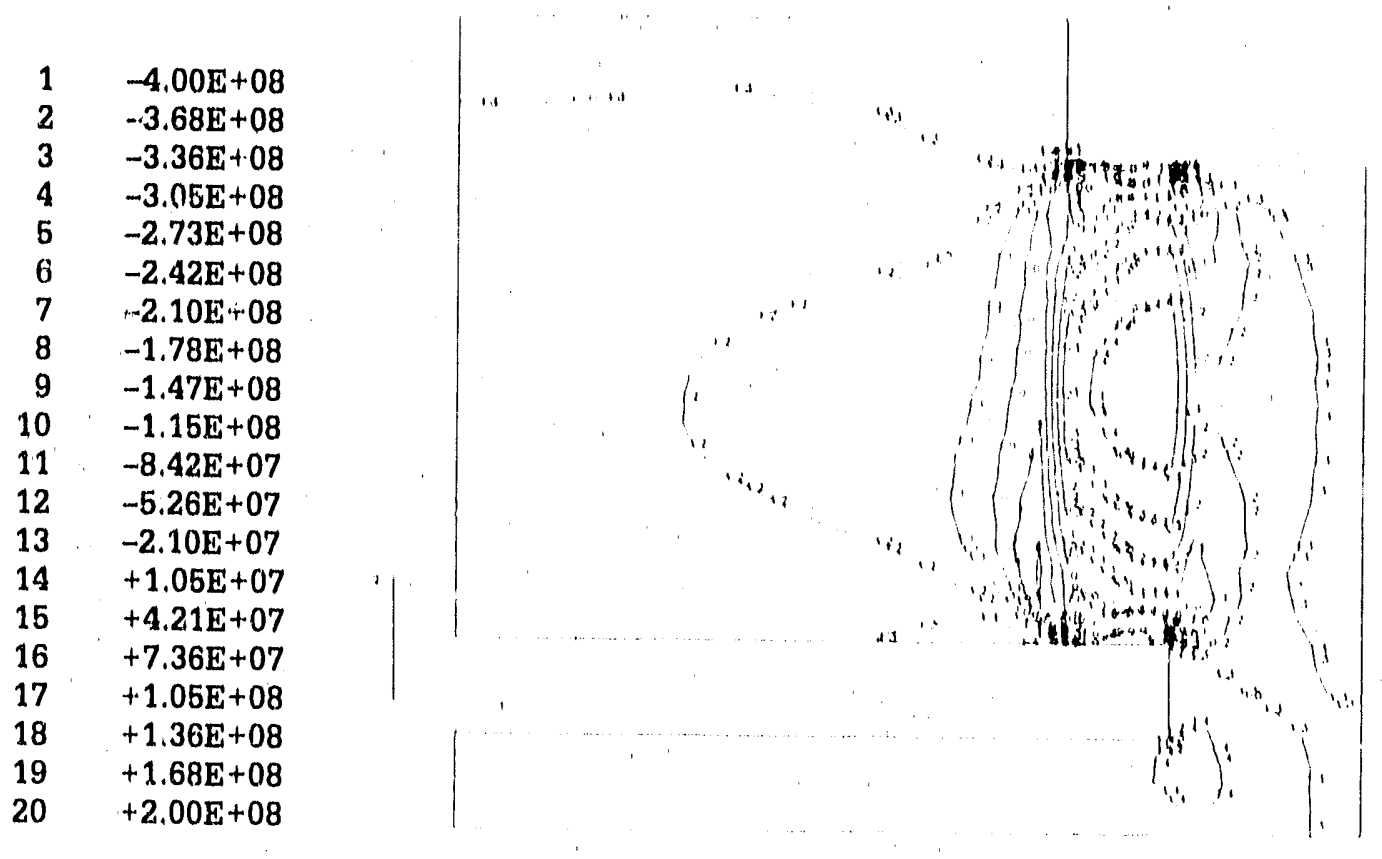

Figure 2.12. Contours of maximum principal stress in ceramic-metal brazing joint with $\mathrm{Ni}$ as the interlayer.

$$
\begin{aligned}
& -2.00 \mathrm{E}+09 \\
& -1.84 \mathrm{E}+09 \\
& -1.68 \mathrm{E}+09 \\
& -1.52 \mathrm{E}+09 \\
& -1.36 \mathrm{E}+09 \\
& -1.21 \mathrm{E}+09 \\
& -1.05 \mathrm{E}+09 \\
& -8.94 \mathrm{E}+08 \\
& -7.36 \mathrm{E}+08 \\
& -5.78 \mathrm{E}+08 \\
& -4.21 \mathrm{E}+08 \\
& -2.63 \mathrm{E}+08 \\
& -1.05 \mathrm{E}+08 \\
& +5.26 \mathrm{E}+07 \\
& +2.10 \mathrm{E}+08 \\
& +3.88 \mathrm{E}+08 \\
& +5.26 \mathrm{E}+08 \\
& +6.84 \mathrm{E}+08 \\
& +8.42 \mathrm{E}+08 \\
& +1.00 \mathrm{E}+09
\end{aligned}
$$

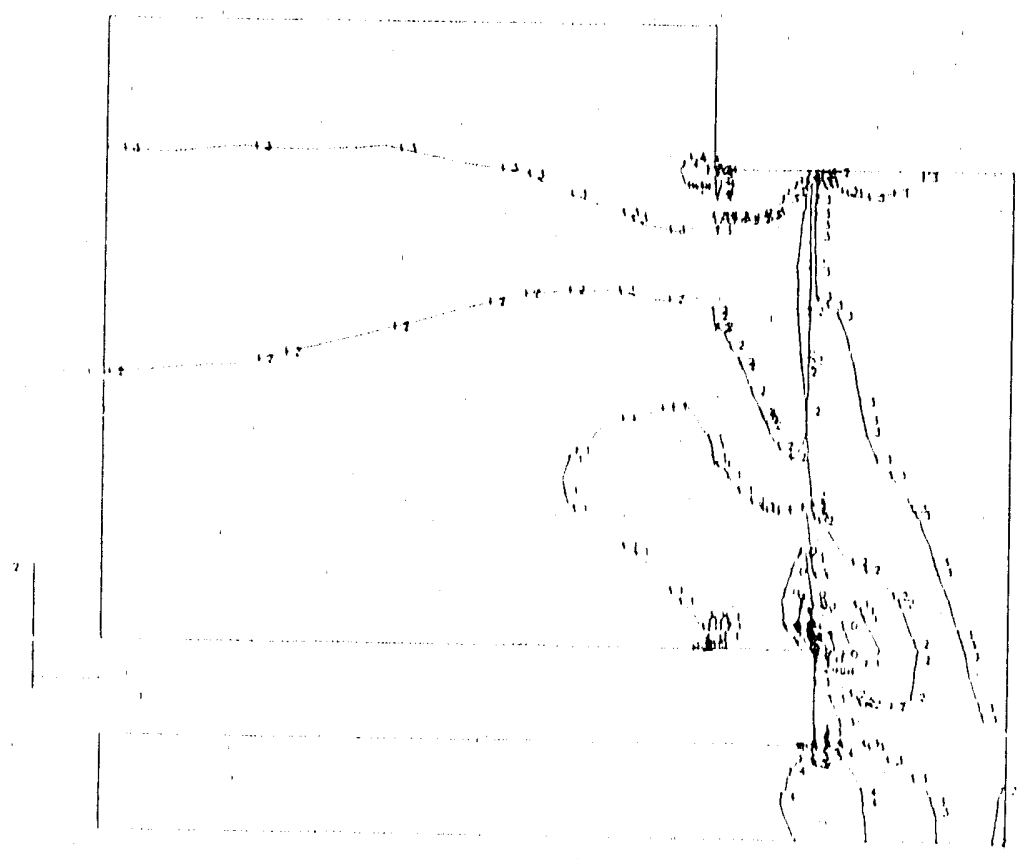

Figure 2.13, Contours of maximum principal stress in ccramic-metal brazing joint with Mo as the interlayer. 
$+4.73 E+01$

$+4.73 E+07$

$+9.47 \mathrm{E}+07$

$+1.42 \mathrm{E}+08$

$+1.89 \mathrm{E}+08$

$+2.36 \mathrm{E}+08$

$+2.84 \mathrm{E}+08$

$+3.31 E+08$

$+3.78 \mathrm{E}+08$

$+4.26 \mathrm{E}+08$

$+4.73 \mathrm{E}+08$

$+5.21 E+08$

$+5.88 \mathrm{E}+08$

$+6.15 \mathrm{E}+08$

$+6.63 \mathrm{E}+08$

$+7.10 \mathrm{E}+08$

$+7.57 \mathrm{E}+08$

$+8.05 \mathrm{E}+08$

$+8.52 \mathrm{E}+08$

$+9.00 E+08$

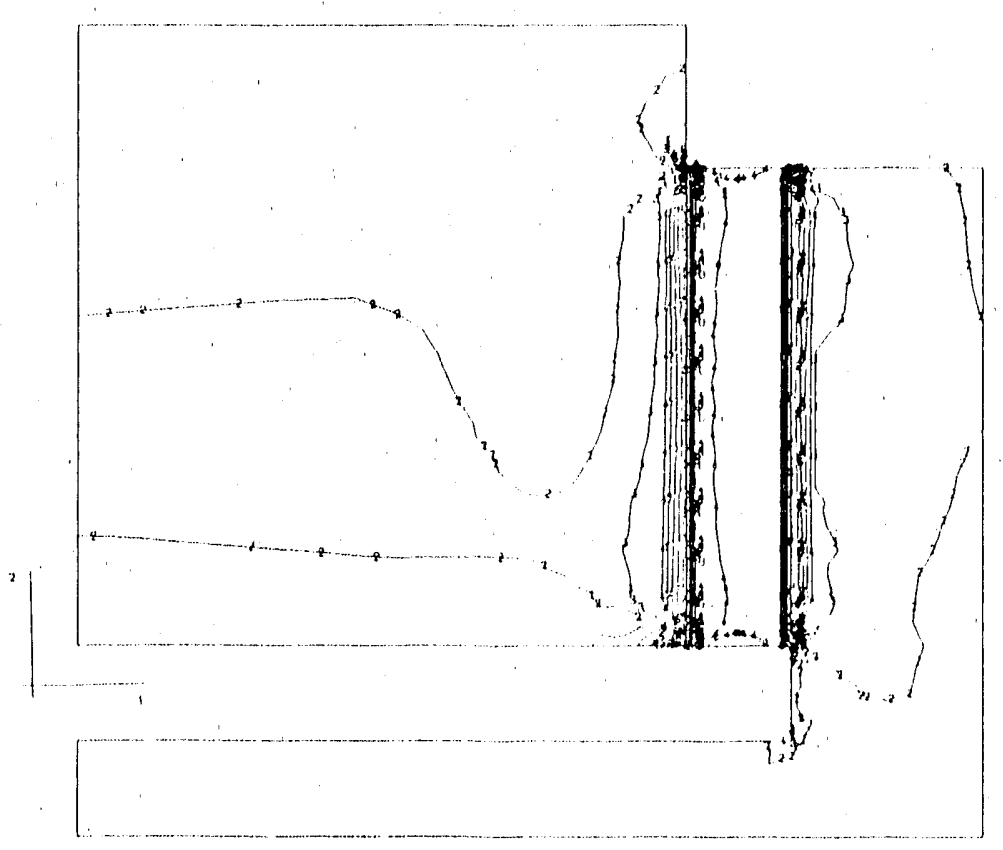

Figure 2.14. Contours of Mises equivalent stress in ceramic-metal braze joint with $\mathrm{Ni}$ as the interlayer.

$$
\begin{aligned}
& +5.78 \mathrm{E}+01 \\
& +5.78 \mathrm{E}+07 \\
& +1.15 \mathrm{E}+08 \\
& +1.73 \mathrm{E}+08 \\
& +2.31 \mathrm{E}+08 \\
& +2.89 \mathrm{E}+08 \\
& +3.47 \mathrm{E}+08 \\
& +4.05 \mathrm{E}+08 \\
& +4.63 \mathrm{E}+08 \\
& +5.21 \mathrm{E}+08 \\
& +5.78 \mathrm{E}+07 \\
& +6.36 \mathrm{E}+07 \\
& +6.94 \mathrm{E}+07 \\
& +7.52 \mathrm{E}+07 \\
& +8.10 \mathrm{E}+07 \\
& +8.88 \mathrm{E}+07 \\
& +9.26 \mathrm{E}+08 \\
& +9.84 \mathrm{E}+08 \\
& +1.04 \mathrm{E}+09 \\
& +1.10 \mathrm{E}+09
\end{aligned}
$$

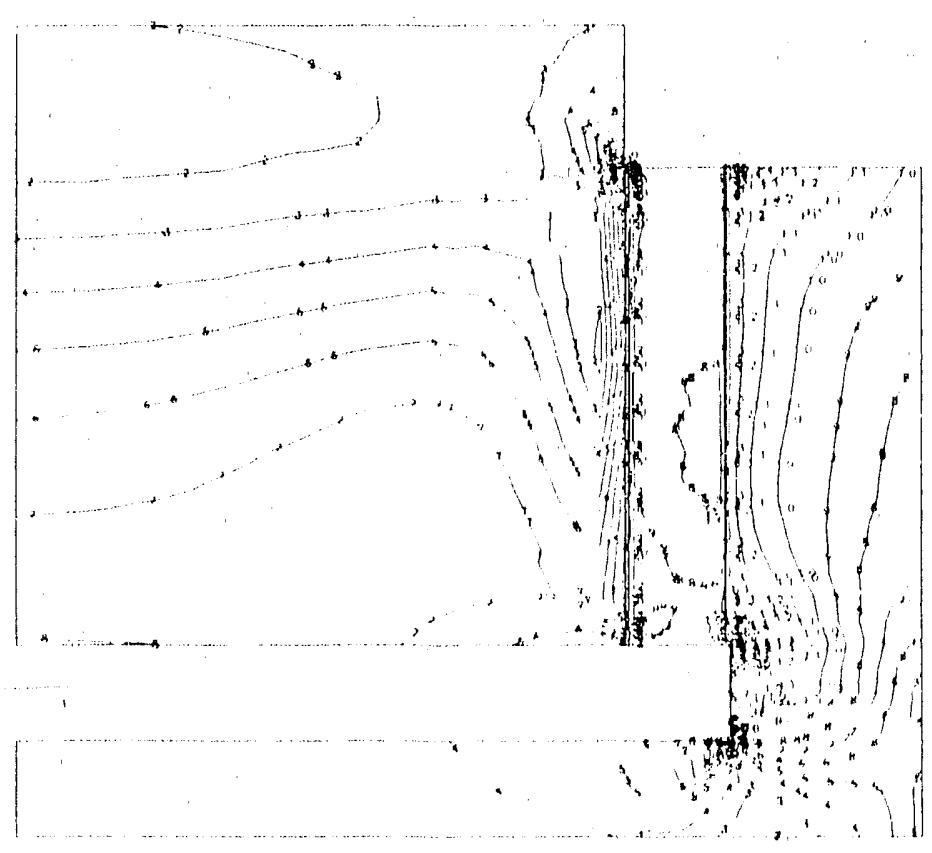

Figure 2.15. Contours of Mises equivalent stress in ceramic-metal braze joint with Mo as the interlayer. 


\subsection{ANALYSIS OF FINAL BRAZE JOINT MODEL}

The objective of this analysis was to find the residual stress and strain state in a detailed model of the ceramic-metal braze joint. These analyses should accurately model the geometry and material properties of the joint used for subsequent torsion tests. The results of this analysis were used to superimpose residual deformations with the deformations imposed by the service torque loads on the structure for strength and reliability predictions.

The temperature- and strain-dependent material propertics of the components given in Section 2.3 were used. In particular, the following material system was selected in this analysis:

$\begin{array}{lll}\text { Ceramic } & - & \text { PY6 } \\ \text { Structural Alloy } & - & \text { Incoloy } 909 \\ \text { Interlayer } & - & \mathrm{Ni} \\ \text { Braze } & - & \mathrm{Au}-5 \mathrm{Pd}-2 \mathrm{Ni}\end{array}$

The brazing process was considered to be "slow" and not to affect the rate-dependent properties of the material system above; therefore, rate effects were not considered in this study.

No cracking or relative motion at the interfaces of component materials was permitted in the FEA model. This was thought to be a valid assumption since most of the interface regions are in compression, thus ensuring contact. Also, the interfaces associated with the braze or nickel layers will remain in contact with other materials throughout the deformation process.

During thermal loading, it was assumed that small strain behavior applics and that the maicrial was initially isotropic. Isotropic hardening of materials was permitted after the von Mises yicld condition was satisficd, based on $\mathrm{J}_{2}$ flow theory. Materials were assumed to be isotropic during and after the deformation phase.

A cylindrical coordinate system was used where the " $z$ " direction was the axial or "long" direction of the structure, " $r$ " was the radial direction, and $" \theta$ " was the circumferential direction. The model was axisymmetric; therefore, the center line, i.c., " $z$ " direction, of the model was constrained in all other degrees of freedom except "z". A single node at the base of the structural alloy, at the center line, was fixed in all degrees of frecdom. No additional constraints were placed on the structure and no forces or pressures were applied to the nodes.

The residal deformation state of the joint was calculated at $20{ }^{\circ} \mathrm{C}$ and at $650^{\circ} \mathrm{C}$. Since the deformation was history-dependent, the following schene was used to study the results at these temperatures. A thermally expanded finite element mesh of the braze joint was created. Thermally expanded means that the dimension of the structure at $20^{\circ} \mathrm{C}$ was increased by $\alpha_{\mathrm{i}} \Delta \mathrm{T}_{\mathrm{i}} \mathrm{L}_{\mathrm{i}}$, where $\alpha_{\mathrm{i}}$ was the thermal expansion coefficient of the $i^{\text {th }}$ matcrial, $\Delta \mathrm{T}_{i}$ was the change in temperature from $20^{\circ} \mathrm{C}$ to the solidus temperature of the braze $\left(11800^{\circ} \mathrm{C}\right)$, and $L_{i}$ was a characteristic dimension. In other words, a stress-frec state was assumed at the solidus temperature, and all portions of the structure reached this temperature. The model was then uniformly, slowly cooled $1020^{\circ} \mathrm{C}$ and the results output. Then the deformed state at $20^{\circ} \mathrm{C}$ was uniformly, slowly heated to 
$650^{\circ} \mathrm{C}$, and the results were then output. This process considers the history dependence of the plastic deformation. At each stage, the temperature was uniform, since it was assumed that the brazing process. and subsequent cooling were slow compared to the thermal conditions of the materials used.

The mesh of the structure is shown in Figure 2.16. The refinement of the mesh in the $z$ and $r$ direction near the braze layers was arrived at through the previous studies on braze-joint shape. The region between the ceramic and the structural alloy consisted of three materials. From the ceramic, a layer of braze was input, then an interlayer of $\mathrm{Ni}$, followed by another braze layer between the nickel and the structural alloy. 1218 quadratic axisymmetric clements were used in this study.

Once the analysis was complete, results were reported for the deformation states at 20 and $650^{\circ} \mathrm{C}$. Stress and strain results were output by $A B \wedge Q U S$ at the integration points for each element and extrapolated to the nodes for contour plots. Deformed shapes were constructed using nodal displacements without extrapolation.

The deformed shape of the structure at $20^{\circ} \mathrm{C}$, magnificd to show detail, is shown in Figure 2.17. Maximum principal stress and von Mises stress at $20^{\circ} \mathrm{C}$ are shown in Figures 2.18 and 2.19 , respectively. Similar results for the braze joint at $650{ }^{\circ} \mathrm{C}$ are shown in Figures $2.20-2.22$. Plots of the results are indicative of trends and stress gradients throughout the structure. When detailed investigation of a region was warranted or when actual values of a stress component were required, then the actual data from the output sets were used. Care was taken to use element data extrapolated from gauss point information and not to average all relevant stress and strain components at material boundaries.

Deformation of the braze joint for 20 and $650^{\circ} \mathrm{C}$ was shown for the entire structure. This indicates which regions have undergone the greatest strain and permits us to select regions of greatest deformation for further study. At both temperatures, the greatest deformation occurs in the braze region. This was expected since the braze had the lowest yield stress of the materials in the joint. The structural alloy exerts a "downward pull" on the braze. This downward pull was attributed to larger changes in length for the metal structural alloy than for the ceramic component. This downward motion puts the braze material at the ends of the joint region in simple shear, thus permitting large plastic deformations of the braze layers. This shear mechanism occurred in both braze arcas.

The deformed shapes of the model at 20 and $650^{\circ} \mathrm{C}$ clearly show that larger deformations existed at $20^{\circ} \mathrm{C}$. This was due to the larger temperature difference from the braze temperature. Therefore, the structure is subject to larger residual strains at room-temperature than at the operating temperature of the joint. Some amount of stress relaxation occurred when the joint was heated from room-lemperature to its operating temperature. Complete relaxation did not occur because the operating temperature is lower than the brazing temperature, and because permanent deformations has occurred in some regions of the struclure.

This relaxation phenomenon is shown in the maximum principal stress distributions at 20 and $6.50^{\circ} \mathrm{C}$, Figures 2.18 and 2.21 . Not only does the value of the maximum principal stress become reduced from $20^{\circ} \mathrm{C}$ to $650^{\circ} \mathrm{C}$, but the location of this maximum also changes. At $20^{\circ} \mathrm{C}$, the $\mathrm{Ni}$ interlayer contains the maximum principal stress, thus performing its function of reducing the likelihood of ceramic fracture. The central region of the braze regions puts 
the ceramic in residual compression, away from the edges. At $650^{\circ} \mathrm{C}$, however, this compression changes to positive values of $\sigma_{1}$ for most of the ceramic material.

The von Mises stress was concentrated in the two braze layers. The von Mises stress is an indication of the amount of distortional energy contained in a volume of material. The large values shown in the braze layer at $20^{\circ} \mathrm{C}$ emphasize the amount of deformation that these regions undergo. The von Mises stress are also an indication of incipient yiclding, depending on the current yield stress of the material. Similar behavior was displayed at 65()$^{\circ} \mathrm{C}$. At $650^{\circ} \mathrm{C}$ the maximum values of von Mises stress were reduced, and the distribution of these maximum values was more diffuse compared to the results at $20^{\circ} \mathrm{C}$, because of the relaxation which occurs at this tempcrature.

In summary, the braze material undergoes large deformations at both room and operating temperatures, and the interlayer provides a mechanism for ensuring that the largest maximum principal stress occurs outside of the ceramic component at room-temperature. Also, some stress relaxation occurs in the structure when heated from room to operating temperature, permanent deformations notwithstanding. 


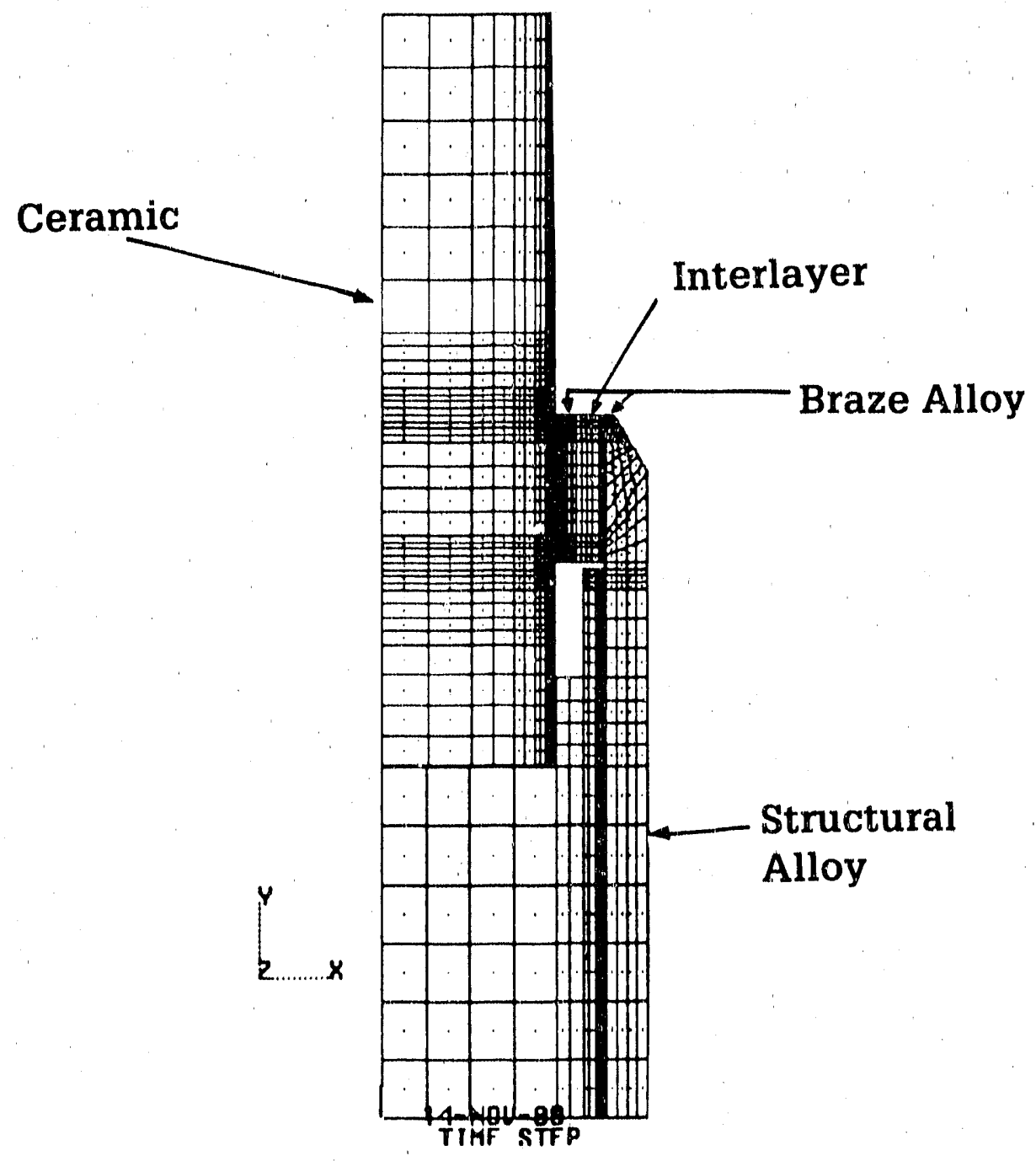

Figure 2.16. The FEA mesh, used for detailed thermal X-Y-Z coordinate system shown, maps to $r-z-\theta$ of the cylindrical coordinate system used in the analysis. 

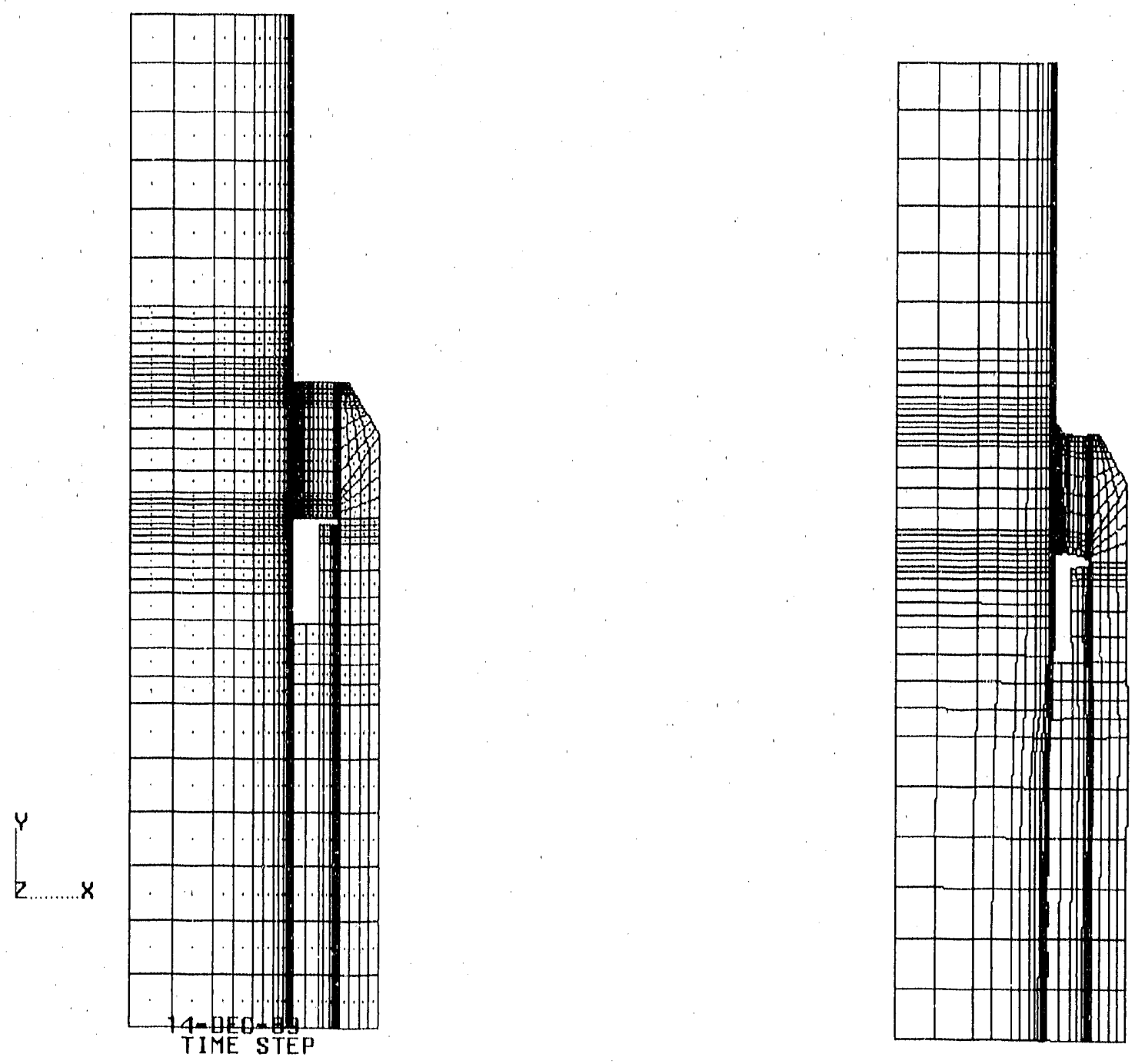

Figure 2.17. (a-right) Mesh at $1180^{\circ} \mathrm{C}$ shows the initial condition without residual stress. (b-left) Mesh at $20^{\circ} \mathrm{C}$ demonstrates the deformation associated with residual stress. 

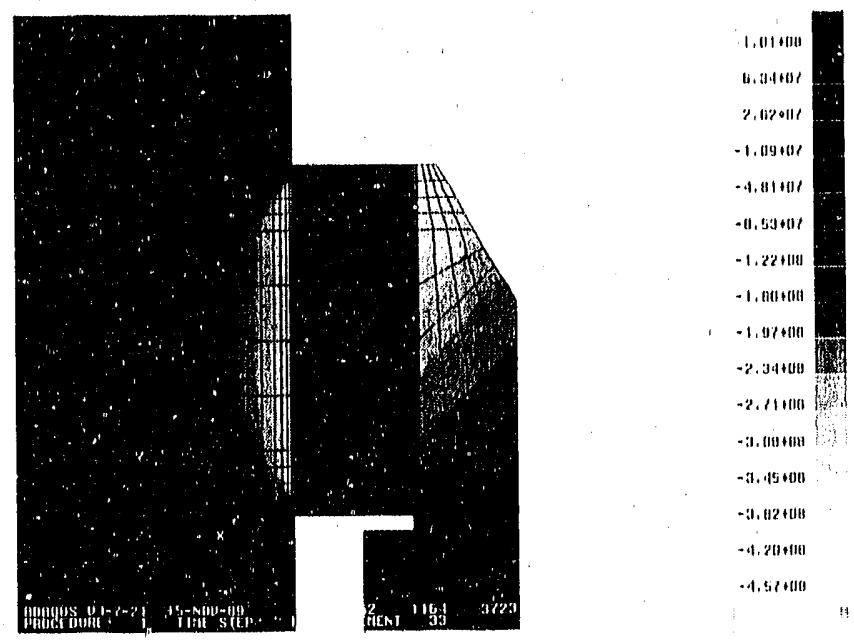

Figure 2.18. Contour plot of maximum principal stress $\left(\sigma_{1}\right.$ in $\mathrm{Pa}$ ) at $20^{\circ} \mathrm{C}$ in the vicinity of the joint.

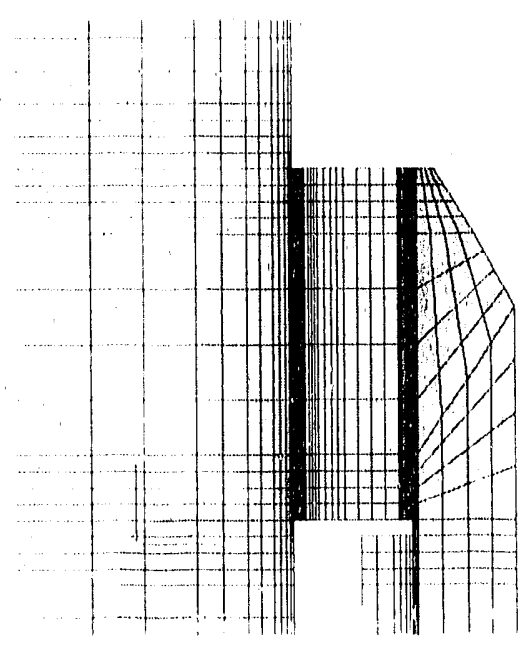

Figure 2.19. Contour plot of von Mises stress (Pa) at $20^{\circ} \mathrm{C}$ in the vicinity of the joint. 

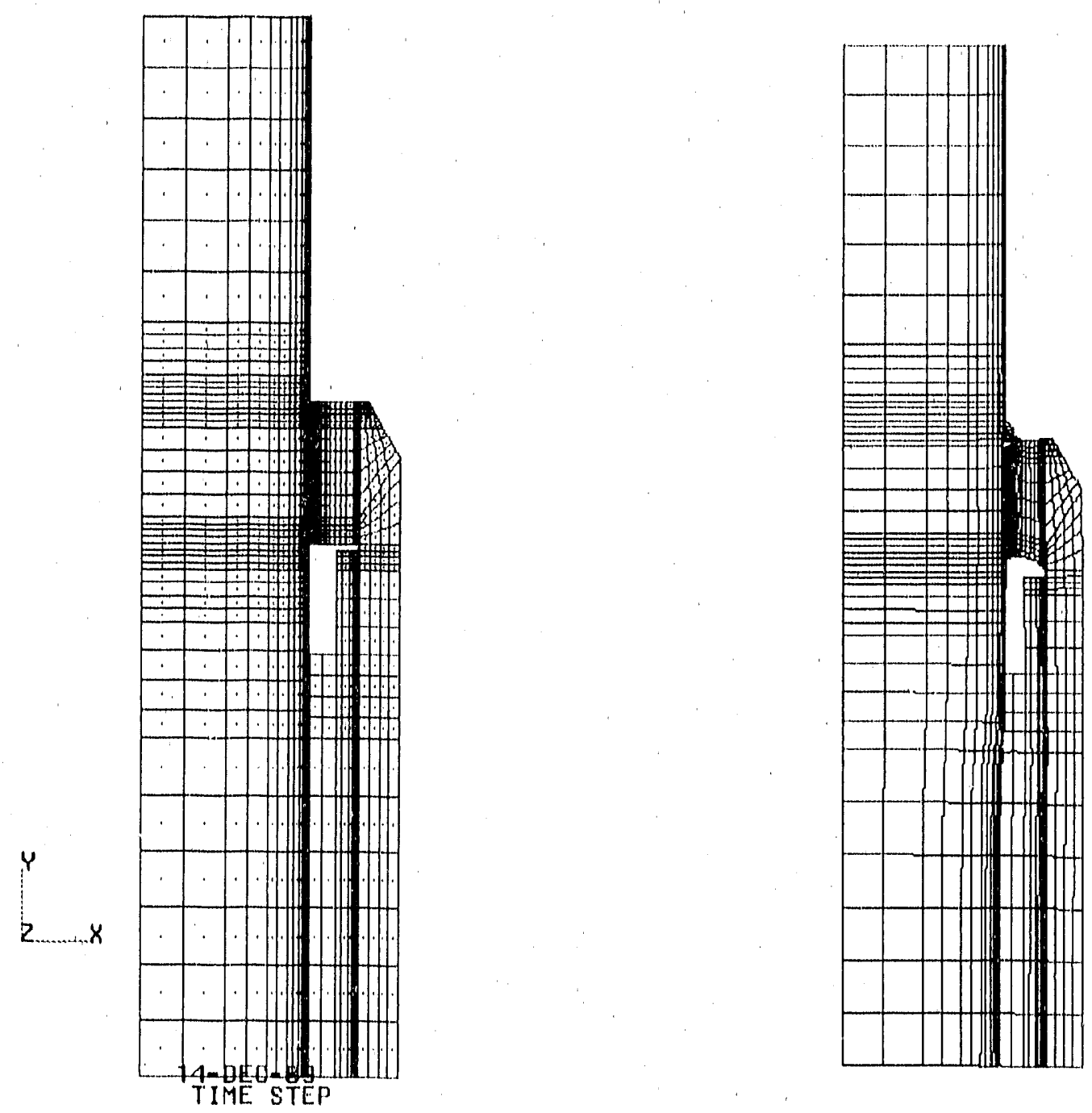

Figure 2.20. (a-right) Mesh at $1180^{\circ} \mathrm{C}$ (b-left) At $650^{\circ} \mathrm{C}$ after reheating from $20^{\circ} \mathrm{C}$. 

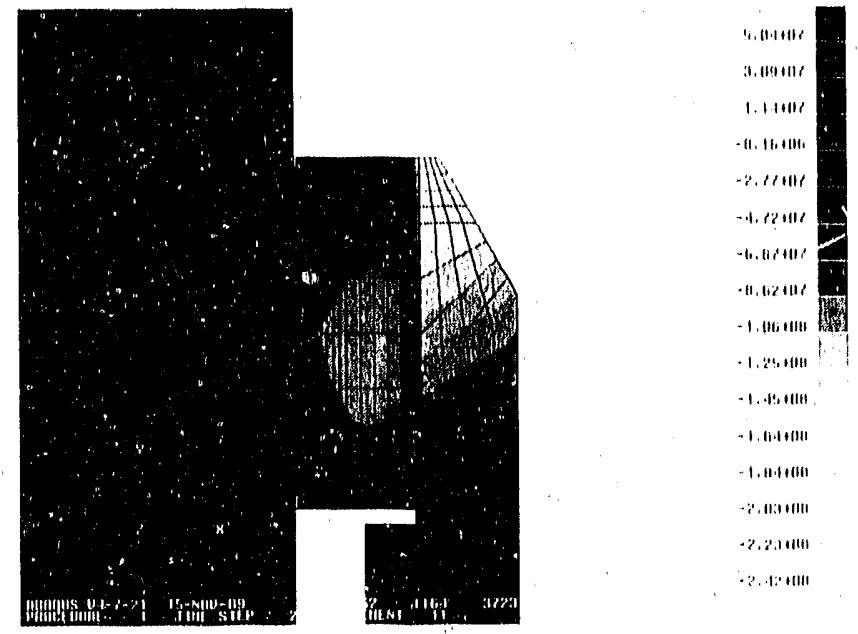

Figure 2.21. Contour plot of maximum principal stress $\left(\sigma_{1}\right.$ in $\left.\mathrm{Pa}\right)$ at $650^{\circ} \mathrm{C}$ in the vicinity of the joint.
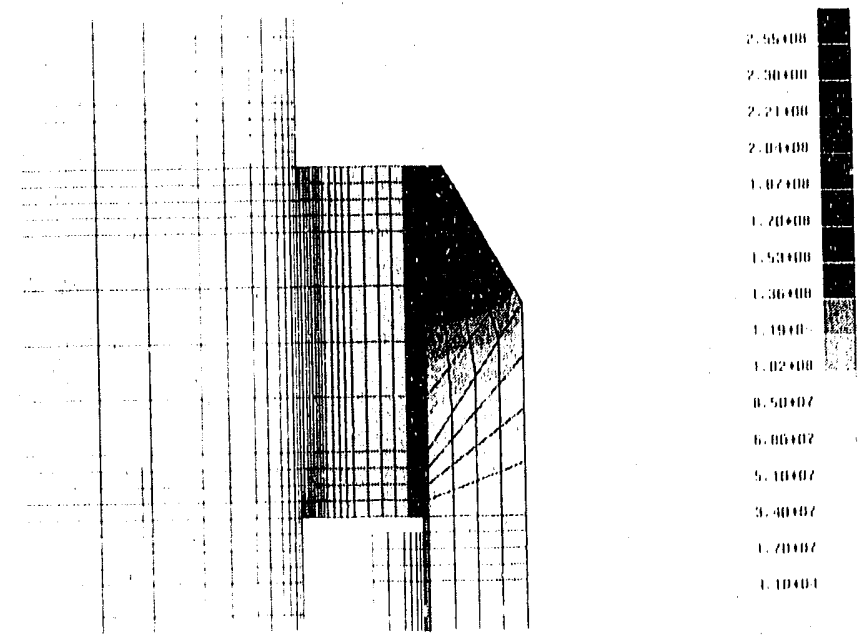

Figure 2.22. Contour plot of von Mises stress (Pa) at $650^{\circ} \mathrm{C}$ in the vicinity of the joint. 


\section{JOIN'T MATERIAL DEVELOPMEN'T}

Brazing is a complex process in which chomical factors, metallurgical factors, and residual stress distributions affect the joint simultancously. All of these lssues must be considered when designing a high-performance joint belween ceramics and melals.

The chemleal dissimlarity between the coramic and the braze gives rise (0) welling and adhesion problems. Dlfferential expansion between joint components places the joint, particularly the coramic, under stress, it is necessary to oplimize the malcrials system under the guidance of analylical mechanics in order to develop ceramic-metal braze joints for high performance applications such as heat engines.

The materials system refers to the ceramic and structural alloy parent materials, the braze, interlayer or compliant layers, and coatings. The gencralized malerials system chosen for this program is shown in figure 3.1. A complete optimizalion of the materials system would require a systematic cvaluation of each of the bulk materials and interfaces in the joint.

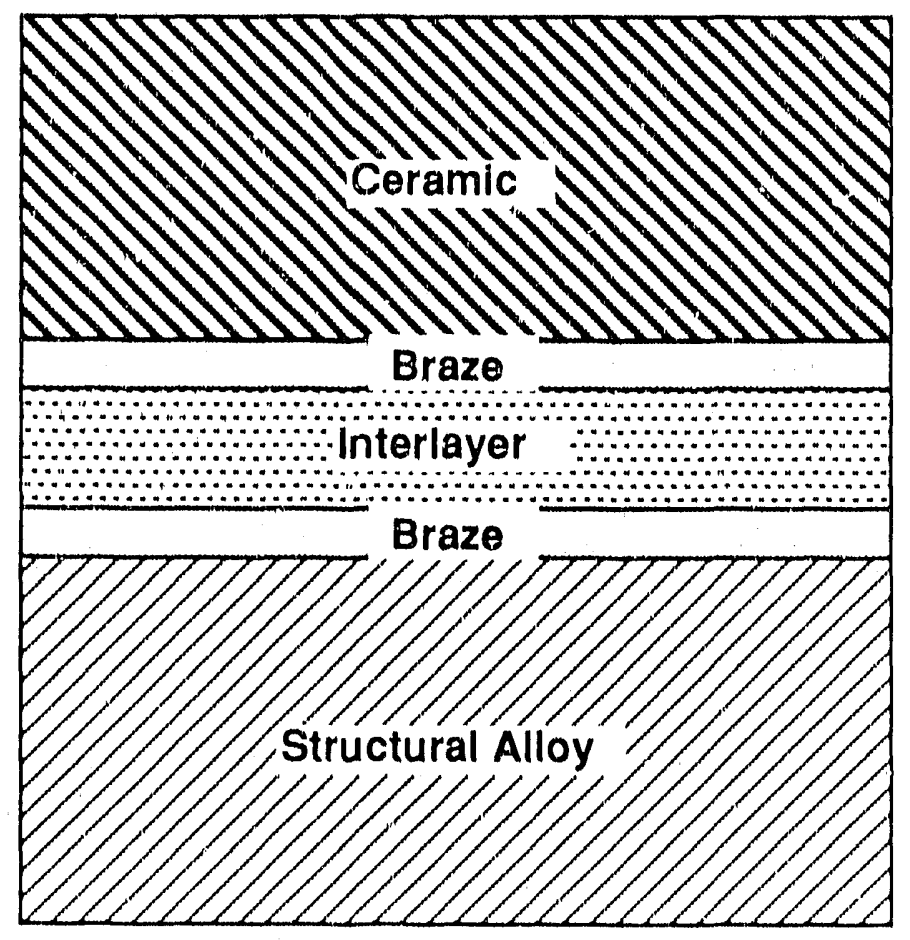

Figure 3.1. Gencralized matcrials system.

The program required development of joints between SizNa and a structural alloy and $\mathrm{SiC}$ and a structural alloy for 650 and $950^{\circ} \mathrm{C}$ applications. The PYG SizN4 and Hexaloy SA SiC materials chosen for evaluation in this 
program were representative of structural ceramies sullable for use in the high-temperature, oxidizing environtacot associated with heat engines, Both PY6 SizN4 and Hexaloy SA SIC are commercially available materials.

SNW 1000 and AY6 $\mathrm{Si}_{3} \mathrm{~N}_{4}$ were used as model materlals, while PY6 $\mathrm{Si}_{3} \mathrm{~N}_{4}$ was the final choice because of its excellent high-temperature strengih and lts compatibllity with the coating materlal selected. Hexaloy SA SIC was chosen as the SiC material. The low-expansion superalloy was an Fe-Ni-Co alloy, Incoloy 909. The Ni-based superalloy was Inconel 718. GTE's Nioro (Au-18Ni) brazc was used as a model braze throughout the program because of its ductllity and oxidation resistance. An experimental braze alloy, Au-5Pd-2Ni, and a commercial braze alloy, 30Au-34Pd-36Nt (Palniro 4), were selected due 10 their oxidation resistance, ductillty, and relatively high meling points. The following section discusses the properties of each component of the foint in more detall.

A general methodology was applied to make the materials sereening effort systematic and comprehensive. For example, in selecting coaling materials, the necessity of chemical reactions at the interface led to examination of published Gibbs free energy data. After cvaluation of thermodynamic data, the reaction kinetics were studied. This involved heating powder mixlures of the ceramic and coating material followed by $x$-ray diffraction. The wetting behavior of a joint system was studied by sessile drop tests. Additional constraints included the necessity of minimizing the damage from chemical reactions at the ceramic-coating interface. A new set of procedures were developed to quantify the potentially damaging effect of interfacial reactions. Using a combination of thermodynamics, reaction kinetics, and finite element analysis (FEA), it was possible to efficienlly sereen materials and to optimize the joint system.

\subsection{INTRINSIC PROPER'TIES OF JOINING MATERIALS}

\section{Structural Alloys}

For the $650^{\circ} \mathrm{C}$ application Incoloy 909 was selected because of its low coefficient of thermal expansion (CTE) as well as its high-temperature properties. Room-temperature tensile propertics of Incoloy $9(99$, after a $10(0)$ hour exposure at $650^{\circ} \mathrm{C}$, were essentially unaffected compared to unexposed material. The low-cycle fatigue strength, fracture toughness, and creep crack growth rate at $540^{\circ} \mathrm{C}$ were better than those of other Incoloy series alloys. Furthermore, rupture strength of age-hardened Incoloy 909 after 3500 hours at 65()$^{\circ} \mathrm{C}$, a typical engine life, is over $20 \mathrm{ksi}$. For the 95()$^{\circ} \mathrm{C}$ application, Inconcl 718 was chosen solely for its high-temperature capabilities. Rupture strength of Inconel 718 after 3500 hours at 65()$^{\circ} \mathrm{C}$ exceeds 40 ksi. Tables 3.1 and 3.2 show the compositions and mechanical propertics of these two structural alloys. Figure 3.2 shows the CTE of Incoloy 909 and Inconel 718 as a function of temperaturi. 
Table 3.1. Compositions of the structural alloys used in this study.

\begin{tabular}{|c|c|c|c|c|c|c|c|c|}
\hline \multirow[t]{2}{*}{ Alloy } & \multicolumn{8}{|c|}{ Composition (Wt \%) } \\
\hline & $\mathrm{Fe}$ & $\mathrm{Nl}$ & $\mathrm{Cr}$ & $\mathrm{Co}$ & $\mathrm{Nb}$ & $\mathrm{TI}$ & Mo & Al \\
\hline Incoloy 909 & 42.17 & 38.2 & $\cdots$ & 13.0 & 4.7 & 1.5 & $\ldots$ & 0.03 \\
\hline Inconel 718 & 16 & $50.55^{*}$ & $17-21$ & $\ldots$ & $4.75-5.5^{*}$ & $0,65-1,15$ & $2.8-3.3$ & $0.2-0.8$ \\
\hline
\end{tabular}

* Inconel 718 has $50-55 \mathrm{Ni}+\mathrm{Co}$ and $4.75-5.5 \mathrm{Nb}+\mathrm{Ta}$.

Note: Incoloy 909 is avallable from Hunington Alloys, Huntington, $W V$, and Inconel 718 is avallable from Carpenter Technology, Reading, PA.

Table 3.2. Properties of the structural alloys used in this study.

\begin{tabular}{|c|c|c|c|}
\hline Property & & Incoloy 909 & Inconel 718 \\
\hline Youngs Modulus & $\begin{array}{r}25^{\circ} \mathrm{C} \\
650^{\circ} \mathrm{C} \\
950^{\circ} \mathrm{C} \\
1100^{\circ} \mathrm{C}\end{array}$ & $\begin{array}{l}23.0 \times 10^{6} \mathrm{psi} \\
22.6 \\
18.4 \\
15.2\end{array}$ & $\begin{array}{l}29.0 \\
23.7 \\
18.1 \\
14.3\end{array}$ \\
\hline $\begin{array}{l}\text { Tensile strength } \\
\text { (0.2\% Yicld strength) }\end{array}$ & $\begin{array}{r}25^{\circ} \mathrm{C} \\
540^{\circ} \mathrm{C} \\
650^{\circ} \mathrm{C}\end{array}$ & $\begin{array}{l}185(150) \mathrm{ksi} \\
168(125) \\
150(125)\end{array}$ & $\begin{array}{ll}195 & (164) \\
171(142) \\
145(125)\end{array}$ \\
\hline Poisson's Ratio & $\begin{array}{r}25^{\circ} \mathrm{C} \\
650^{\circ} \mathrm{C} \\
950^{\circ} \mathrm{C} \\
1100^{\circ} \mathrm{C}\end{array}$ & $\begin{array}{l}0.337 \\
0.352 \\
0.354 \\
0.401\end{array}$ & $\begin{array}{l}0.294 \\
0.283 \\
0.337 \\
0.402\end{array}$ \\
\hline $\begin{array}{l}\text { Smooth bar rupture } \\
\text { strength in air at } 650^{\circ}\end{array}$ & $\begin{array}{l}\mathrm{C} \\
100 \mathrm{hr} \\
1000 \mathrm{hr} \\
3500 \mathrm{hr}\end{array}$ & $\begin{array}{l}75 \mathrm{ksi} \\
50 \\
35\end{array}$ & $\begin{array}{r}107 \\
87 \\
\ldots\end{array}$ \\
\hline $\begin{array}{l}\text { Weight gain after } 500 \\
\text { in air at } 6500^{\circ} \mathrm{C} \\
\text { Stress } 10 \text { produce } 0.2 \% \\
\text { crecp after } 100 \text { hrs }\end{array}$ & $\begin{array}{l}\text { hr } \\
\text { plastic } \\
650^{\circ} \mathrm{C} \\
76()^{\circ} \mathrm{C}\end{array}$ & $6 \mathrm{mg} / \mathrm{cm}^{2}$ & $\begin{array}{l}90 \\
14\end{array}$ \\
\hline
\end{tabular}




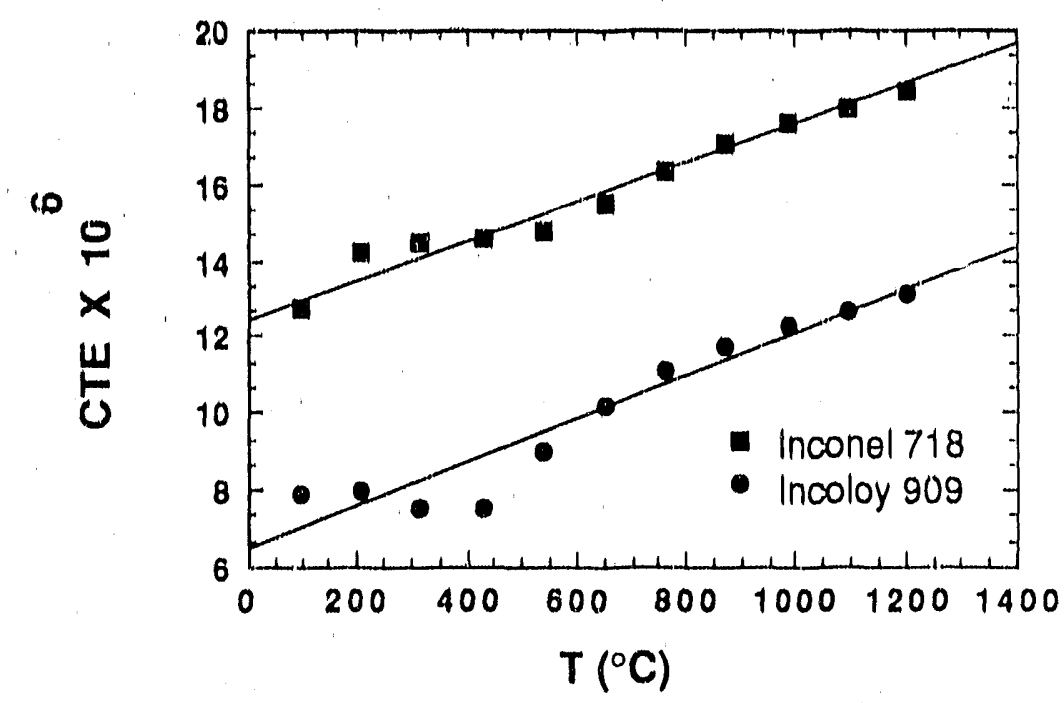

Figure 3.2. Coefficient of thermal expansion (C'TE) of Incoloy 909 and Inconel 718 as a function of temperature.

\section{Structural Ceramies}

GTE's PY6 Si3n 4 and Sohio's Hexaloy SA SiC were selected as the structural ceramic matcrials. PY6 $\mathrm{Si}_{3} \mathrm{~N}_{4}$ was sclected over both $\mathrm{SNW} 1000$ and AY6 SizN4 duc to its supcrior high-temperature strength and its compatibility with the coating material. The CTE of PY6 is $3.4-4.0 \times 10^{-6} /{ }^{\circ} \mathrm{C}$ in the temperature range of $25-1000^{\circ} \mathrm{C}$, while that of $\mathrm{SiC}$ is $4.0 \times 10^{-6} /{ }^{\circ} \mathrm{C}$ in the temperature range of $25-750^{\circ} \mathrm{C}$. PY 6 retains excellent high-temperature strength up to $1300^{\circ} \mathrm{C}$; the strength in 4-point bending was over 60 $\mathrm{ksi}$ at $1300^{\circ} \mathrm{C}$. Table 3.3 shows the compositions of Hexaloy SA SiC and the various $\mathrm{Si}_{3} \mathrm{~N}_{4}$ materials, and Table 3.4 lists propertics of PY6 $\mathrm{Si}_{3} \mathrm{~N}_{4}$ and Hexaloy $\mathrm{SA} \mathrm{SiC.}$ The SNW $1000 \mathrm{Si}_{3} \mathrm{~N}_{4}$, AY6 $\mathrm{Si}_{3} \mathrm{~N}_{4}$, and PY6 $\mathrm{Si}_{3} \mathrm{~N}_{4}$ will be referred to as SNW10)0, AY6, and PY6 throughout the remainder of the report. In general, PY6 $\mathrm{Si}_{3} \mathrm{~N}_{4}$ has a lower CTE, a belter fracture toughness, and a higher strength than Hexaloy SA SiC. 
Table 3.3. Compositions of the different ceramics used in this study.

\begin{tabular}{r|cccc}
\hline Material & \multicolumn{4}{|c}{ Composition (Wt \%) } \\
& $\mathrm{Y}_{2} \mathrm{O}_{3}$ & $\mathrm{Al}_{2} \mathrm{O}_{3}$ & Other & Balance \\
\hline Hexaloy SA SiC & $\ldots$ & $\ldots$ & $0.5 \mathrm{~B}$ & $\mathrm{SiC}^{-}$ \\
SNW1000 Si3N4 & 13 & 2 & $\ldots$ & $\mathrm{Si}_{3} \mathrm{~N}_{4}$ \\
$\mathrm{AY}_{3} \mathrm{Si}_{3} \mathrm{~N}_{4}$ & 6 & 2 & $\ldots$ & $\mathrm{Si}_{3} \mathrm{~N}_{4}$ \\
PY6 Si3N4 & 6 & $\cdots$ & $\ldots$ & $\mathrm{Si}_{3} \mathrm{~N}_{4}$ \\
\hline
\end{tabular}

Table 3.4. Properties of Hexaloy SA SiC and PY6 Si3N4.

Property

PY6 $\mathrm{Si}_{3} \mathrm{~N}_{4}$

Hexaloy SA SiC

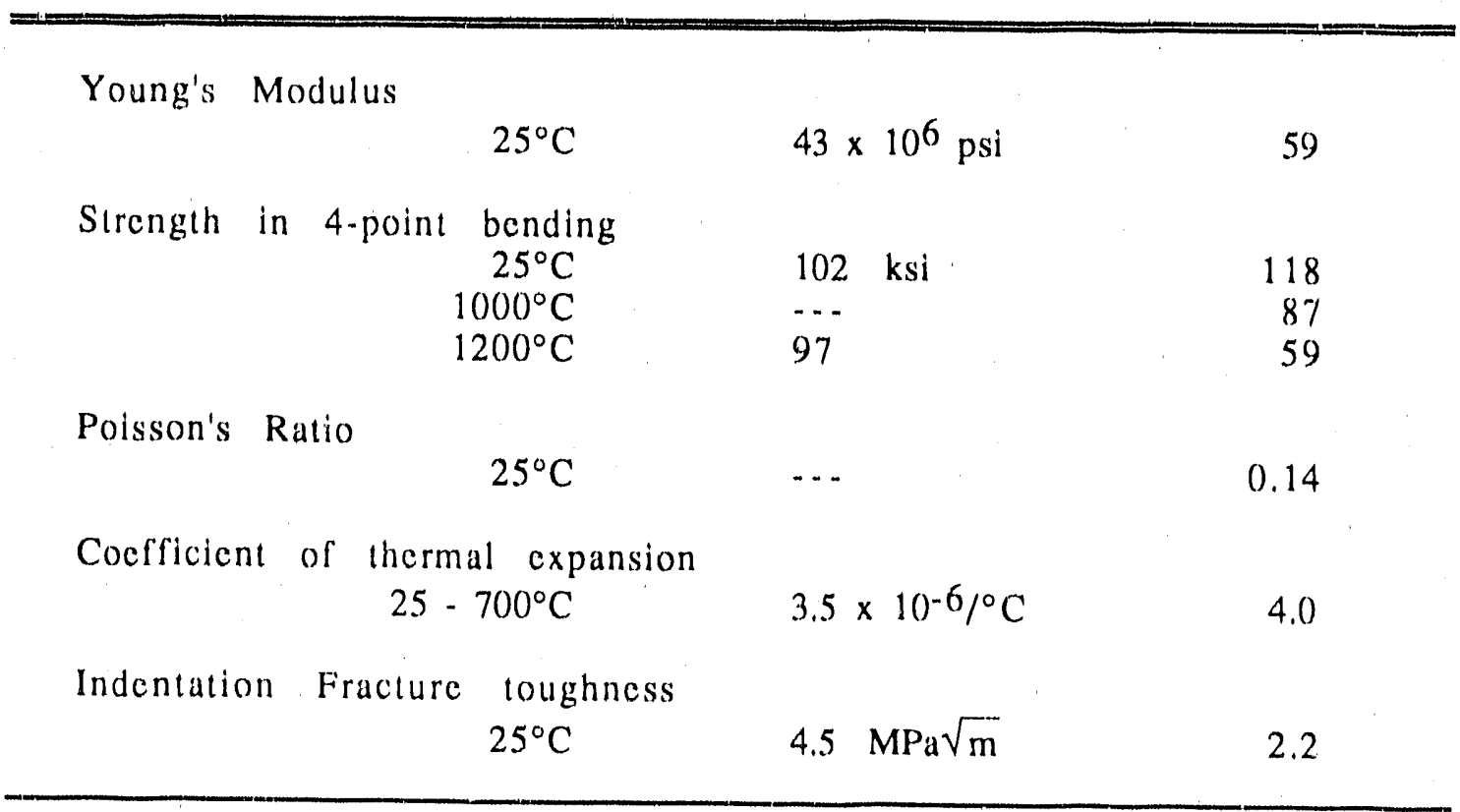

\section{Braze Alloys}

The propertics of the final braze alloys, $\mathrm{Au}-5 \mathrm{Pd}-2 \mathrm{Ni}$ and $30 \mathrm{Au}-34 \mathrm{Pd}-36 \mathrm{Ni}$ (Palniro 4), are summarized in Table 3.5. The major difference between these two braze alloys is that the Au-5Pd-2Ni braze alloy has a much lower yield strength than does the $30 \mathrm{Au}-34 \mathrm{Pd}-36 \mathrm{Ni}$ braze alloy. Both alloys have melting points higher than $11000^{\circ} \mathrm{C}$ and adequate ductility, both of which are needed for the $650^{\circ} \mathrm{C}$ application. 
Table 3.5. Room-temperature properties of the braze alloys.

\begin{tabular}{|c|c|c|}
\hline Property & $A_{11}-5 \mathrm{Pd}-2 \mathrm{Ni}$ & $\begin{array}{c}30 \mathrm{Au}-34 \mathrm{Pd}-36 \mathrm{Ni} \\
(\text { Palniro } 4)\end{array}$ \\
\hline Liquidus Temperature & $1131^{\circ} \mathrm{C}$ & 1169 \\
\hline Solidus Temperature & $1100^{\circ} \mathrm{C}$ & 1135 \\
\hline Young's Modulus & $4.1 \times 10^{6} \mathrm{psi}$ & 4.7 \\
\hline $\begin{array}{l}\text { Tensile strength of fully } \\
\text { annealed material } \\
(0.2 \% \text { Yield strength })\end{array}$ & $27.3(16.8) \mathrm{ksi}$ & $120(90.8)$ \\
\hline $\begin{array}{l}\% \text { elongation } \\
\text { (in } 2 " \text { gauge length) }\end{array}$ & $28 \%$ & $>17 \%$ \\
\hline $\begin{array}{l}\text { Coefficient of thermal } \\
\text { expansion }\end{array}$ & 15.5 & .14 .2 \\
\hline Strain hardening coefficient & $\ldots$ & 0.249 \\
\hline
\end{tabular}

\subsection{COATING MATERIALS DEVELOPMENT}

For most brazing systems, a reactive coating on the ceramic or a reactive component to the braze is needed to provide a driving force for wetting. The thermodynamics of reactions between active metals and ceramics are important in predicting the behavior of ceramic-metal interactions.

The wetting of a ceramic by a metal depends on the chemical compatibility between the two. The concept of chemical compatibility includes the nature of the wetting atmosphere, chemical bonds, chemical reactions, surface energy of the ceramic, and surface tension of the metal $8-10$.

For weakly reacting systems, such as $\mathrm{Pt}$ on $\mathrm{Al}_{2} \mathrm{O}_{3}$, the wetting angle, $\theta$, can be described by the familiar Young equation ${ }^{10}$ :

$$
\gamma_{S V}-\gamma_{S L}=\gamma_{L V} \cos \theta
$$

where $\gamma_{S V}, \gamma_{S L}$, and $\gamma_{L V}$ are the solid-vapor, solid-liquid, and liquid-vapor interfacial energies, respeciively, and $\theta$ is the wetting angle. Wetting is said to occur for $\theta$ less than $90^{\circ}$. The work of adhesion, W, is the free energy change associated with the separation of a unit area of interface and is described by the Dupre equation: 


$$
\mathrm{W}=\gamma_{\mathrm{SV}}+\gamma_{\mathrm{LV}}-\gamma_{\mathrm{SL}}
$$

Combining equations 3.1 and 3.2 ,

$$
W=\gamma_{L V}(1+\cos \theta)
$$

In reactive systems, where chemical reactions occur at the ceramicmetal interface, the free energy associated with the reaction can be much larger than the energies of the surfaces involved ${ }^{11}$. In systems of this type, such as $\mathrm{Ti}$ on $\mathrm{Al}_{2} \mathrm{O}_{3}$, the surface energies are insignificant, and the wetting reaction is driven by the free energy change associated with the reaction at the ceramic-metal interface. For a system of pure liquid B wetting pure solid $A$, forming phase $C\left(A_{x} B y\right)$, the equilibrium wetting angle, $\theta_{e}$, is always smaller than it would have been if a reaction had not taken place at the interface.

The driving force for wetting, $\mathrm{dE} / \mathrm{dr}$, is given by the sum of the contribution due to reactions between the substrate and liquid, $\sigma$, and the contribution due to surface energies, $\Gamma(\theta)$ :

$$
\begin{gathered}
\frac{1}{2 \pi r} \frac{d E}{d r}=\sigma+\Gamma(\theta) \\
\Gamma(\theta)=\gamma_{B}\left(\cos \theta-\cos \theta_{c}\right) \text { and } \cos \theta_{C}=\frac{\gamma_{A}-\gamma_{A C}-\gamma_{B C}}{\gamma_{B}} . \\
\sigma=\frac{\rho_{A} t_{A}}{x M_{A}} \Delta G_{f},
\end{gathered}
$$

where $E$ is the internal energy of the system, $\triangle G_{f}$ is the Gibbs free energy of formation of the compound $A_{x} B y, \rho_{A}$ is the density of $A, t_{A}$ is the thickness of compound $A$ that reacts 10 form compound $A_{x} B_{y}, x$ is the number of $A$ atoms in compound $A_{x} B_{y}$, and $M_{A}$ is the atomic mass of $A$. By comparing the values of $\sigma$ and $\Gamma(\theta)$, the relative importance of the interfacial reaction and the surface energies to the wetting process can be cvaluated.

As an example, $\sigma$ and $\Gamma(\theta)$ can be calculated for a $\mathrm{Au}-\mathrm{Ni}$ braze welling a $\mathrm{Ti}$ coated $\mathrm{Si}_{3} \mathrm{~N}_{4}$ substratc. Assume that the reaction proceeds by the $\mathrm{Au}-\mathrm{Ni}$ braze dissolving the $\mathrm{Ti}$ coating, and that the $\mathrm{Ti}$ and $\mathrm{Si}_{3} \mathrm{~N}_{4}$ react to form $\mathrm{TiN}$. To calculate $\sigma$, we use $\rho_{T i}=4.5 \mathrm{gm} / \mathrm{cm}^{3}, t_{\mathrm{Ti}}=0.05 \mu \mathrm{m}, \mathrm{M}_{\mathrm{Ti}}=49 \mathrm{gm} / \mathrm{molc}, \mathrm{x}=4$, and $\Delta \mathrm{G}_{\mathrm{f}}=-80 \mathrm{kcal} / \mathrm{molc}$ TiN. From Equation 3.6, $\sigma=-90,000 \mathrm{crg} / \mathrm{cm}^{2}$, and becausc the cosine tcrm in Equation 3.5 cannot be larger than 1, we approximate $\Gamma(\theta)=$ $\gamma_{B} \equiv 660 \mathrm{crg} / \mathrm{cm}^{2} 12$. These numbers indicate that the free energy of the reaction at the interface provides a very large driving force for wetting.

Somu of the most promising coating materials were sclected and their wetting behavior was studied. These will be described in the following section. 
These materials were also investigated to verify the effects of the coatings on the mechanical propertics of the ceramic substratc and on the joint strength of brazed coupons using a model system such as Mo-(Au-18Ni)-SNW1000.

\section{Screening of Candidate Coating Materials}

A series of tests were conducted to determine the optimal coating for use in ceramic-metal brazing. Candidate coating materials were selected on the basis of published thermodynamic data 13 . Nitrides and silicides were the expected reaction products. Given favorable thermodynamics, the reaction kinetics were evaluated with powder mixtures and $x$-ray diffraction.

An accelerated test was used to examine reaction kinctics 10 determine the most effective coatings to promote wetting and adhesion between the brayc and the $\mathrm{Si}_{3} \mathrm{~N}_{4}$. In this procedure, candidate coating matcrials were mixed with pure, commercially available $\mathrm{Si}_{3} \mathrm{~N}_{4}$ powder in a ratio of $1: 1$ by volume. The mixtures were compacted in a die with a diameter of $9.5 \mathrm{~mm}$ to produce $3.2 \mathrm{~mm}$ thick discs and heat-treated at $1200^{\circ} \mathrm{C}$ and $1500^{\circ} \mathrm{C}$ for 24 hours in vacuum $\left(10^{-4}\right.$, 10-5 torr). This extended exposure of the samples to high-temperature accelerated the reaction between $\mathrm{Si}_{3} \mathrm{~N}_{4}$ powder and candidate coating materials. Heat-treated samples were ground into powder and analyzed by $x$ ray diffraction to identify the reaction products.

Table 3.6 shows the standard frec energy changes for the probable reactions between $\mathrm{Si}_{3} \mathrm{~N}_{4}$ and the candidate coating matcrials. Coating compounds such as $\mathrm{B}_{4} \mathrm{C}, \mathrm{Al}_{4} \mathrm{C}_{3}$, and $\mathrm{B}_{2} \mathrm{O}_{3}$ did not react to an appreciable extent with $\mathrm{Si}_{3} \mathrm{~N}_{4}$ in spite of favorable driving forces. Reactive elements such as $\mathrm{Ti}$, $\mathrm{Zr}, \mathrm{Hf}$, and Ta resulted in substantial quantitics of $\mathrm{TiN}, \mathrm{ZrN}, \mathrm{HCN}$, and $\mathrm{TaN}$, respectively, at $1500^{\circ} \mathrm{C}$. Al reacted with $\mathrm{Si}_{3} \mathrm{~N}_{4}$ to form $\mathrm{AlN}^{14,15}$. Oxide and silicide formation were observed with $\mathrm{V}$ and $\mathrm{Nb}$. In the case of $\mathrm{Ti}$, which is the most common choice as a coating material, the driving force favors the formation of various silicides as shown below:

$$
\begin{array}{ll}
\mathrm{Si}_{3} \mathrm{~N}_{4}+3 / 2 \mathrm{Ti} \rightarrow 3 / 2 \mathrm{TiSi} 2+2 \mathrm{~N}_{2} \Uparrow & \Delta \mathrm{G}_{\mathrm{xn}}^{\circ}=+10.9 \mathrm{kcal} / \mathrm{mol} \\
\mathrm{Si}_{3} \mathrm{~N}_{4}+5 \mathrm{Ti} \rightarrow \mathrm{Ti} 5 \mathrm{Si}_{3}+2 \mathrm{~N}_{2} \Uparrow & \Delta \mathrm{G}_{\mathrm{xn}}^{\circ}=-85.3 \mathrm{kcal} / \mathrm{mol} \\
\mathrm{Si}_{3} \mathrm{~N}_{4}+3 \mathrm{Ti} \rightarrow 3 \mathrm{TiSi}+2 \mathrm{~N}_{2} \Uparrow & \Delta \mathrm{G}_{\mathrm{xn}}^{\circ}=-37.0 \mathrm{kcal} / \mathrm{mol}
\end{array}
$$

$\Delta \mathrm{G}_{\mathrm{x} \mathrm{n}}^{\circ}$ is the free energy of reaction in the standard state at 120()$^{\circ} \mathrm{C}$. However, since $\mathrm{TiN}$ formation is preferred when $\mathrm{Ti}$ and $\mathrm{Si}_{3} \mathrm{~N}_{4}$ come to contact, there is a relatively insignificant amount of silicide formation after reactions at 1200) $1500^{\circ} \mathrm{C}$ for 24 hours. Similar reactions secmed to occur with $\mathrm{Zr}$, $\mathrm{Hf}$, and $\mathrm{Ta}$ in the formation of nitrides and silicides. It was apparent that $\mathrm{V}$ and $\mathrm{Nb}$ favor silicide formation at $1500^{\circ} \mathrm{C}$. From this preliminary screcning procedure, Ti, $\mathrm{Zr}, \mathrm{Hf}, \mathrm{Al}$, and $\mathrm{Ta}$ were chosen as coating matcrials for $\mathrm{Si}_{3} \mathrm{~N}_{4}$-based ceramic substrates. 


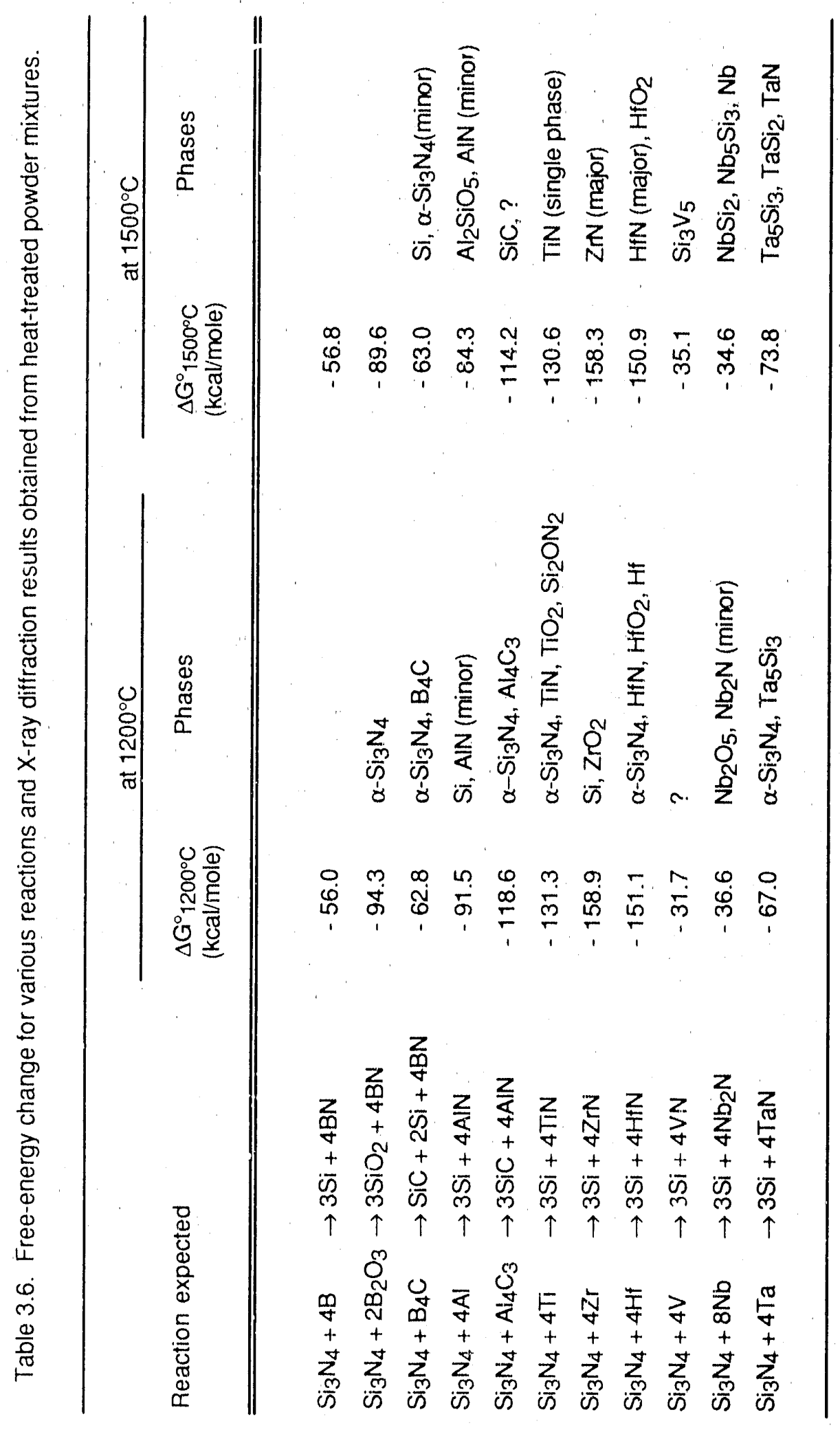


The same approach was used in selecting possible coatings for brazing $\mathrm{SiC}$ as was used for $\mathrm{Si}_{3} \mathrm{~N}_{4}$. Possible chemical reactions were examined from a thermodynamic standpoint using the JANAF data. Reactions of the lype listed below, in Table 3.7, were considered.

Table 3.7. Reactions considered in sclection of coating materials for SiC.

\begin{tabular}{|c|c|c|}
\hline $\mathrm{Si}+\mathrm{C}$ & $\rightarrow \mathrm{SiC}$ & at $1500 \mathrm{~K}=-17.943 \mathrm{kcal} / \mathrm{mol}$ \\
\hline $\mathrm{SiC}+\mathrm{Ta}$ & $\rightarrow \mathrm{Si}+\mathrm{TaC}$ & $\Delta \mathrm{G}_{\mathrm{xn}}^{\circ}$ at $150(0 \mathrm{~K}=-33.561 \mathrm{kcal} / \mathrm{mol}$ \\
\hline $\mathrm{SiC}+\mathrm{Ti}$ & $\rightarrow \mathrm{Si}+\mathrm{TiC}$ & $\Delta \mathrm{G}_{\mathrm{xn}}^{\circ}$ at $1500 \mathrm{~K}=-4(0.185 \mathrm{kcal} / \mathrm{mol}$ \\
\hline $\mathrm{SiC}+\mathrm{Zr}$ & $\rightarrow \mathrm{Si}+\mathrm{ZrC}$ & $\Delta \mathrm{G}_{\mathrm{xn}}^{\circ}$ at $1500 \mathrm{~K}=-43.453 \mathrm{kcal} / \mathrm{mol}$ \\
\hline $\mathrm{SiC}+\mathrm{Hf}$ & $\rightarrow \mathrm{Si}+\mathrm{HrC}$ & $\Delta \mathrm{G}_{\times \mathrm{n}}^{\circ}$ at $1500 \mathrm{~K}=-49.155 \mathrm{kcal} / \mathrm{mol}$ \\
\hline
\end{tabular}

Since TaC, TiC, ZrC, and HeC have a lower free energy of formation than $\mathrm{SiC}$, these reactions are favored. In general, SiC is unstable at high temperatures compared with $\mathrm{Si}_{3} \mathrm{~N}_{4}$.

Cross-section samples were prepared for transmission electron microscopy from a SNW100)-Ti-(Au-18Ni) brazed joint and from a SiC-Ti-(Au$18 \mathrm{Ni}$ ) brazed joint. Figure 3.3 shows the cross-section of the SNW10())-Ti-(Au$18 \mathrm{Ni}$ ) brazed joint. The reaction layer was identified as TiN. The interface between the braze and the ceramic is shown in Figure 3.4 for the SiC-Ti-(Au$18 \mathrm{Ni}$ ) brazed joint. The reaction layer was identified by electron diffaction and electron encrgy loss spectroscopy as TiC. In both of these samples, no titanium silicides were seen in the interface region. The silicon liberalcd from the formation of TiN and TiC probably dissolved into the molten braze. 



Figure 3.3. TEM image of the interface in a brazed joint between Au-18Ni braze and $\mathrm{Ti}$ coated $\mathrm{Si}_{3} \mathrm{~N}_{4}$. 

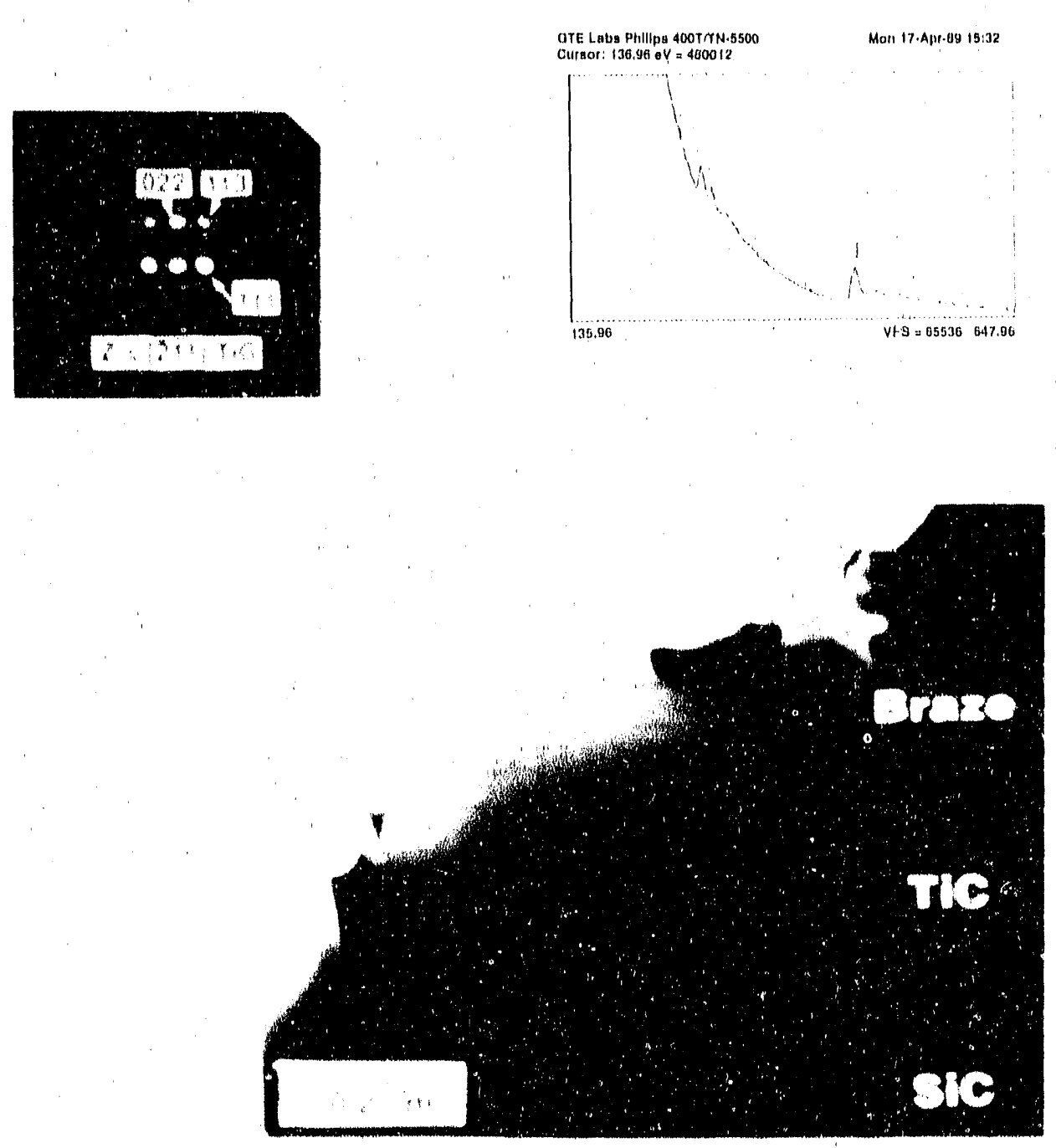

Figure 3.4. TEM image of the interface in a brazed joint between Au-18Ni braze and $\mathrm{Ti}$ coated $\mathrm{SiC}$. 


\section{Wetting Behavior}

Coatings applied to ceramic surfaces must promote wetting of the ceramic by the braze in order to be useful. Welling behavior was studied using the sessile drop method with a video camera recording the drop shape for contact angle measurements. The substrate surface was polished to a finish of $0.1 \mu \mathrm{m}(3 \mu \mathrm{in})$ and coatings were applied using an clectron beam cvaporator at $300^{\circ} \mathrm{C}$ in a $10^{-5} \cdot 10^{-6}$ torr vacuum. Two grams of braze alloy were melted on the coated substrates. Contact angles between substrates and liquid braze were measured as a function of temperature and time. Coatings investigated included $\mathrm{Ti}, \mathrm{Zr}, \mathrm{HF}, \mathrm{Ta}$, and $\mathrm{Al}$. Substrate materials were SNW10()) and Hexaloy SA SiC.

The results of the wetting tests on SNW1000 are given in Figure 3.5. Ti, $\mathrm{Zr}$, and $\mathrm{Hf}$ performed comparably, reaching a contact angle of about ()$^{\circ}$ in approximately 250 seconds. Ta exhibited a wetting angle of $20^{\circ}$ at the end of the test. Liquid Au-18Ni did not wet the Al coated surface of SNW1000, $\theta>150^{\circ}$ at $1000^{\circ} \mathrm{C}$, indicating that the $\mathrm{Al}$ coatings did not interact chemically with the $\mathrm{Si}_{3} \mathrm{~N}_{4}$ at the testing temperature. Therefore, Al was ruled out as a coating matcrial.

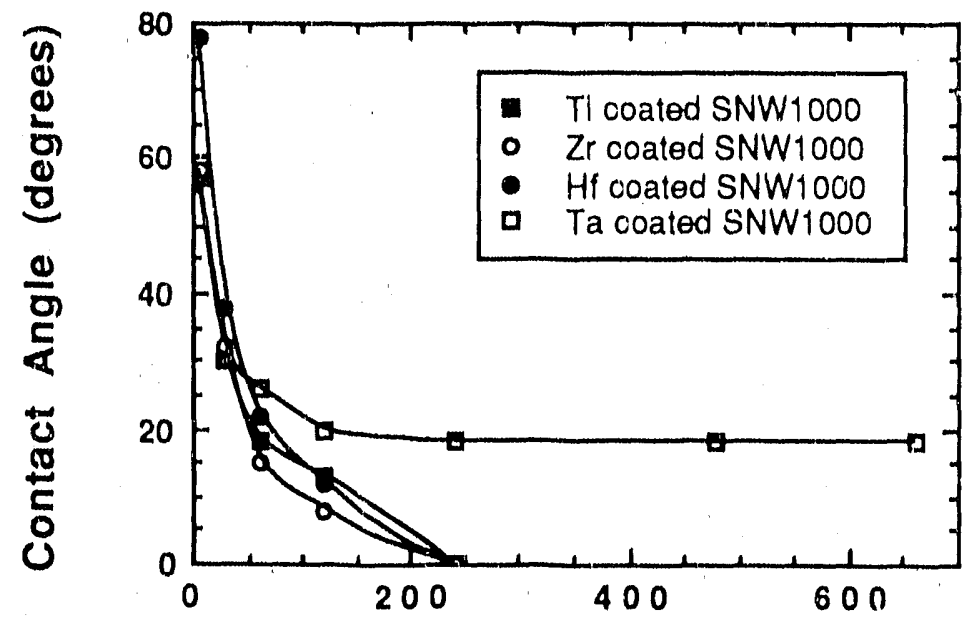

Time (seconds)

Figure 3.5. Welling of Au-18Ni braze on Ti, Zr, Hr, and Ta coated SNW1000.

Ti coatings on Hexaloy $\mathrm{SA} \mathrm{SiC}$ reached a $0^{\circ}$ contact angle in 60 seconds, Figure 3.6. The other coalings showed contact angles of about $15^{\circ}$ with Au$18 \mathrm{Ni}$. In terms of wetting behavior, the coatings were roughly comparable. Therefore, choices between these must be based on other considerations, such as mechanical propertics and chemical interactions at the interface. 


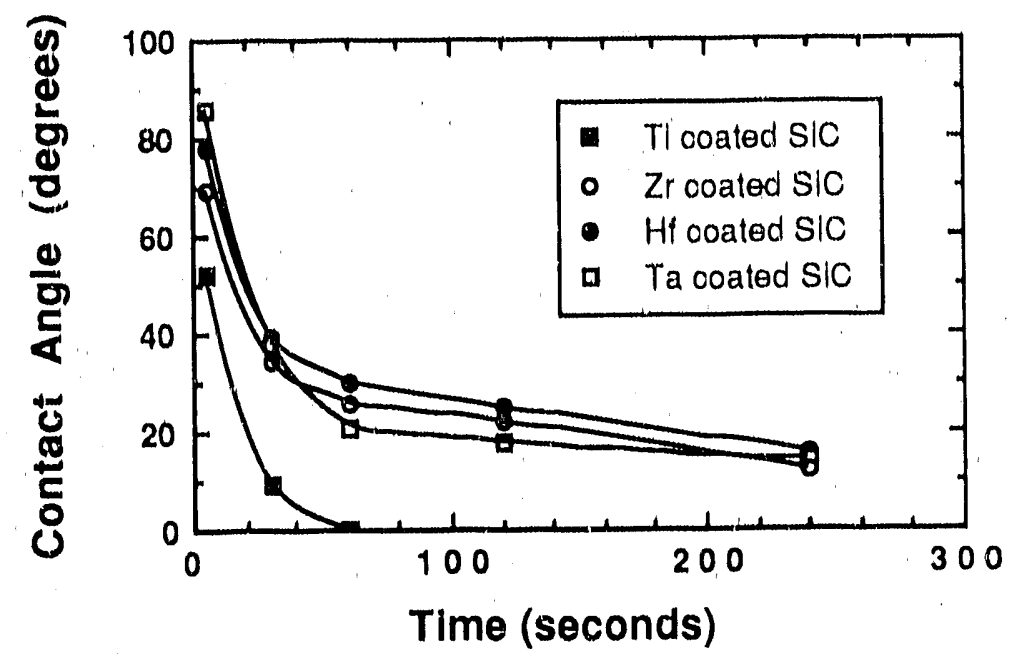

Figure 3.6. Wetting of Au-18Ni braze on Ti, Zr, Hf, and Ta coated SiC.

\section{Effect of Coatings on the Mechanical Properties of the Coramic}

Reactive coatings were applied to ceramics to provide adequate adhesion and wetting between the braze and the coramic. It is desirable to have coating matcrials which can perform without degrading the propertics of the ceramic substrates. It is common to find that massive reaction products cause deterioration of the mechanical propertics of parent materials due to the change in properties and volume, and the strain and thermal mismatch. In the current study, a methodology was developed to evaluate the effect of coatings on the mechanical strength of the substrate.

The effect of $\mathrm{Ti}, \mathrm{Zr}, \mathrm{Hf}$, and $\mathrm{Ta}$ coatings on the mechanical propertics of ceramic matcrials was investigated using modulus of rupture (MOR) lests. As shown in Figure 3.7, MOR bars were machined from various $\mathrm{Si}_{3} \mathrm{~N}_{4}$ ceramics and then coated and vacuum heat-treated to examine the cffect of reactive coatings on the mechanical propertics of the ccramic substrate. Effort was made to minimizc the effect of lot-10-lot variations in mechanical propertics on the interpretation of test results. The same number of MOR bars were prepared from each ceramic blank for cach coating. One side of the MOR bars' $(25.4 \mathrm{~mm} \times 2.54 \mathrm{~mm} \times 1.3 \mathrm{~mm})$ surface was polished to $0.1 \mu \mathrm{m}$ and coated with one of the reactive coating materials. Coatings were electron beam deposited at $300^{\circ} \mathrm{C}$ in a $10^{-5}-10^{-6}$ torr vacuum. A thickness of $3 \mu \mathrm{m}$ was used, except for $\mathrm{Hf}$, which had a $6 \mu \mathrm{m}$ coating. Coated MOR bars were exposed 1094()$^{\circ} \mathrm{C}$ for 10 minutes and loaded at room-temperature in 4-point bending. An Instron Model 1320 and strain rate of $0,0085 \mathrm{~mm} / \mathrm{s}(0.02 \mathrm{in} / \mathrm{min})$ were use for the tests. Scanning electron microscopy (SEM) was used to understand the role of the coating layer and interface reactions. 


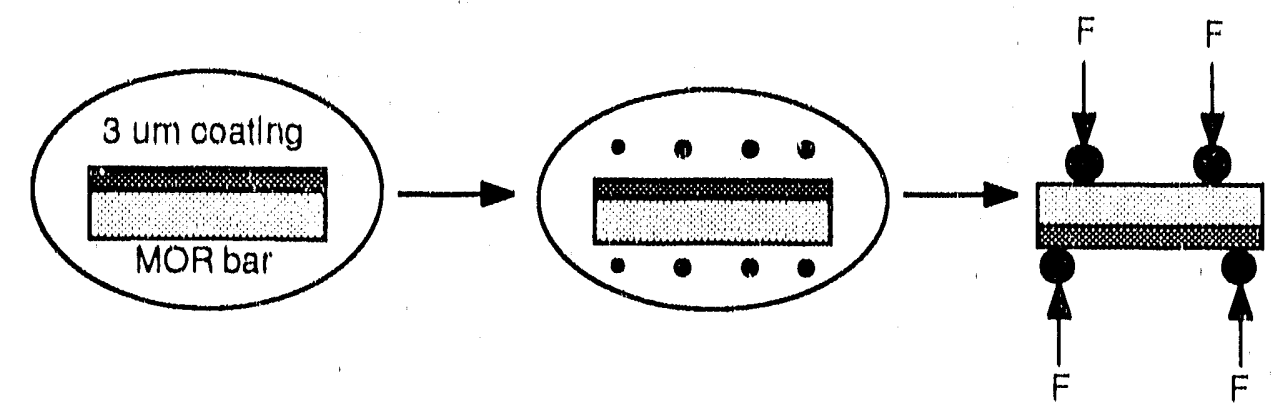

$\begin{array}{lll}\text { Electron beam deposition } & \text { Brazing cyole: } & \text { MOR test with } \\ \text { of coatling at } 300^{\circ} \mathrm{C} \text { under } & 940^{\circ} \mathrm{C}, 10 \mathrm{mln} . & \text { coated side In } \\ \text { vacuum } & \text { under vacuum } & \text { tension }\end{array}$

Figure 3.7. Procedure 10 evaluate the effect of coating on the mechanical properiles of ceramic matcrials.

Si3 $\mathbf{N} 4$ _System. Figure 3.8 shows a Weibull plot of SNW 1000 MOR bars with various coatings. The interactions between the reactive coatings and the ceramic substrate caused a reduction in strength of $5 \%-20 \%$ compared with as-polished bars. In contrast, the MOR strengths of the coated bars without heat-treatment were essentially unchanged. Furthermore, the Weibull slope of as-polished bars was steeper than that of heat-treated, coated bars. The difference in Weibull slope was attributed to the relatively shorl reaction time between the coatings and the ceramic substrate. The short reaction time resulted in nonuniformity in the reaction at the ceramic-metal interface. The MOR strength of as-polished bars was equivalent to that of uncoated, vacuum heat-treated bars.

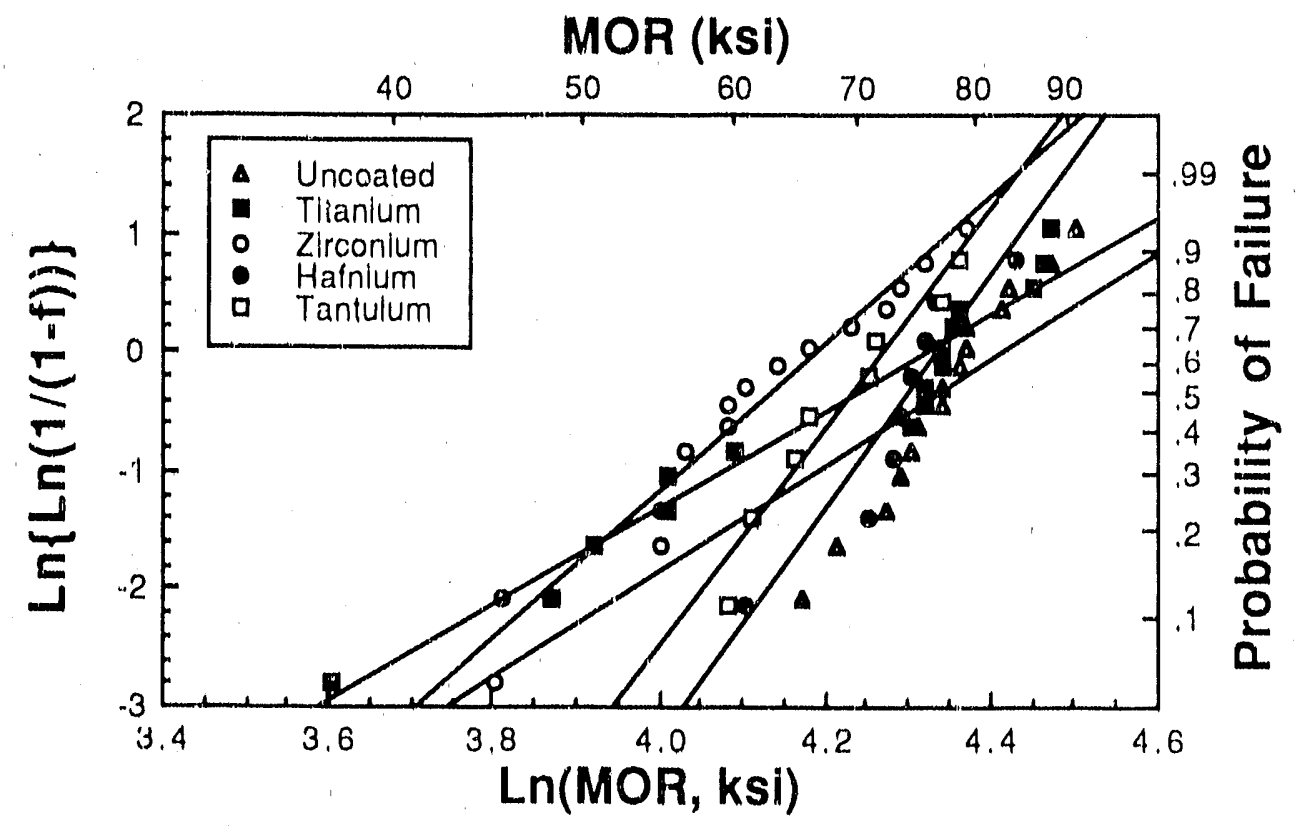

Figure 3.8. Effects of Ti, Zr, Hr, and Ta coatings on the MOR strength of SNW1000. 
The formation of various oxides, such as $\mathrm{THO}_{2}, \mathrm{ZrO}_{2}, \mathrm{HrO}_{2}$, and $\mathrm{T}^{\prime} \mathrm{O}_{2}$, was expected due to the vacuum level used for the heatutreatments in the experiments discussed above. From Auger analysls, oxygen contumination during the coating process was found to be instgnificant. In order to separale the effect of oxide formation from the elfect of substrate-conting reactions, similar experiments were carried out in which reactive contings were immediately followed by $\mathrm{Ni}$ coating in vacuum. Figure 3.9 showed that the combined $(\mathrm{Ti}, \mathrm{Ni})$ coating reduced the MOR strength as much as the $\mathrm{Ti}$ coating did. This indicates that the reduction in MOR strength was directly related io ceramic-reactive coating reactions. It was also found that the MOR strength decreases with an increase of coating thickness.

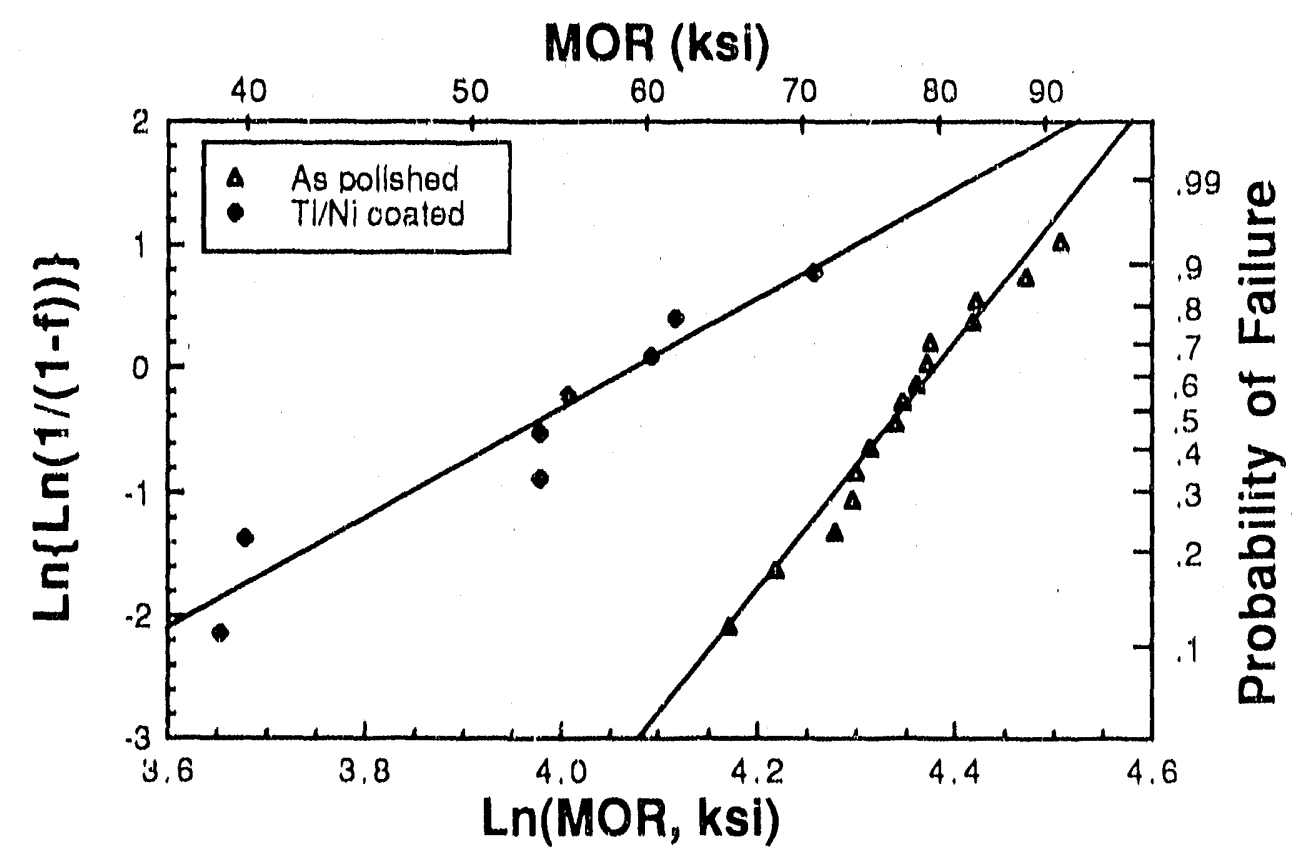

Figure 3.9. Effects of Ti-Ni coating on the MOR strength of SNW1()(),

A study was done with a nonreactive coating, $\mathrm{Ni}$, to detcrmine whether the coating process itsclf was responsible for the reduction of the mechanical properties of $\mathrm{Si}_{3} \mathrm{~N}_{4}$. The MOR bars, coated with 3.() $\mu \mathrm{m} \mathrm{Ni}$, were exposed 10 a brazing thermal cycle, $940^{\circ} \mathrm{C}$ or higher for 10 minutes, and tested by 4-point bending. In contrast to the reactive coatings, the $\mathrm{Ni}$ coating had no effect on the MOR strength after the heat treatment, Figure 3.10. In the as-coaled, no heat-treatment condition it was found that the MOR strenglh values were at least equivalent to those obtained from aspolished bars for all coatings. An additional nonreactive Ni layer on the ceramic bar always increased the strength of the bar, probably by reducing the number of potential areas of crack initiation sites. 


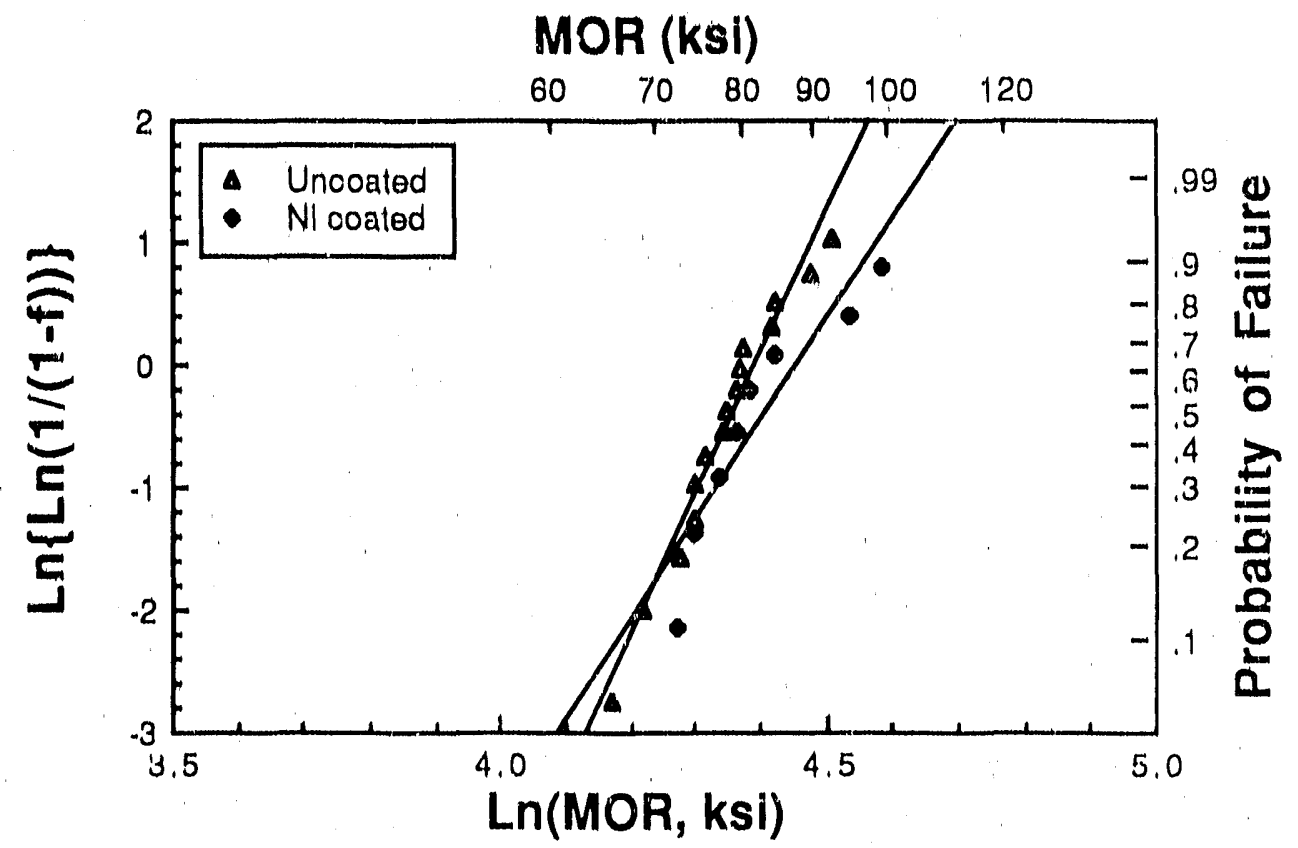

Figure 3.10. Effects of $\mathrm{Ni}$ coating on the MOR strength of SNW10()().

SEM micrographs of $\mathrm{Ni}$ and $\mathrm{TI}$ coating are shown in Figure 3.11. Both MOR bars were exposed to a brazing cycle after coating and were testod by 4 point bending. The fractured pleces were placed together with the coated sides adjacent for metallography. The Ni coating remained intact on the $\mathrm{Si}_{3} \mathrm{~N}_{4}$ during the test without secondary cracks in the layer near the fracture area, Figure 3.11a: This may indicate that the $\mathrm{Ni}$ layer did not facilitate crack initiation. A similar result was found for Ti, Figure 3.11b. The apparent lack of cracks in the coatings reinfored the conclusion that $\mathrm{TiO}_{2}$ or other cnvironmental products did not cause degradation of the mechanical properties.
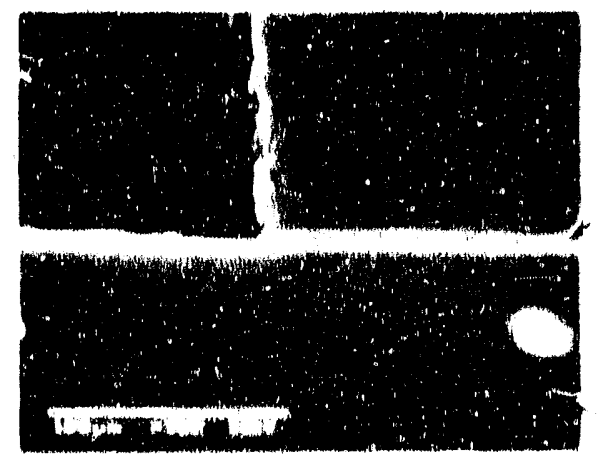

(a)

\section{Coating}

MOR Bar

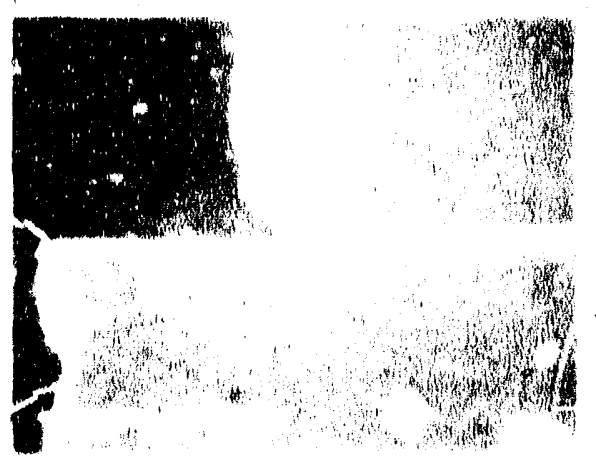

(b)

Figure 3.11. SEM micrographs of (a) Ni coated and (b) Ti coated MOR bars, after heal-treatment. 
$\mathrm{Zr}$ and Hi contings caused the least damage to the ceramic MOR strongth, while Th coating caused the mosl. The slopes of Welbull plots also indicate that the $T$ coaling caused the most varlability in properties. This Implies that the reaction between Tl and the ceramic is more aggressive and time dependent than other coating matcrials.

MOR tests were used to evaluate the effect of coatings on the mechanleal properties of AYG and PYG. Bars were coaled with various materials in vacuum and exposed to $980^{\circ} \mathrm{C}$ for 10 minutes, Figure 3.12 shows the Welbull plots for AY6, Tl coatings caused a dramatic $50 \%$ reduction in MOR, similar to that secn for ti coatings on SNW100). The influcnce of' $\mathrm{Zr}$ or $\mathrm{Hf}$ coatings on the MOR strength was minimal. Ta conlings decreased the MOR strength by $20-50 \mathrm{ksi}$. The impact of various coatings including $T$ on the MOR strength of PY 6 was almost insignificant, Figure 3.13.

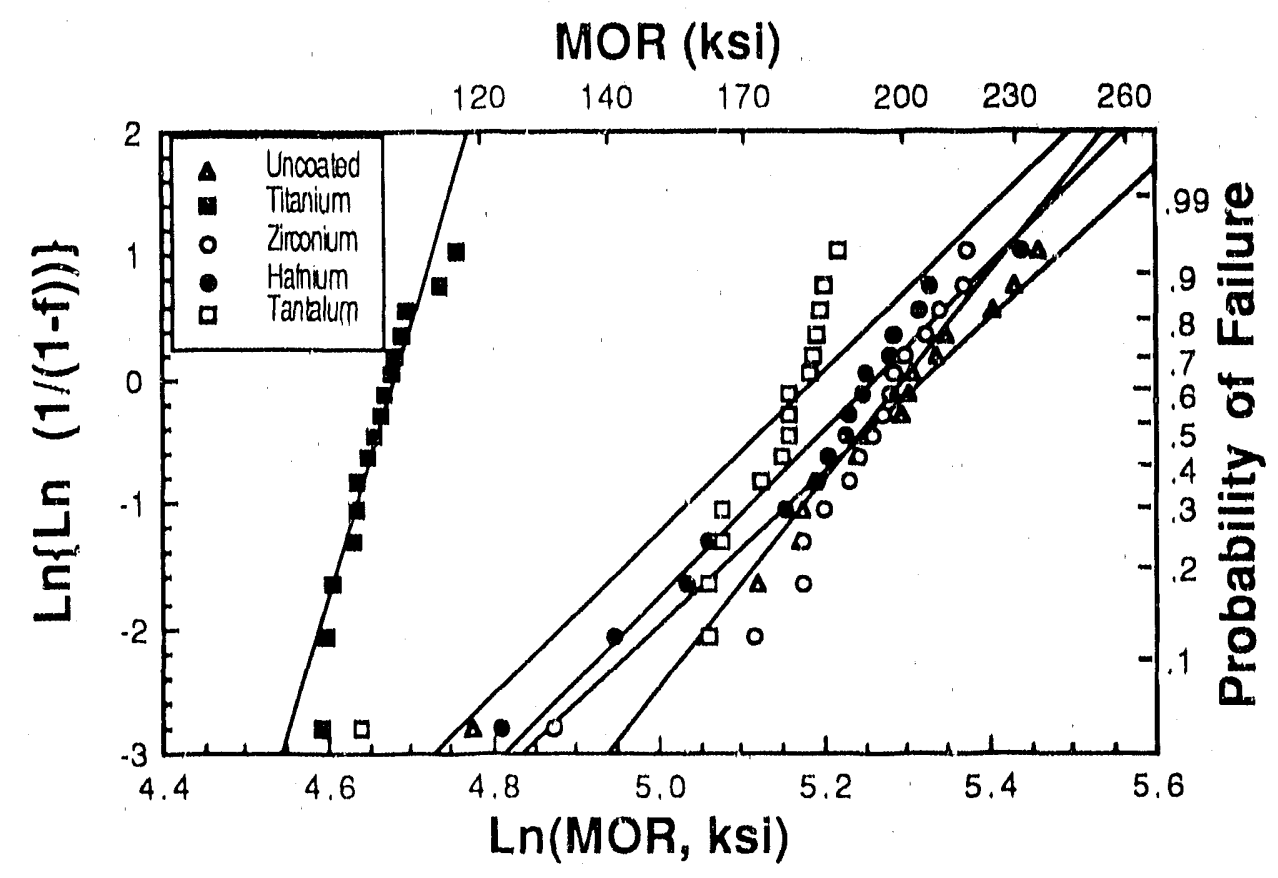

Figure 3.12. E'icels of Ti, Zr, Hi, and Ta coatings on the MOR strength of AY6. 


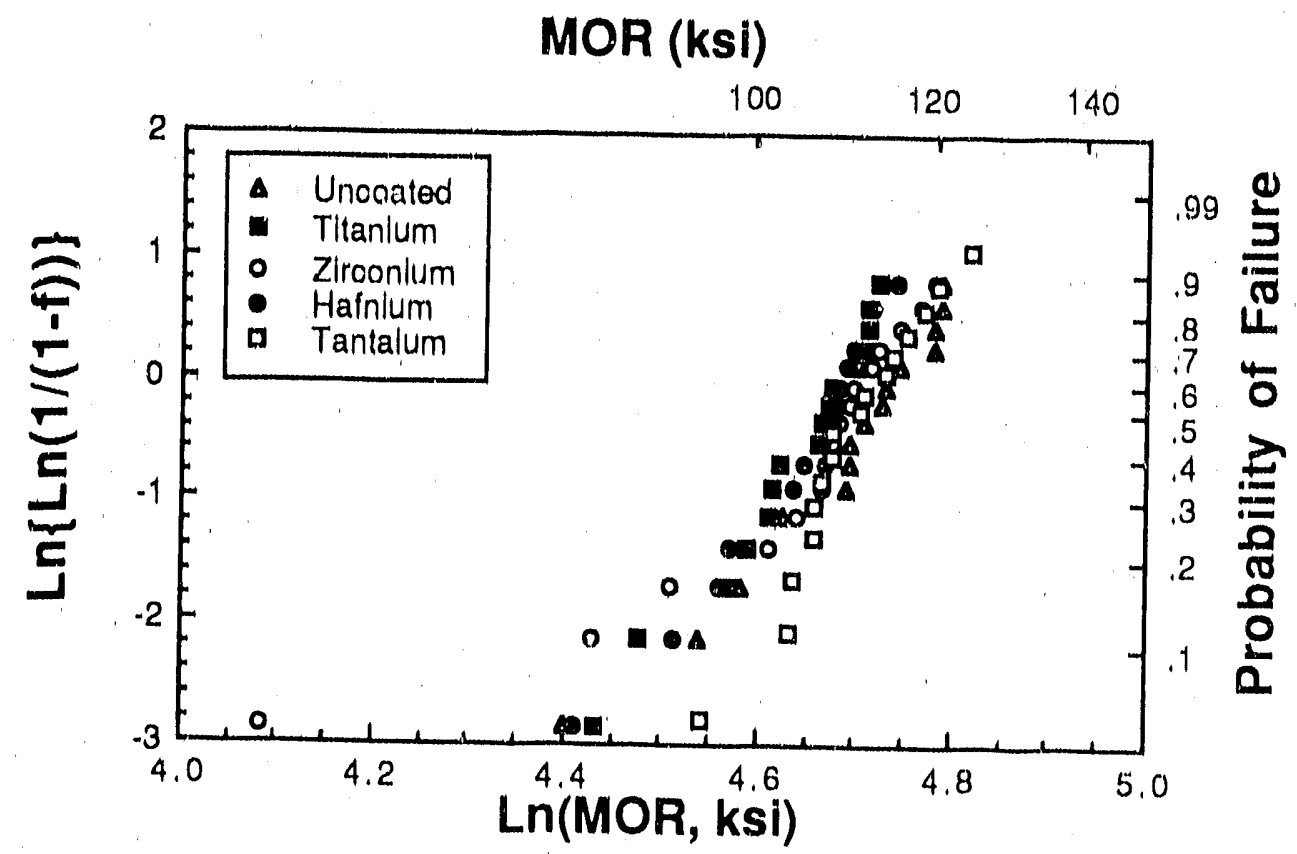

Figure 3.13. Effects of Ti coatings on the MOR strength of PY6.

Separate cxperiments indicate that $\mathrm{Ti}$ coatings reduced the MOR strength of $\mathrm{Si}_{3} \mathrm{~N}_{4}$ by reacting with the grain boundary glass phase in the $\mathrm{Si}_{3} \mathrm{~N}_{4}$ matcrials. SNW1000 and AY6 were affected strongly by $\mathrm{Ti}$ coallings. These both contain $2 \mathrm{wt} \% \mathrm{Al}_{2} \mathrm{O}_{3}$, Table 3.3, which causes the grain boundary phase to be more glassy. The theory that the glassiness of the grain boundary affects the degree of degradation of the MOR strength of $\mathrm{Si}_{3} \mathrm{~N}_{4}$ is also supported by similar experiments with $\mathrm{Si}_{3} \mathrm{~N}_{4}-\mathrm{TiC}_{\text {. }} \mathrm{Si}_{3} \mathrm{~N}_{4}$-TiC also showed a small decrease in strength after $\mathrm{Ti}$ coating. Si3 N4-TiC has about $1.2 \mathrm{wt} \% \mathrm{Al}_{2} \mathrm{O}_{3}$ along with 39 wt\% TlC, which can minimizc the impact on strength from Ti
coating.

SiC System. A series of coated SiC MOR bars were prepared to evaluate the effect of various coatings on the mechanical propertics of SiC. Groups of 15 samples were cither coated with $3 \mu \mathrm{m}$ of $\mathrm{Ti}, \mathrm{Zr}$, Hf, or $\mathrm{Ta}$ or were uncoated. They were then subjected to a thermal cycle at $9800^{\circ} \mathrm{C}$ for 10 minutes. MOR testing was done in the same manner as with $\mathrm{Si}_{3} \mathrm{~N}_{4}$, i.c., the coated side was placed in tension to measure any change in strength caused by the interfacial reactions. The results are shown in Figure 3.14. The uncoalcd specimens serve as baseline values. Ta coatings resulted in a small but noticeable improvement in MOR strength. Ti and $\mathrm{Zr}$ cach had small negative cflects on the MOR strength. Hf had an extremely damaging impact on the MOR strength of the
SiC samples. 


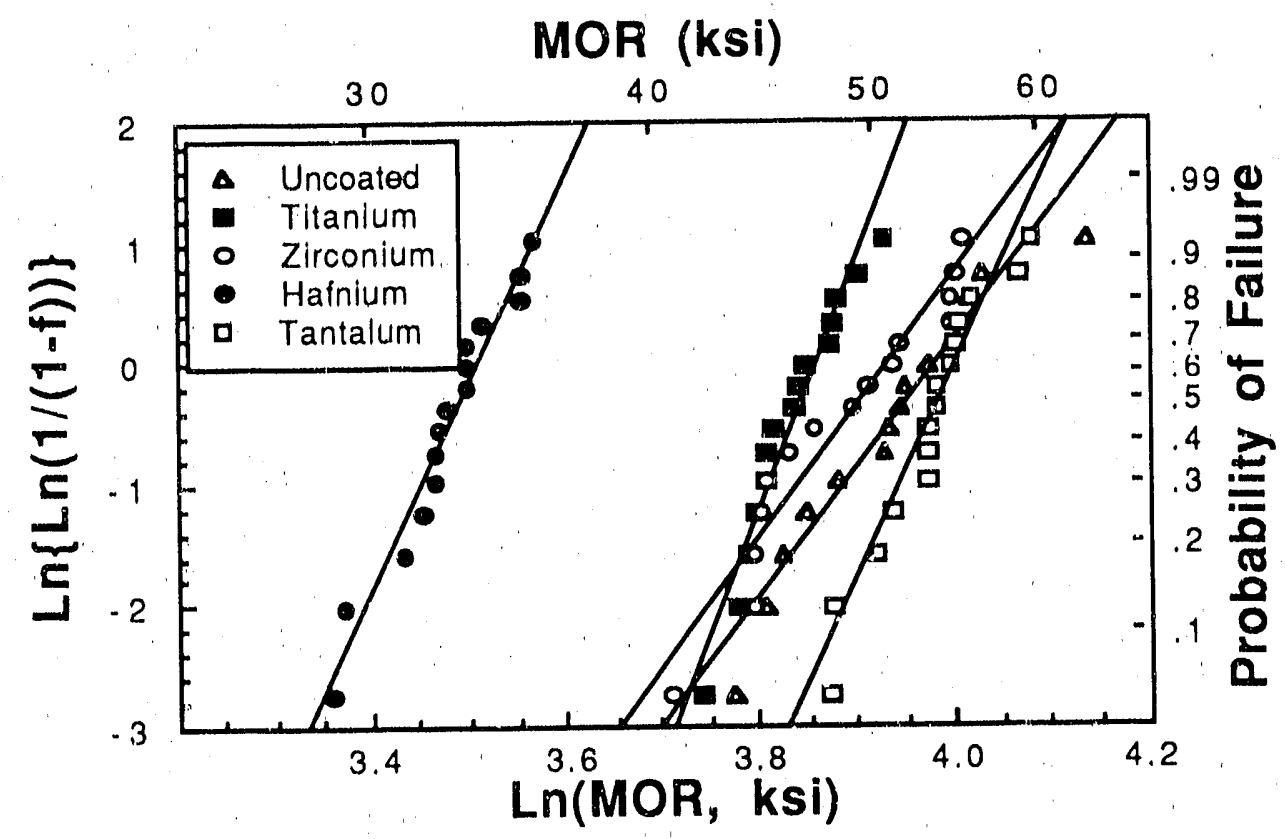

Figure 3.14. Effects of $\mathrm{Ti}, \mathrm{Zr}, \mathrm{Hf}$, and Ta coatings on the MOR strength of Hexaloy SA SiC.

$\mathrm{Zr}$ and $\mathrm{Hf}$ coatings were suitable for SNW 1000, and $\mathrm{Ta}$ was the preferred coating material for Hexaloy $\mathrm{SA} S \mathrm{SiC}$, with $\mathrm{Ti}$ and $\mathrm{Zr}$ as second and third choices, respectively, Ti was considered to be unacceptable for SNW1000 and AY6, whereas the impact of $\mathrm{Ti}$ coating was minimal for PY6. Hf was detrimental for Hexaloy SA SiC.

\section{Mechanical Strength and Microstructure}

The bchavior of matcrial systems was characterized by shear testing of rectangular brazed coupon specimens as shown in Figure 3.15. The effects of coatings, and other joint components such as the ceramic, braze, and structural alloy, on the joint strength of two dissimilar matcrials produced by brazing was studied as a system.

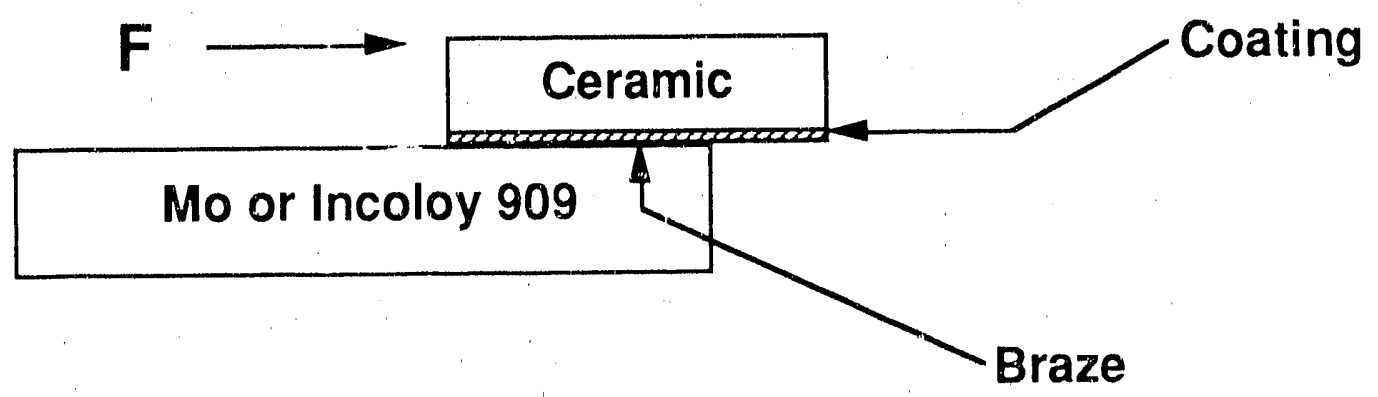

Figure 3.15. Schernatic of the shear test samples. 
Various ceramic-metal joints were prepared and tested to evaluate the joint strengths. All substrate materials were polished to a $0.1 \mu \mathrm{m}$ finish, and the polished surfaces of the ceramic substrate were coated with one of the coating materials to promote the wetting of the braze alloy. Joints were brazed with Au-18Ni at $980^{\circ} \mathrm{C}$ for 10 minutes and shear tested with an Instron 1320 in compression mode. The same joint area, i.e., $1.0 \mathrm{~cm}^{2}\left(0.15 \mathrm{in}^{2}\right)$, was used in all tests for comparison. Failure loads were recorded at the point of the first load drop to avoid inflated strength values due to scraping during shear tests. Most of the strength values are an average of two or three tests.

Si3 $\mathbf{N}_{4}$ System. Three different joint systems were prepared: Incoloy 909-SNW1000, Mo-SNW1000, and SNW1000-SNW1000 using Au-18Ni braze alloy with various coating materials. Table 3.8 shows the shear test results for the joint systems. $\mathrm{Zr}$ and $\mathrm{Hf}$ were the preferred coating materials over Ti. The joints of Mo to $\mathrm{Si}_{3} \mathrm{~N}_{4}$ were significantly stronger than those of Incoloy 909 to $\mathrm{Si}_{3} \mathrm{~N}_{4}$. The low CTE of Mo $\left(\sim 6 \times 10^{-6} /{ }^{\circ} \mathrm{C}\right.$ in the range of $\left.20-925^{\circ} \mathrm{C}\right)$ resulted in higher joint strengths compared to Incoloy 909 , with a CTE of $\sim 9 \times 10^{-6} /{ }^{\circ} \mathrm{C}$ in the range of $20-627^{\circ} \mathrm{C}$. The residual stress due to the difference in the CTE between SNW1000 and Incoloy 909 was sometimes large enough to crack the ceramic surface after a brazing cycle.

Table 3.8. $\mathrm{Si}_{3} \mathrm{~N}_{4}$ shear coupon test data.

\begin{tabular}{|c|c|}
\hline Materials system & $\begin{array}{ll}\text { Average } & \text { shear } \\
\text { strength } & (\mathrm{ksi})\end{array}$ \\
\hline Incoloy $909-(\mathrm{Au}-18 \mathrm{Ni})-\mathrm{Ti}-\mathrm{SNW} 1000$ & 0.7 \\
\hline Incoloy $909-(\mathrm{Au}-18 \mathrm{Ni})-\mathrm{Zr}-\mathrm{SNW} 1000$ & $3: 0$ \\
\hline Incoloy 909-(Au-18Ni)-Hf-SNW 1000 & 3.8 \\
\hline Mo-(Au-1 8Ni)-Ti-SNW 1000 & 7.1 \\
\hline $\mathrm{Mo}-(\mathrm{Au}-18 \mathrm{Ni})-\mathrm{Zr}-\mathrm{SNW} 1000$ & 11.5 \\
\hline Mo- $(\mathrm{Au}-18 \mathrm{Ni})-\mathrm{Hf}-\mathrm{SNW} 1000$ & 7.7 \\
\hline SNW 1000-Ti-(Au-18Ni)-SNW 1000 & 42.3 \\
\hline SNW $1000-\mathrm{Zr}-(\mathrm{Au}-18 \mathrm{Ni})-\mathrm{SNW} 1000$ & 45.1 \\
\hline SNW 1000-Ta-(Au-18Ni)-SNW 1000 & 27.5 \\
\hline
\end{tabular}

The effect of coatings on the shear strength appeared to be minimizcd when a joint had a low residual stress at the braze interface. The results from the SNW1000-SNW1000 joints which had almost zero residual stress at the interface support this observation. The difference in the shear strength between SNW1000-SNW1000 and other systems was attributed to differential 
expansion, implying that Incoloy 909-SNW1000 and Mo-SNW1000 joints had large residual stresses, approximately $30-40 \mathrm{ksi}$.

The fracture modes of these three systems were distinct from each other. All samples of the Incoloy 909-SNW1000 joints were found to be either cracked in the ceramic portion after brazing or had significant unbonded areas, and no strength. In the Mo-SNW 1000 joints, a mixed fracture mode was seen where the crack path was associated with both the ceramic and the Mo. In this system, cracks which initiated in the ceramic propagated into the Mo substrate. In both systems, Incoloy 909-SNW1000 or Mo-SNW1000, cracking was initiated at a point in the ceramic substrate where the maximum tensile stress was predicted by finite element analysis ${ }^{6}$. The SNW1000-SNW1000) joints did not show any pattern in the crack path, implying that there were no highly stressed regions in the system for preferred crack propagation.

Sic Srstem. 'lable 3.9 shows the shear test results of three joint systems: Incoloy 909-SiC, Mo.SiC, and SiC-SiC. These tests provide a considerable amount of information concerning the effect of differential contraction on residual stress, SiC cracking, interlayer effectiveness, and shear properties.

Table 3.9. SiC shear coupon test results.

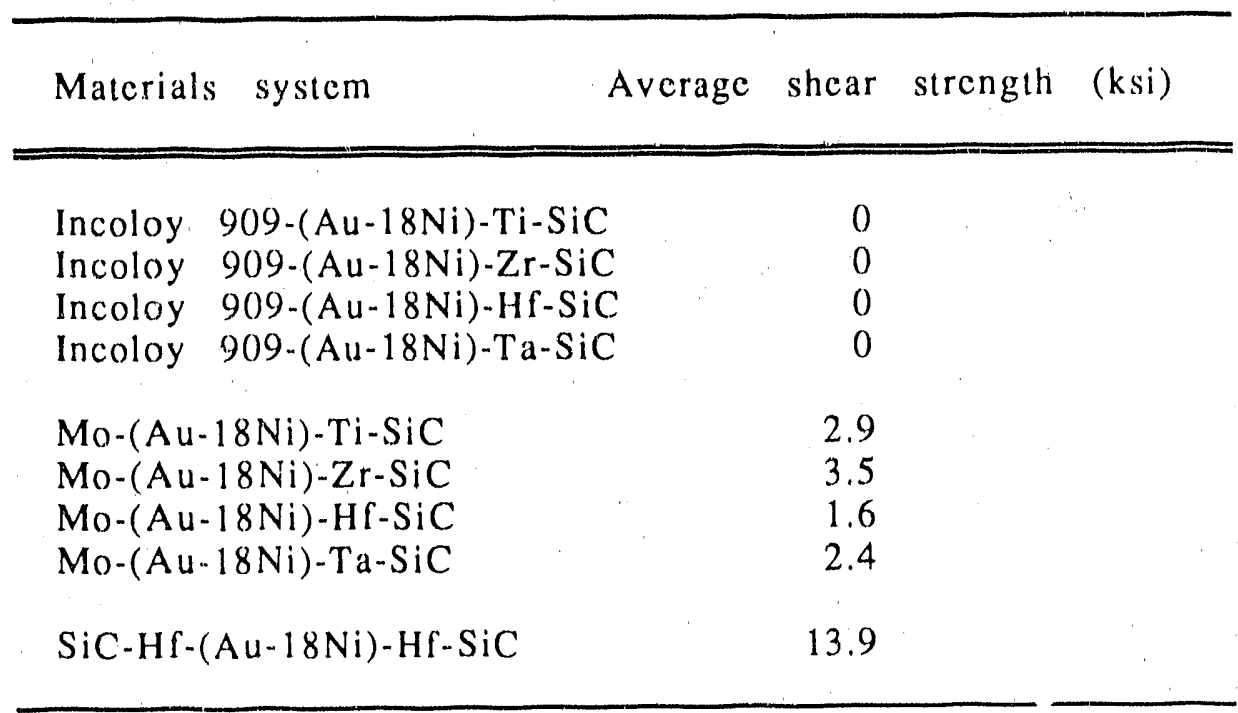

The Incoloy 909-SiC samples all failed on cooling to room-temperature. They were unable to withstand the relatively large differential contraction between Incoloy 909 and $\mathrm{SiC}$. The lower expansion of Mo made it possible to make braze couples for shear tests with reasonable strengths.

The work on $\mathrm{SiC}$ joining included two pairs of SiC-SiC joints. Each piece of $\mathrm{SiC}$ was coated with $3 \mu \mathrm{m}$ of $\mathrm{Hf}$, brazed with Au-18Ni, and shear tested. The mean shear stress of these samples was $13.9 \mathrm{ksi}$. This was significantly higher than was obtained with SiC-metal joints in the variety of configurations discussed above. The low values reported for SiC-metal joints raised the 
concern that perhaps chemical degradation, rather than residual stress from differential expansion, was responsible. The coating used for the SiC-SiC joints, Hf, had resulted in the largest reduction in propertics in the coated MOR tests. However, the fact that even the most chemically damaging coating yielded high shear strength values in the absence of differential expansion demonstrated that chemical attack was not the primary factor responsible for the low strength of SiC-metal pairs. All of the tested SiC samples had a common feature: i. e., they all falled entirely in the ccramic. This is significant in terms of interpretation of results, since it makes it possible to rule out the effect of unbonded areas in the brazed joint.

The coating material effected the mechanical strength of the Mo-SiC joints, as seen with the MOR strength tests of the coated $\mathrm{SiC}$ MOR bars. $\mathrm{Ti}$ and $\mathrm{Zr}$ were the best coatings for Mo-SiC joints.

\section{Effects of Brazing Processes}

A series of tests were performed to determine whether Mo diffusion into the liquid braze, with the resultant effect on liquidus temperature, would limit the acceptable window of processing variables. Figure 3.16 shows the extent of Mo diffusion in the SNW 1000) Zr-(Au-18Ni)-Mo system. Significant diffusion of Mo is noted in the braze layer after $980^{\circ} \mathrm{C}$, for $10 \mathrm{~min}$. Based on this observation, two extreme processing conditions were selected: 1) brazing at $960^{\circ} \mathrm{C}$ for 3 minutes and 2) brazing at $1100^{\circ} \mathrm{C}$ for 30 minutes in order 10 determine the effect of the diffusion on bonding performance.

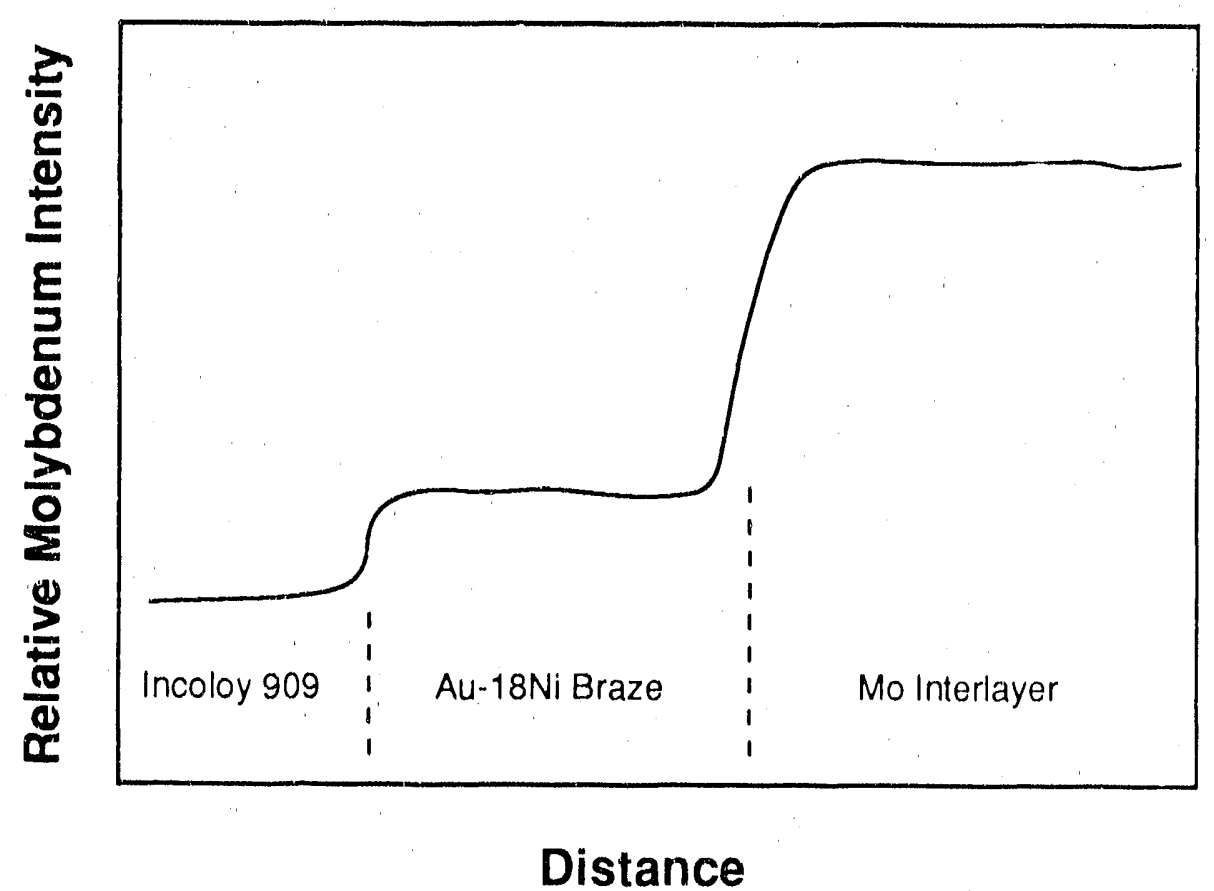

Figure 3.16. Microprobe result showing the extent of Mo diffusion in the SNW1000-Zr-(Au-18Ni)-Mo-Incoloy 909 system. 
Fast diffusion of Mo is evident for both sets of brazing conditions. Brazing at $960^{\circ} \mathrm{C}$ for 3 minutes resulted in a braze layer of $40-45 \mu \mathrm{m}$ in thickhess which had moderate alloying with Mo, 20 $\mu \mathrm{m}$ thick. Brazing at $1100^{\circ} \mathrm{C}$ for 30 minutes extended the Mo diffusion further and caused severe alloying with braze alloy, $30 \mu \mathrm{m}$ in thickness. The diffusion and the reaction between braze alloy and Mo in the presence of a liquid phase were extensive in both cases, even at $960^{\circ} \mathrm{C}$ for 3 minutes. However, acceptable brazes were obtained over the wide range of processing variables. A faceted phase in the braze layer after brazing at $1100^{\circ} \mathrm{C}$ for 30 minutes, was probably due to the interaction between $\mathrm{Zr}$ and $\mathrm{Mo}-(\mathrm{Au}-18 \mathrm{Ni})$ phase.

Table 3.10 shows the results of shear strength testing. As shown in this table, there is no noticcable difference in strength among threc different processing conditions. Also, excellent bonding was obtained in all three cases. It was concluded from this investigation that brazing conditions such as temperature and holding time have little effect on bonding performance.

Table 3.10. The effect of processing parameters on bond strength of Mo-SNW1000 joints.

\begin{tabular}{|c|c|c|}
\hline Brazing Conditions & $\begin{array}{c}\text { Shear } \\
\text { Strength (ksi) }\end{array}$ & $\begin{array}{l}\text { Bonding } \\
\text { Results }\end{array}$ \\
\hline $\begin{array}{l}960^{\circ} \mathrm{C} \text { for } 3 \mathrm{~min} . \\
960^{\circ} \mathrm{C} \text { for } 3 \mathrm{~min} . \\
960^{\circ} \mathrm{C} \text { for } 3 \mathrm{~min} . \\
960^{\circ} \mathrm{C} \text { for } 3 \mathrm{~min} . \\
\text { Average }\end{array}$ & $\begin{array}{r}5.4 \\
2.1 .5 \\
9.4 \\
11.9 \\
12.1\end{array}$ & $\begin{array}{l}\text { excellent } \\
\text { excellent } \\
\text { cxecllent } \\
\text { excellent }\end{array}$ \\
\hline $\begin{array}{l}1100^{\circ} \mathrm{C} \text { for } 30 \mathrm{~min} . \\
1100^{\circ} \mathrm{C} \text { for } 30 \mathrm{~min} . \\
1100^{\circ} \mathrm{C} \text { for } 30 \mathrm{~min} . \\
1100^{\circ} \mathrm{C} \text { for } 30 \mathrm{~min} . \\
\text { Averagc }\end{array}$ & $\begin{array}{r}18.9 \\
5.7 \\
12.7 \\
10.8 \\
12.0\end{array}$ & $\begin{array}{l}\text { excellent } \\
\text { excellent } \\
\text { excellent } \\
\text { excellent }\end{array}$ \\
\hline $\begin{array}{l}980^{\circ} \mathrm{C} \text { for } 10 \mathrm{~min} . \\
980^{\circ} \mathrm{C} \text { for } 10 \mathrm{~min} . \\
980^{\circ} \mathrm{C} \text { for } 10 \mathrm{~min} . \\
\text { Average }\end{array}$ & $\begin{array}{r}11.3 \\
18.9 \\
4.2 \\
11.5\end{array}$ & $\begin{array}{l}\text { excellent } \\
\text { excellent } \\
\text { excellent }\end{array}$ \\
\hline
\end{tabular}

Two additional brazed joints were used to study the reactions between the braze and $\mathrm{Si}_{3} \mathrm{~N}_{4}$ and the braze and Mo. Backscattered electron images along with $\mathrm{Si}, \mathrm{Au}, \mathrm{Ni}, \mathrm{Mo}, \mathrm{Ti}$, and $\mathrm{Zr}$ elemental $\mathrm{x}$-ray maps were taken from the $\mathrm{Ti}$ coated $\mathrm{Si}_{3} \mathrm{~N}_{4}-\mathrm{Mo}$ and $\mathrm{Zr}$ coated Si3 $\mathrm{N}_{4}-\mathrm{Mo}$ joints which were brazed with Au$\mathrm{Ni}$ alloy at $980^{\circ} \mathrm{C}$ for 10 minutes, Figure 3.17 and Figure 3.18 , respectively. The Si $x$-ray maps showed that Si was only present in the SizN4, and are not shown. 
In both joints, the molten braze aggressively attacked the Mo. This reaction was essentially between the Mo and the $\mathrm{Ni}$ in the braze alloy. The braze alloy was enriched in $\mathrm{Au}$ as columnar grains of a Mo-rich Mo-Ni phase formed at the braze-Mo interface and grew into the molten braze. This phase was surrounded by a Au-rich phase. After the Mo-rich Mo-Ni layer grew to 10-20 $\mu \mathrm{m}$ thick, an additional Mo-Ni phase formed.

In the $\mathrm{Zr}$ coatcd $\mathrm{Si}_{3} \mathrm{~N}_{4-\mathrm{M}} \mathrm{M}$ joint, a $\mathrm{Ni-Zr}$ phase was present in the $\mathrm{Au}$ rich region of the braze. In the $\mathrm{Ti}$ coated $\mathrm{Si}_{3} \mathrm{~N}_{4}$-Mo joint, the phase that formed in the braze was a Ni-rich Ni-Mo phase.

The $\mathrm{Zr}$ and $\mathrm{Ti}$ were concentrated at the $\mathrm{Si}_{3} \mathrm{~N}_{4} /$ braze interface and did not dissolve into the braze to any appreciable extent. The Au was uniformly distributed throughout what was the molten phase at the brazing temperature. In both joints, the Au was also concentrated at the Mo/braze interface. The Au formed a semicontinuous layer between the Mo and the Mo-rich, Mo-Ni crystals. 


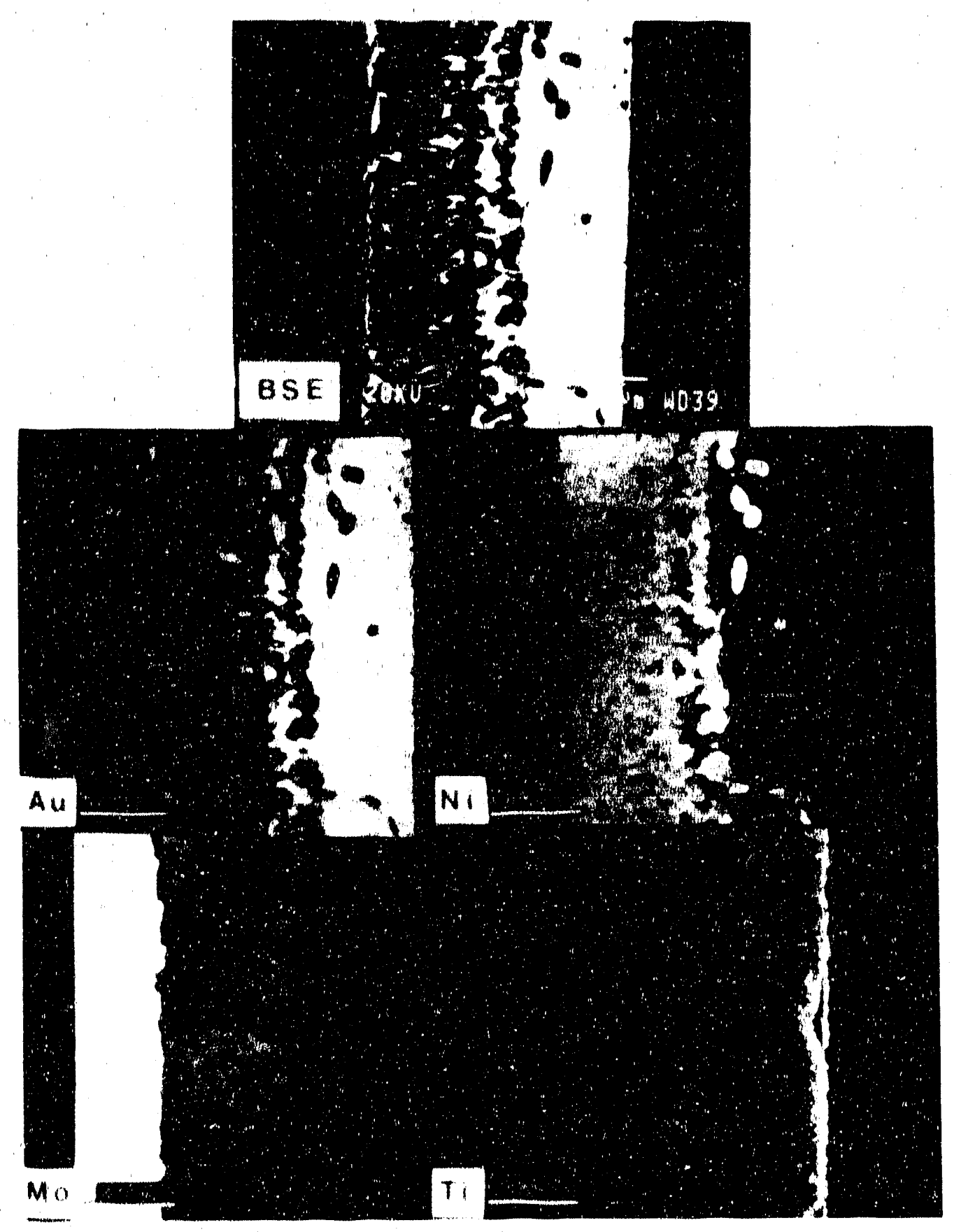

Figure 3.17. Backscattered electron image (BSE) and $x$-ray maps of a brazed joint between Ti coated SNW 1000 and Mo. Sample was vacuum brazed with the Au-18Ni alloy for 10 minutes at $980^{\circ} \mathrm{C}$. 


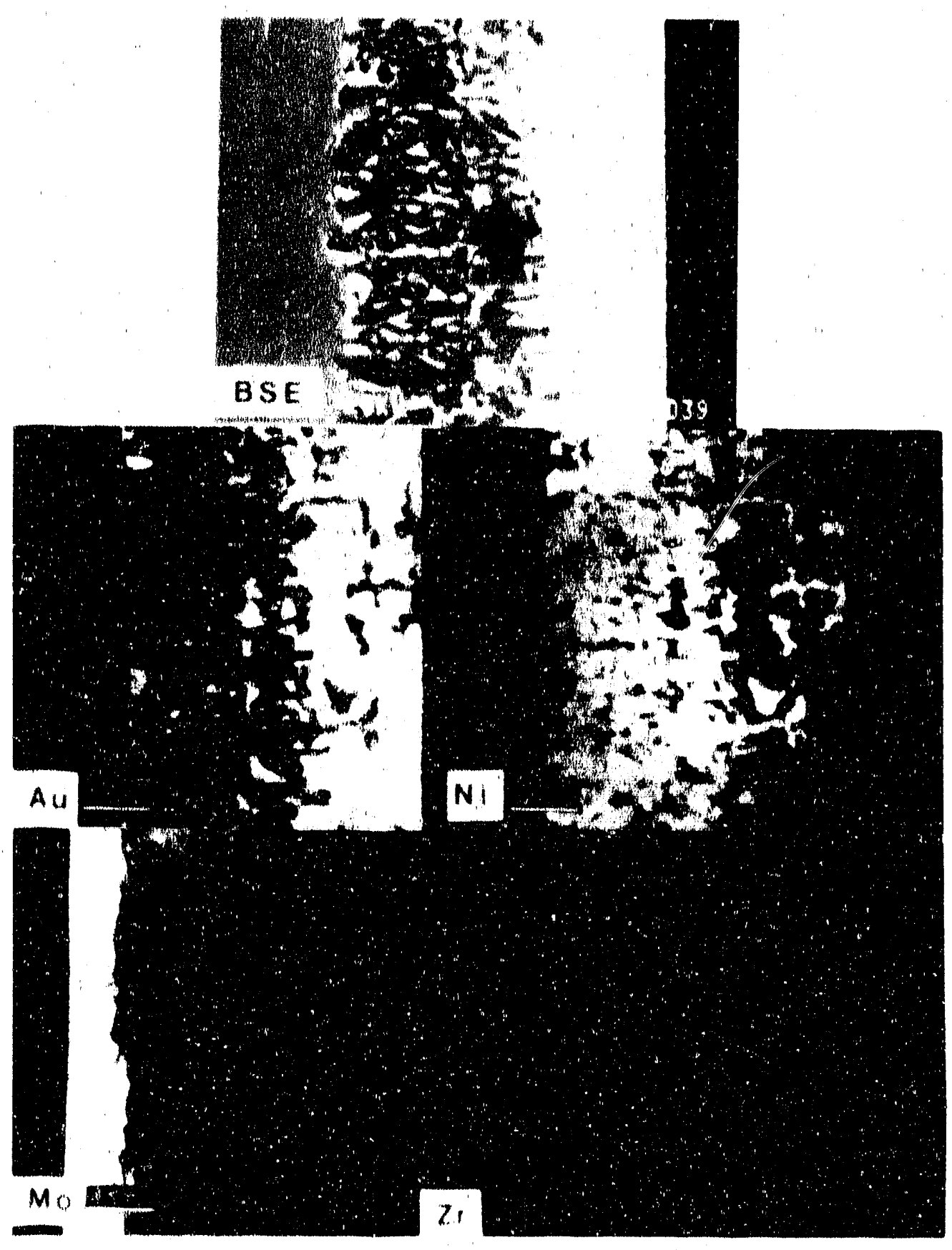

Figure 3.18. Backscattered electron image (BSE) and $x$-ray maps of a brazed joint between $\mathrm{Zr}$ coated SNW1000 and Mo. Sample was vacuum brazed with the $\mathrm{Au}-18 \mathrm{Ni}$ alloy for 10 minutes at $980^{\circ} \mathrm{C}$. 


\subsection{INTERLAYER MATERIALS DEVELOPMENT}

There are 1 wo approaches 10 minimize the effects of thermal stresses. The first is by selecting the metal, ceramic, and braze system to minimiac the CTE differences17-22. However, in most cases, this is not practical; the particular ceramic and metal components of the joint are selected based on other propertics and requirements such as strength, chemical inertness, or application temperature. The second, and most common, way to handle the thermal stresses is 10 usc an interlayer to minimize them.

Suganuma of al. 17 studied the effects of Mo and $\mathrm{Nb}$ interlayers on the residual stress and bond strength of $\mathrm{Al}_{2} \mathrm{O}_{3}-\mathrm{stcel}$ joints and found that low CrE metals reduced the residual stresses in the joini by a factor of 2 . Analytical mechanics studics in this program also showed the effectiveness of interlayers in accommodating residual stress resulting from differential expansion, Section 2.2. Therefore, in ceramic-metal joint systems, an interlayer was used to manage the CTE mismatch.

Analytical mechanics indicated that low CTE and low yicld strength were the properties sought from the interlayer materials. In practice, it is not possible to have both of these properties simultaneously in one material. Two different classes of interlayer materials, i.c., low expansion materials and low yicld strength materials, were used to determine the effectiveness of these matcrials as interlayers $18,23,24$. The optimum thickness of each interlayer material was also studied. Mo, Nb, and $W$ were sclected for their low CTE, high stiffness, and high yield strength, while $\mathrm{Cu}$ and $\mathrm{Ni}$ were chosen for their low yield strength and low stiffness 25 .

Interlayer materials were screened using rectangular coupon samples and shear tests as mentioned in the previous sections. Figure 3.19 shows a brazed coupon sample containing an interlaycr. The results of shear strength measurements are the average of $3-6$ tests.

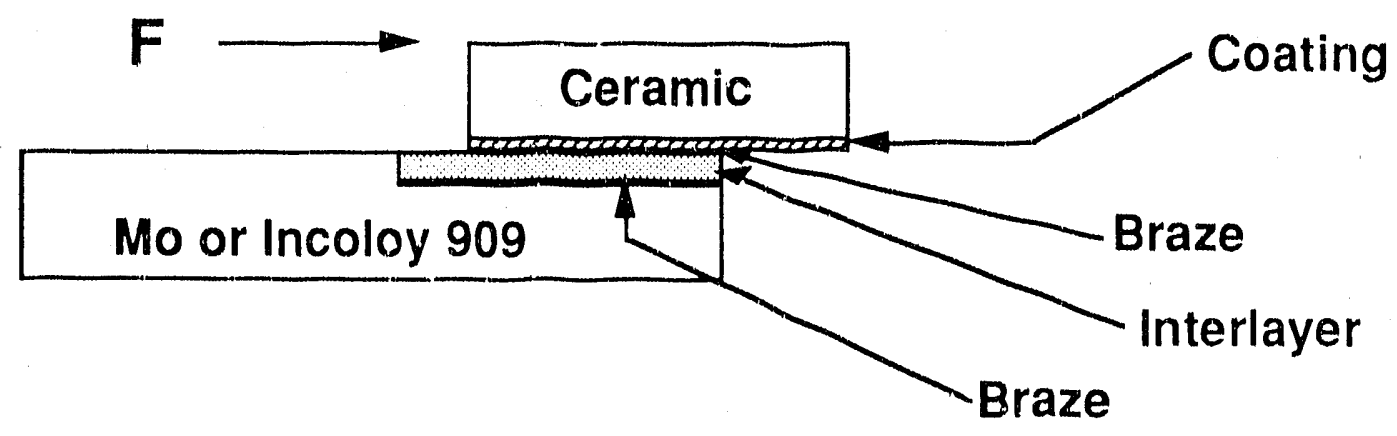

Figure 3.19. Schematic of the shear test samples containing an interlayer. 


\section{Iuterlaver for $\mathrm{Sl}_{3} \mathrm{~N}_{4}$ Sustem}

For the $\mathrm{Si}_{3} \mathrm{~N}_{4}$ system, test coupons were prepared by onc-step bruzing using Au-18Ni brazc at $980^{\circ} \mathrm{C}$ for 10 minules in vacuum. As shown in Table 3.11 , a signiflcant difference in bond strength was found botween iwo classes of interlayer materials, except $W$, even though all these malcrials were processed with the same brazing conditions. In particular, the joint strength values obtained from the Mo interlayer system were low compared with those from the $\mathrm{Cu}$ and $\mathrm{Ni}$ interlayer systems. This experimental data was consistent with the modeling predictions that Ni would outperform Mo, Section 2.3.

Table 3.11. Effect of interlayer material and thicknoss on shear strenglh.

Materials System
Interlayer

Thickness (inch)
Shear

Strength (ksi)

\begin{tabular}{lccc}
\hline & & \\
SNW 1000-Zr-(Au-18Ni)-Nb-Incoloy & 909 & 0.04 & 6.9 \\
SNW 1000-Zr-(Au-18Ni)-Mo-Incoloy & 909 & $0.01,0.04$ & 10.2 \\
SNW 1000-Zr-(Au-18Ni)-W-Incoloy & 909 & 0.04 & 17.4 \\
SNW 1000-Zr-(Au-18Ni)-Cu-Incoloy & 909 & $0 .(02,0.04$ & 19.2 \\
SNW 1000-Zr-(Au-18Ni)-Ni-Incoloy & 909 & $0.005-(0.02$ & 15.0 \\
\hline
\end{tabular}

The geometry of test samples resulted in inconsistent, improper bonding between the ceramic and metal. This was duc to the bimetal warp associated with thermal mismatch between the interlayer and the Incoloy $9(09$. This warping was particularly noticeable in refractory interlayer matcrials which exhibited $40-90 \%$ unbonded area, rather than in soft interlayer materials like $\mathrm{Cu}$ and $\mathrm{Ni}$. The $\mathrm{Cu}$ interlayer system provided excellent bonding performance, $>95 \%$ bonded area, with high shear strength. Samples with a $0.020 "$ thick $\mathrm{Cu}$ interlayer showed the highest shear value, $23.1 \mathrm{ksi}$. Since the thickness of the interlayser materials changed the sensitivity to the warping problem, it was difficult to understand the effect of thickness on the joint strength. Thicker interlayers secmed to work better with stiff matcrials like $\mathrm{W}, \mathrm{Nb}$, and $\mathrm{Mo}$, while $\mathrm{Cu}$ and $\mathrm{Ni}$ had a greater range in thickness for brazing with this test geometry.

It was found that the system with the $\mathrm{Cu}$ interlayer fractured predominantly at the interface between the braze and the ceramic. For the systems with Mo, fracture occurred in the ceramic. The system with a copper or nickel interlayer, low strength and high CTE materials, was effective in reducing residual stresses generated by the CTE mismatch.

Shear strengths of the ceramic-ceramic joint were in the range of 4()-4.5 ksi. This ceramic-ceramic joint strength gives the base strength for a joint with minimal residual stress. This allows the level of residual strenglh in metal-ceramic joints, with interlayers, to be approximated. 
Overall results Indloated that materlals such as Mo and $W$ seemed to be moderate cholces for their intermedlate CTE and high-temperature capability. It is belloved that the low oxidation resistance of these materials can be addressed by ulilizing designs which do not expose them to oxygen. Mo was chosen over $W$ since Mo has slightly more ductility than $W$. Cu and $\mathrm{NI} w e r e$ also shown to be promising metals for use at relatively low temperature.

\section{Interlurer for SiC System}

A two-step brazing praclice was used to ayold the warping problem of the interlayers encountered during brazing process in the $\mathrm{Si}_{3} \mathrm{~N}_{4}$ system, During the first step, a 73.8Au-26.2Ni braze alloy was used to braze the $\mathrm{Cu}$ or Mo Interlayer to Incoloy 909. The liquidus and solidus of the $73.8 \mathrm{Au}-26.2 \mathrm{Ni}$ braze are $1010^{\circ} \mathrm{C}$ and $980^{\circ} \mathrm{C}$, respectively. After this first brazing step, the sample surface was repolished and then brazed to SiC with Au-18Ni. The 950$)^{\circ} \mathrm{C}$ liculdus of Au-18Ni made it possible to perform the second braze without remeling the first.

The samples survived cooling to room-temperature when the interlayer was 0,(040" thick using oither $\mathrm{Cu}$ or Mo. Samples using thin, 0.010" $\mathrm{Cu}$ or Mo were unable to survive the cooling cycle. The results of these tests are shown in Table 3,12 .

With a $\mathrm{Ni}$ interlayer, a very strong reaction was secn between the $\mathrm{NI}$ and the SiC, forming a two-phase mixture of nickel-silicide and graphite 26 . Based on the severity of this reaction, nickel interlayers should not be used with SiC when the braze alloy dissolves a large amount of nickel from the interlayer. Since a $\mathrm{Cu}$ interlayer can not perform at high temperatures, Mo was selected as an interlayer for the SiC system.

Table 3.12. Effect of interlayer material and thickness on shear strength.

\begin{tabular}{lccc}
\hline Matcrials System & $\begin{array}{c}\text { Interlayer } \\
\text { Thickness (inch) }\end{array}$ & $\begin{array}{c}\text { Shear } \\
\text { Strength (ksi) }\end{array}$ \\
\hline SiC-Ta-(Au-18Ni)-Cu-Incoloy & 909 & $0.01,0.04$ & 0.4 \\
SiC-Zr-(Au-18Ni)-Cu-Incoloy 909 & 0.04 & 2.6 \\
SiC-Ta-(Au-18Ni)-Mo-Incoloy & 909 & 0.04 & 0.3 \\
\hline
\end{tabular}

All observed failures from SiC systems were in the ceramic, indicating that unbonded areas did not play a role. Reactive metal coatings on the ceramic appeared to affect the ceramic strength in brazed coupons. However, residual stress was the principal factor affecting strength level in brazed pairs. 


\subsection{BRAZING ALLOY DEVELOPMENT}

Most ceramte-metal braze systems are based on chemical Interactions occurring at the interface 27 . The free energy change for the reaction between the braze, coating material, and ceramic is frequently used to predict the success or fallure of a candidate braze system.

Many brazes are binary alloys with addilions of reactive metals, such as $\mathrm{T} 1$ or $\mathrm{Zr}^{28}: 32$. For mechanical joints, the current maximum use-temperalures are near $400^{\circ} \mathrm{C}$. Combining a use-temperature of $400^{\circ} \mathrm{C}$ and the desire 10 minimize creep and thermal stresses results in typical brazing temperatures in the range of $800-1000^{\circ} \mathrm{C}$, Binary alloys of $\mathrm{Ag}-\mathrm{Cu}$ and $\mathrm{Au}-\mathrm{Nl}$ are commonly used, with $\mathrm{Sn}$ or In sometimes added to further lower the melting lemperature of the braze. These precious metal braze alloys have the advantages of high ductility and good flow characteristics. However, some of these brazing alloys have poor oxidation resistance 33 .

The work on braze alloy development was focused on bulk brazing alloys. In order to be of interest, the braze material must mect the following requirements:

- Wet the ceramic, but not necessarily have to flow.

- Have a melting temperature above $1100^{\circ} \mathrm{C}$ for the $650^{\circ} \mathrm{C}$ application.

- Contain elements with a low vapor pressure at the brazing temperature.

- Resist oxidation up to 1000 hours at $650^{\circ} \mathrm{C}$ in air.

- Be capable of forming a slight fillet between the ceramic and metal.

- Be sufficiently ductile.

- Meet the mechanical stress requirements at $650^{\circ} \mathrm{C}$.

\section{Experimental Alleys}

A total of seven different alloy systems were studied as possible 650$)^{\circ} \mathrm{C}$ braze alloys. The braze alloy systems were all Au-based for good ductilily and oxidation resistance. All of the systems contained $\mathrm{Ti}$. The Ti acted as an active alloy addition to promote wetting and adhesion between the braze alloy and the ceramic. To adjust the melting point, a third and possibly fourth clement was selected from $\mathrm{Pd}, \mathrm{Ni}, \mathrm{In}, \mathrm{Sn}$, and Si. The various alloy systems evaluated are listed below:

$\begin{array}{ccc}\text { Au-Ti } & \text { Au-Cu-Ti } & \text { Au-Ni-Si-Ti } \\ \text { Au-In-Ti } & \text { Au-Ni-Sn-Ti } \\ \text { Au-Ni-Ti } & \\ \text { Au-Si-Ti } & \end{array}$

The experimental alloys were prepared by weighing 5 -gram samples to 0.01 gram accuracy, and melting them in a skull melter under an argon atmosphere, The buttons were remelted about 4 times to homogenize.

43 of the alloys studied were based on the most favorable Au-Ni-Si-Ti alloy compositions. The liquidus and solidus for these alloys were about 1(02.5 
and $950^{\circ} \mathrm{C}$ respectively, In total, 59 alloys were investigated. They were testod for ductility by cold rolling. Of these alloys, 56 wore melted on alumina for wettability tests, Of the most ductlle alloys, 48 were studied by differential thermal analysis (DTA).

Tests showed that the above alloys wet alumina $\left(99.5 \% \mathrm{Al}_{2} \mathrm{O}_{3}\right)$ well; however, some dewetting was noted when high brazing temperatures were used. The hardening effect of 1 wt $\% \mathrm{Ti}$ was very pronounced. The effect of $\mathrm{Ti}$ on the melting temperature of the alloy was slight. Ni had a hardening effect on the alloy, but much less than $\mathrm{Tl}$, by wt, percent. The addition, $\mathrm{Nl}$ decreased the meling temperature of the braze. The addition of Si decreased the contact angle and increased wetting of the ceramic. The molting temperature was very slightly affected by the addition of 1 wt\% Si. All of the above alloys were ruled out for the $650^{\circ} \mathrm{C}$ application due to their low melting points.

A series of Au-Pd-Ni-Ti alloys were developed to meet the 650 and $950^{\circ} \mathrm{C}$ requirement. These alloys wetted both $\mathrm{Si}_{3} \mathrm{~N}_{4}$ and $\mathrm{Mo}$ at $1100^{\circ} \mathrm{C}$ in a $10^{-5}$ torr vacuum, A high-temperature braze between $\mathrm{Si}_{3} \mathrm{~N}_{4}$ and $\mathrm{Si}_{3} \mathrm{~N}_{4}$ was made at $1450^{\circ} \mathrm{C}$ using a Au-Pd-Ti alloy. To meet the mechanical properties at $650^{\circ} \mathrm{C}$, a solidus temperature of about $1050^{\circ} \mathrm{C}$ was targeted. Table 3.13 shows the compositions and properties of the Au-Pd-Ni-Tl alloys.

Table 3.13. Alloys studied for the $650^{\circ} \mathrm{C}$ application.

\begin{tabular}{|c|c|c|c|c|c|c|}
\hline $\begin{array}{c}\text { Alloy } \\
\text { Number }\end{array}$ & \multicolumn{4}{|c|}{$\begin{array}{l}\text { Composition } \\
\left(W_{t} \%\right)\end{array}$} & $\begin{array}{c}\mathrm{T}_{\mathrm{L}} / \mathrm{TS} \\
\left({ }^{\circ} \mathrm{C}\right)\end{array}$ & $\begin{array}{c}\text { Knoop } \\
\text { Hardness }\end{array}$ \\
\hline $\begin{array}{l}53-0 \\
53-21 \\
53-15 \\
53-22 \\
53-16\end{array}$ & $\begin{array}{r}92 \mathrm{Au} \\
91.75 \mathrm{Au} \\
91.50 \mathrm{Au} \\
91.25 \mathrm{Au} \\
91.0 \mathrm{Au}\end{array}$ & $\begin{array}{ll}5 & \mathrm{Pd} \\
5 & \mathrm{Pd} \\
5 & \mathrm{Pd} \\
5 & \mathrm{Pd} \\
5 & \mathrm{Pd}\end{array}$ & $\begin{array}{l}2 \mathrm{Ni} \\
2 \mathrm{Ni} \\
2 \mathrm{Ni} \\
2 \mathrm{Ni} \\
2 \mathrm{Ni}\end{array}$ & $\begin{array}{r}1.0 \mathrm{Ti} \\
1.25 \mathrm{Ti} \\
1.50 \mathrm{Ti} \\
1.75 \mathrm{Ti} \\
2.00 \mathrm{Ti}\end{array}$ & $\begin{array}{l}1114 / 1084 \\
1113 / 1078 \\
1133 / 1078 \\
1124 / 1078 \\
1119 / 1082\end{array}$ & $\begin{array}{l}117 \\
138 \\
170 \\
190 \\
209\end{array}$ \\
\hline
\end{tabular}

Alloys with $1.5 \% \mathrm{Ti}$ and above were found 10 be too hard and would not allow the braze layer to plastically deform during the post-braze cooling cycle.

$\mathrm{Si}_{3} \mathrm{~N}_{4}$ and Mo were brazed using alloy composition 53-21 as a $0.004^{\prime \prime}$ thick braze foil, and brazing conditions of $1110^{\circ} \mathrm{C} \pm 10^{\circ} \mathrm{C}$ for $2-3$ minutes under a $10^{-}$ 5 torr vacuum. Excess time and temperature will alter the brazing alloy composition, making the alloy less ductile. Substituting $\mathrm{Zr}$ for $\mathrm{Ti}$ degraded the properties of these brazc alloy systems.

The optimum amount of $\mathrm{Ti}$ addition was determined to be $1.25 \mathrm{wt} \%$. The Ali-5Pd-2Ni-1.25 Ti braze had enough $\mathrm{Ti}$ to promote wetting of the ceramic but not too much to reduce ductility of the braze to an unacceptable level, However, wetting experiments between the Au-5Pd-2Ni-1.25Ti braze and $\mathrm{Si}_{3} \mathrm{~N}_{4}$ resulted in uneven welling. This uneven wetting led to the development of a braze without $\mathrm{Ti}$. Welting between the braze and $\mathrm{Si}_{3} \mathrm{~N}_{4}$ ceramic was achicved 
with the use of a $3 \mu \mathrm{m}$ thick $\mathrm{Tl}$ coating on the $\mathrm{Si}_{3} \mathrm{~N}_{4}$ coramic. The $\mathrm{Au}-5 \mathrm{Pd}-2 \mathrm{Ni}$ braze consistently wet the Ti coated SizN4. Therefore, tho Au-5Pd-2Ni bramo alloy was solected for the $650^{\circ} \mathrm{C}$ application.

Alloys of Au-Pd-Tl were developed for the $950^{\circ} \mathrm{C}$ application, as shown in Table 3.14. The $950^{\circ} \mathrm{C}$ braze alloy was based on precious metals since the braze foint must survive the $950^{\circ} \mathrm{C}$ temperature for an extended lime in an oxidixing air atmosphere. The braze temperalure or the solidus temperature of the brazing alloy should bo about $1450^{\circ} \mathrm{C}$. For purposes of this study, SizN4-SizN4 joints were made and brazing was carried out at $140\left(0^{\circ} \mathrm{C}, 1450\right)^{\circ} \mathrm{C}$, and 150()$^{\circ} \mathrm{C}$.

Table 3.14. Alloys studied for the $950^{\circ} \mathrm{C}$ application.

\begin{tabular}{|c|c|c|c|}
\hline $\begin{array}{c}\text { Alloy } \\
\text { Number }\end{array}$ & \multicolumn{3}{|c|}{$\begin{array}{l}\text { Composition } \\
\left(\mathrm{Wl}_{\mathrm{t}} \%\right)\end{array}$} \\
\hline $\begin{array}{l}53.6 \\
53.9\end{array}$ & $\begin{array}{l}39.2 \mathrm{Au} \\
48.5 \mathrm{Au}\end{array}$ & $\begin{array}{l}\text { 60) } \mathrm{Pd} \\
50 \mathrm{Pd}\end{array}$ & $\begin{array}{l}0.8 \mathrm{TH} \\
1.5 \mathrm{Ti}\end{array}$ \\
\hline
\end{tabular}

These Au-Pd alloys had melting lemperatures in the range of the melting tomperatures of structural alloys such as Incoloy $9(09$ and Inconel 718. Therefore, the development of these Au-Pd alloys in Table 3.14 was not pursued further, Consequently, Au-Pd-Ti and other commercial alloys were selected for the $950^{\circ} \mathrm{C}$ application.

\section{Cemmercial Alloys}

Table 3.15 shows the compositions and melting points of several commercially avallable, high-temperature brazc alloys. Au and $P d$ were llic base metals selected to provide the necessary ductility and oxidation resistance. Palnt and Palniro 1, 4, and 7 were selected and examined in terms of joint strength, application temperature, and compatibility with other joint components. 
Table 3.15. Composition and melting points of commercial braze alloys.

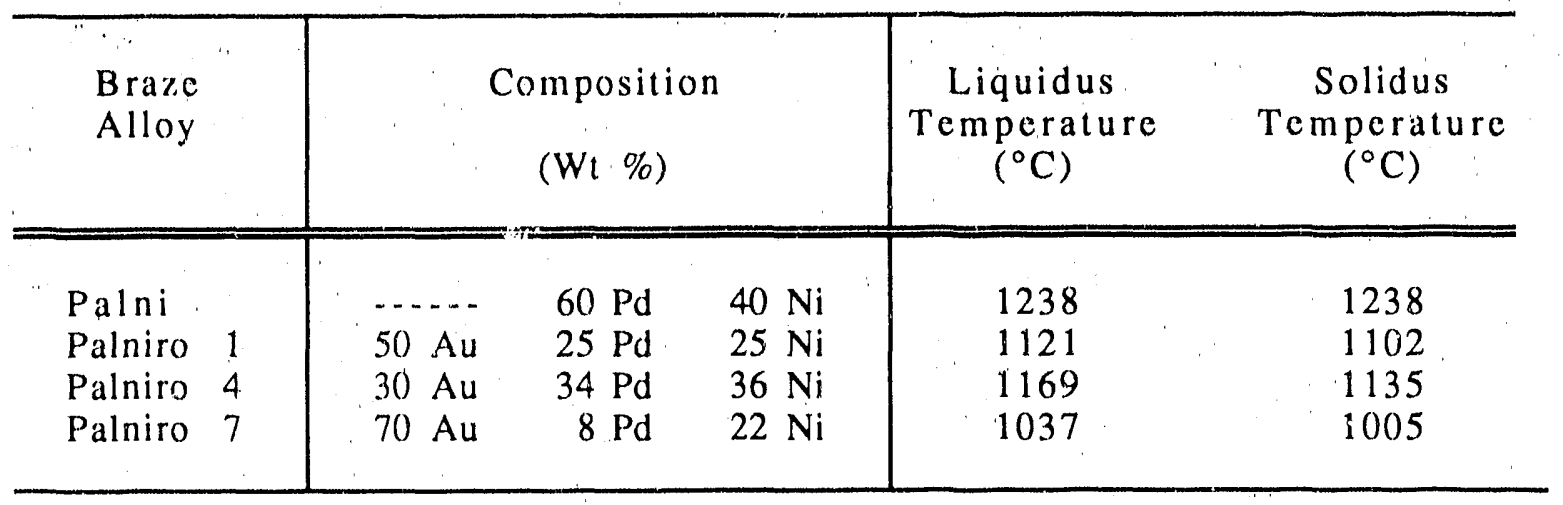

Wetting tests of the $950^{\circ} \mathrm{C}$ braze alloys were conducted on $\mathrm{Ti}$ coated SNW1000. The procedure was previously described. The test temperatures were $110 \%$ of the alloy's liquidus in ${ }^{\circ} \mathrm{K}$. All of the braze alloys wet the substrate. Figure 3.20 shows the wetting angle as a function of time for all four braze alloys.

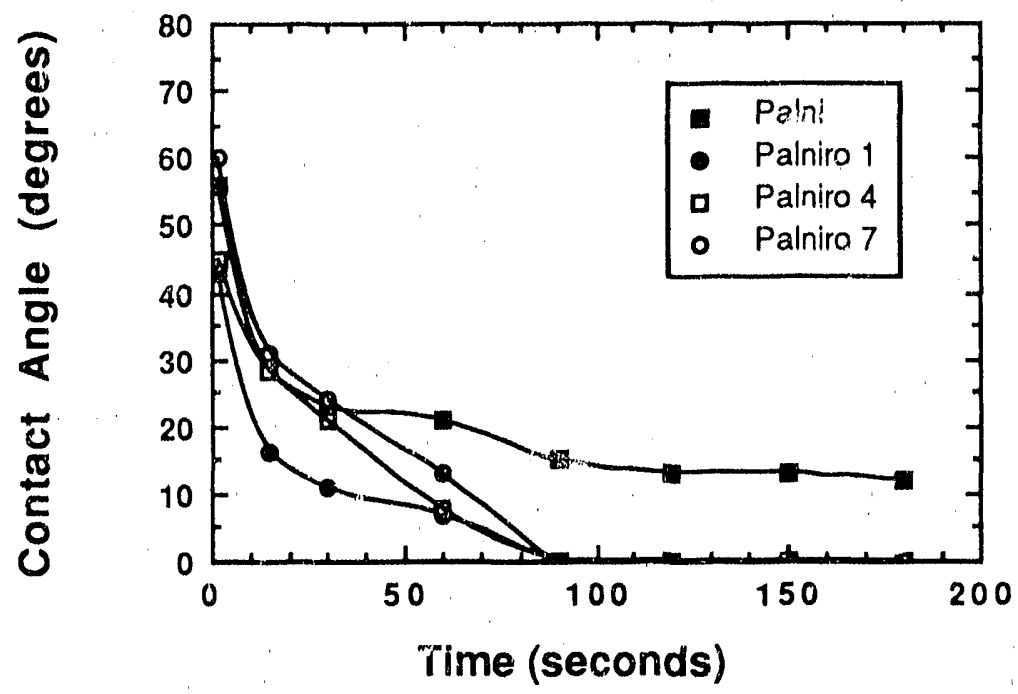

Figure 3.20. Wetting angle of $950^{\circ} \mathrm{C}$ brazes (Palni and Palniro 1, 4, and 7) on Ti coaled DY6.

When a $\mathrm{Zr}$ coaling was used for the wetting tests with Palni braze, a large amount of outgassing occurred. Wotting sests were carried out in a mass spectrometer/vacuum system to determine the nature and source of this gas. Mass spectroscopy showed that a large amount of $\mathrm{N}_{2}$ gas was given off as the Palni braze wet the $\mathrm{Zr}$ coated SNW1000, Table 3.16. Experiments with the 
Au-5Pd-2Ni-1.25Ti and Au-18Ni brazes showed much smaller amounts of outgassing. The data suggest that the $\mathrm{Pd}$ in the Palni braze reacts with $\mathrm{Si}_{3} \mathrm{~N}_{4}$ to form $\mathrm{Pd}_{2} \mathrm{Si}$ or $\mathrm{PdSi}$ and $\mathrm{N}_{2}$. This type of strong outgassing reaction could result in a significant amount of unbonded area in the brazed joint. Thutefore, the $\mathrm{Zr}$ coating was not used with $\mathrm{Pd}$ containing alloys.

In screening the commercial alloys for the $950^{\circ} \mathrm{C}$ application, Palniro 1 and 7 were ruled out due to their relatively low melting points. Palni and Palniro 4 were investigated further with high-temperature testing, described in Section 4.1.

Table 3.16. Mass spectroscopy results for braze, coating, ceramic interactions at $1300^{\circ} \mathrm{C}$.

\begin{tabular}{ccc}
\hline Sample & Total Gas Pressure & Major Gas Spccics \\
\hline SNWr000 & $193 \mu \mathrm{m}$ & $\mathrm{N}_{2}, \mathrm{H}_{2}$ \\
Palni w/o Zr & 75 & $\mathrm{~N}_{2}$ \\
Palni-Zr & 800 & $\mathrm{~N}_{2}$ \\
\hline
\end{tabular}




\section{FINAL JOINT SELECTION}

In the previous sections, the potential materials for each layer in the joint system were screened using a model system such as SNW1000-(Au-18Ni)Mo. Mechanical strength of the joints was mostly evaluated at roomtemperature, knowing that the joint properties at room-temperature were significantly affected by residual stress due to thermal mismatch in ceramicmetal joints. At high temperatures, however, the role of the residual stress becomes less important, while the strength of the brazed area becomes critical. Also, a lap joint geometry was used for testing for screening. From an analytical mechanics point of view, a cylindrical joint has a definite advantage in performance with a given bonded area compared to a butt joint. While lap-joint samples provide a general indication of the ability to bear a load in the presence of residual stress, the stress conditions in these joints are less severe than the actual cylindrical samples. Therefore, cylindrical samples were required to finalize the material system. In selecting final systems for the 650 and $950^{\circ} \mathrm{C}$ applications, attention was paid to (1) the high-temperature strength of the systems, and (2) the material system's compatibility during brazing, using a cylindrical joint geometry.

\subsection{HIGH-TEMPERATURE STRENGTHS OF THE SYSTEMS}

$\mathrm{Si}_{3} \mathrm{~N}_{4}$ System. The high-temperature strength of joints with the Palni and Palniro scries brazes was measured with coupon lap joint samples. The substrate materials chosen for $950^{\circ} \mathrm{C}$ were $\mathrm{Zr}$ or Ti coated SNW1000, Mo, and $\mathrm{Nb}$ as model systems.

Hot shcar testing was performed in an argon atmosphere. The test temperature, $500^{\circ} \mathrm{C}$, was selected due to the temperature limit of the testing fixture. The samples were equilibrated at $500^{\circ} \mathrm{C}$ for 30 minutes before being tested at a crosshead speed of $0.01 \mathrm{inch} / \mathrm{min}$. Ti was substituted for $\mathrm{Zr}$ as a coating for the Nb-SNW 1000 coupons. This substitution was made because a strong interaction between the $\mathrm{Zr}$ coating and braze alloys at $1200^{\circ} \mathrm{C}$ prevented the Nb-SNW 1000 system from bonding.

Table 4.1 shows the results of hot shear tests. The braze alloys studied did not show significant weakening at $500^{\circ} \mathrm{C}$. For the SNW $1000-\mathrm{Zr}-\mathrm{Mo}$ system, Palniro 4 resulted in a high shear strength. However, Palni provided strength equivalent to the room-temperature strength of the SNW1000-Zr-(Au-18Ni)-Mo system. Fracture always occurred in the braze. This type of fracture implies that the thermal stresses developed at the ceramic-metal interface were not high enough to cause cracking of the ceramic. Overall results from this limited number of tests indicate that the performance of the brazed joints at $500^{\circ} \mathrm{C}$ is better than or equivalent to strength levels seen at room-temperature. This was, supported by the FEA study, Section 2.5. The increase in joint strength at $500^{\circ} \mathrm{C}$ is primarily due to the reduction of the thermal mismatch between the ceramic and metal substrates. 
Table 4.1. Results of hot shear tests.

\begin{tabular}{|c|c|c|c|c|}
\hline Material System & $\begin{array}{l}\text { Bond } \\
\text { Area } \\
\left(\mathrm{cm}^{2}\right)\end{array}$ & $\begin{array}{c}\text { Testing } \\
\text { Temperature } \\
\left({ }^{\circ} \mathrm{C}\right)\end{array}$ & $\begin{array}{l}\text { Shear } \\
\text { Strength } \\
\quad(\mathrm{ksi})\end{array}$ & Comments \\
\hline SNW.1000-Zr-Palni-Nb & 0.96 & $\cdots$ & $-\cdots$ & \multirow{6}{*}{$\begin{array}{l}\text { No bonding } \\
\text { after brazing }\end{array}$} \\
\hline SNW $1000-Z r-P a l n i r o \quad 4-N b$ & 0.96 & $\cdots$ & $\ldots$ & \\
\hline SNW 1000-Ti-Palni-Nb & 0.96 & 525 & 12.3 & \\
\hline SNW 1000-Ti-Palniro 4-Nb & 0.96 & 525 & 7.4 & \\
\hline SNW 1000-Zr-Palni-Mo & 0.96 & 525 & 6.2 & \\
\hline SNW 1000-Zr-Palni-Mo & 0.96 & 525 & 4.8 & \\
\hline SNW $1000-Z r-P a l n i r o \quad 4-M o$ & 1.10 & $525^{\prime}$ & $>15.2$ & \multirow{2}{*}{$\begin{array}{l}\text { No railure } \\
\text { at } 15.2 \mathrm{ksi} \\
\text { Failed during } \\
\text { preloading }\end{array}$} \\
\hline SNW1000-Zr-Palniro 4-Mo & 1.10 & 525 & -- & \\
\hline
\end{tabular}

With this information, a group of coupon specimens were brazed and sheared to evaluate the remaining issues in materials systems development. These results are summarized in Table 4.2. The shear strengths of Ti coated PY6 brazed to Mo with either $\mathrm{Au}-5 \mathrm{Pd}-2 \mathrm{Ni}$ or $30 \mathrm{Au}-34 \mathrm{Pd}-36 \mathrm{Ni}$ (Palniro 4) were excellent. Shear strengths at $500^{\circ} \mathrm{C}$ reached up to $24 \mathrm{ksi}$ and $36 \mathrm{ksi}$, for Au-5Pd$2 \mathrm{Ni}$ and $30 \mathrm{Au}-34 \mathrm{Pd}-36 \mathrm{Ni}$, respectively. The PY6-Ti-(30Au-34Pd-36Ni)-Mo joint was strong enough to deform the Mo without breaking.

SiC Sestem. Mechanical property results are reported in Table 4.3 for $\mathrm{SiC}-\mathrm{Mo}$ joints. However, comparable samples of $\mathrm{SiC}-\mathrm{Ni}$ joints were not obtained because of the large differential expansion between the $\mathrm{SiC}$ and $\mathrm{Ni}$ and compatibility problems between these two, as described in the previous section. These difficultics resulted in all of the SiC-Ni coupon samples failing during cool down from the brazing temperature. Based on the above results, Mo was chosen as the interlayer for high-temperature use, and the SiC-(30) Au34Pd-36Ni)-Mo and SiC-(Au-5Pd-2Ni)-Mo systems were selected for further study. 


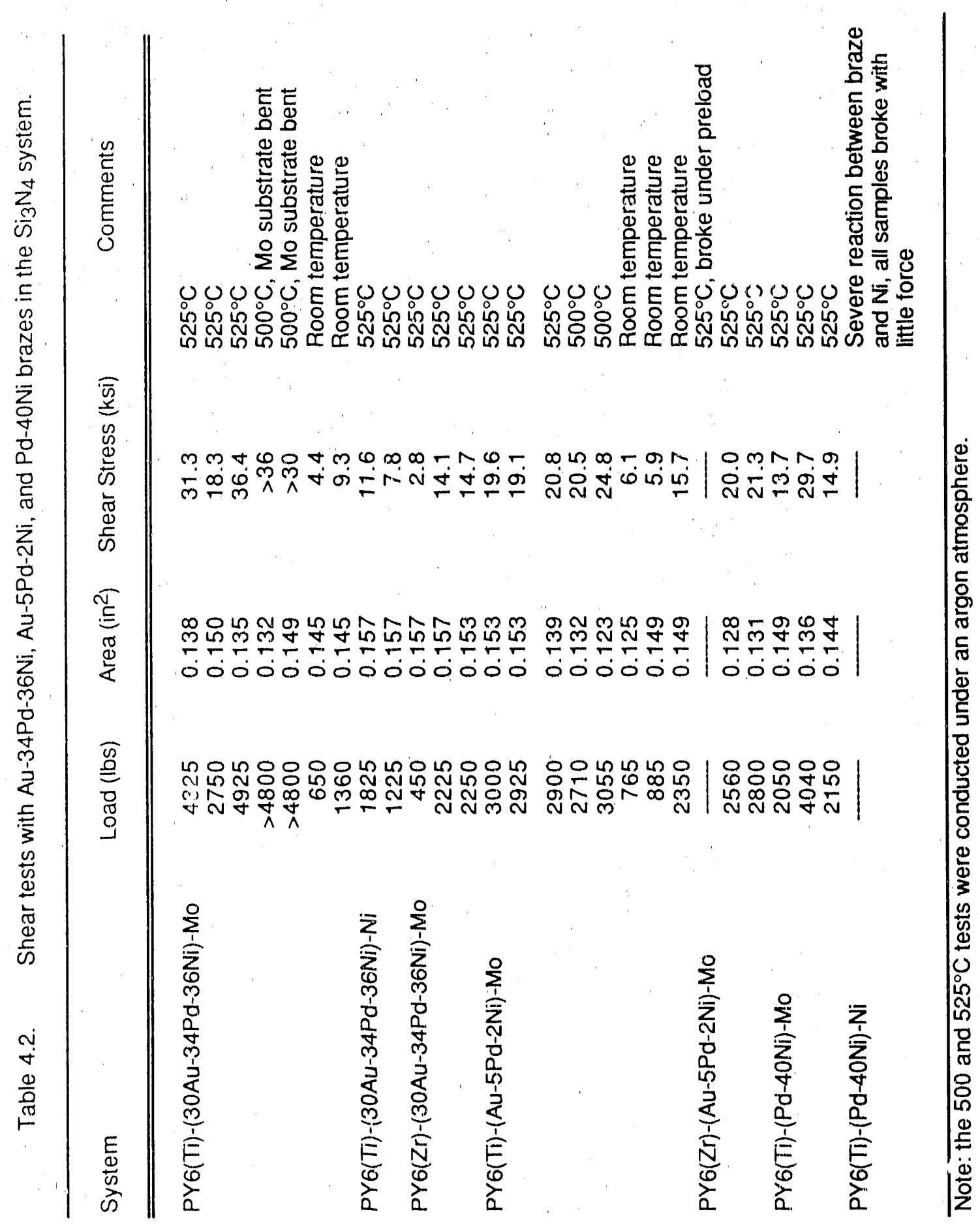




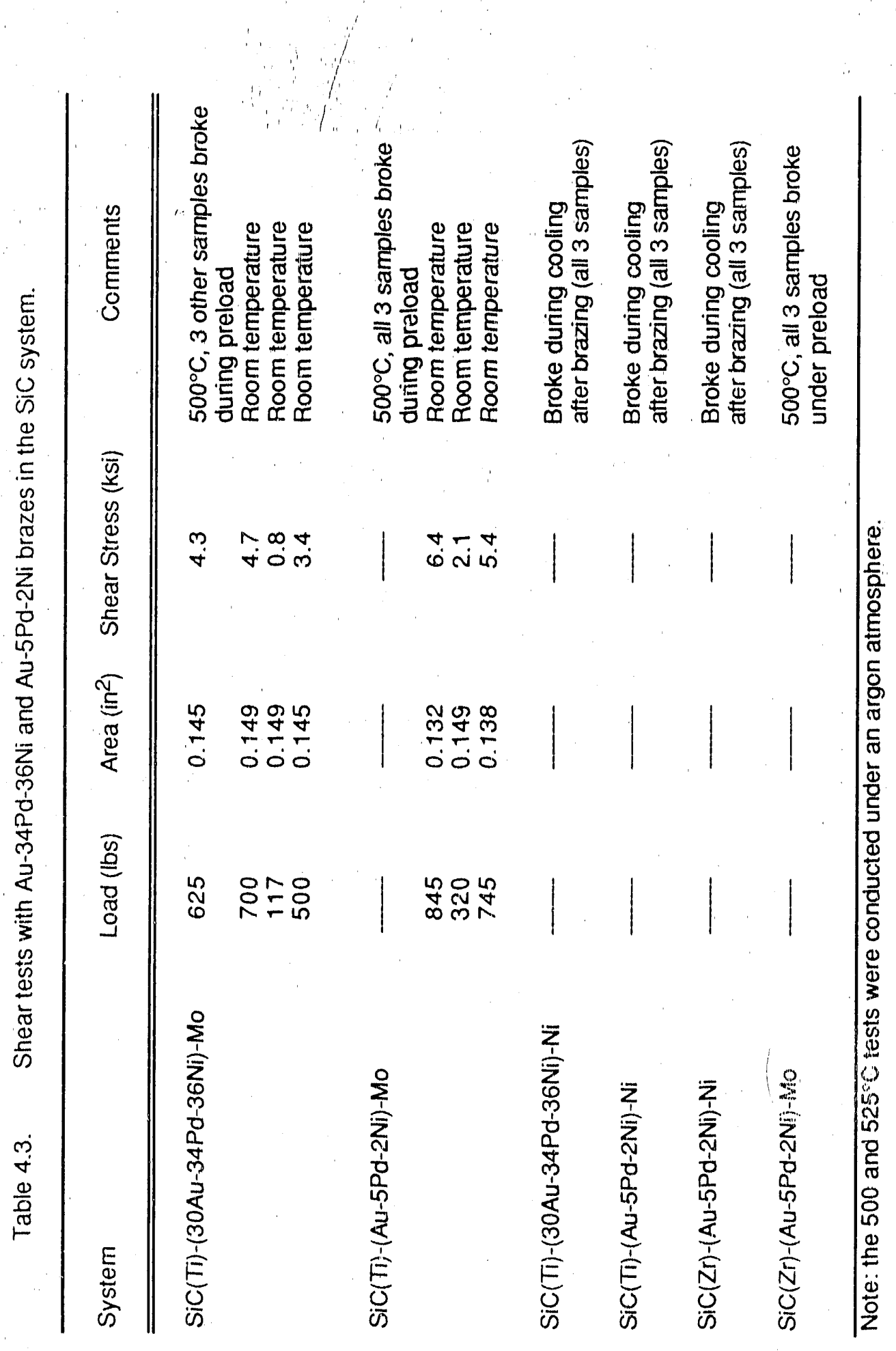




\subsection{SYSTEMS COMPATIBILITY}

A cylindrical geometry was selected for the ccramic-metal joint since it is easier to control residual stresses in a cylindrical joint. However, the vertical cylindrical geometry of the samples resulted in more extensive interactions between the braze, structural alloy, and interlayer matcrials than was seen with the horizontally oriented coupon samples. Furthermore, the vertical cylindrical geometry makes the system more sensitive to processing conditions and chemical interactions among the components in the system.

In the brazing process, suppression of the braze melting point due to alloying with the surrounding joint components has a significant effect on overall brazing performance. This melting point suppression is especially problematic with the cylindrical geometry. Suppression of the melting point will prolong the solidification time of the braze, further accelerating alloying. This effect was demonstrated with the Inconel 718-(Au-5Pd-2Ni)-Ni-Ti-PY6 system. Brazing was performed at $1180^{\circ} \mathrm{C}$ for $3-4$ minutes in vacuum. This joint system resulted in excessive liquid phase formation, resulting in very poor bonding. DTA of the brazc alloyed with $\mathrm{Ni}$ from the interlayer and from the Inconel 718 showed that the melting point of the braze had changed from $1140^{\circ} \mathrm{C}$ to $997^{\circ} \mathrm{C}$. X-ray fluorescence confirmed that the composition of the brazc changed from $2 \% \mathrm{Ni} 1026 \% \mathrm{Ni}$.

The Incoloy 909-Ni-Ti-PY6 system gave reasonable joints with the Au$5 \mathrm{Pd}-2 \mathrm{Ni}$ brazc, in contrast with the Inconel 718-Ni-Ti-PY6 system above. This is probably duc to the difference in the $\mathrm{Ni}$ and $\mathrm{Fe}$ contents of Incoloy 9(0) $(42 \mathrm{Fc}-38 \mathrm{Ni}-13 \mathrm{Co}-4.7 \mathrm{Nb})$ and Inconcl $718(55 \mathrm{Ni}-16 \mathrm{Fc}-20 \mathrm{Cr}-5 \mathrm{Nb}) . \mathrm{Fc}, \mathrm{Cr}$, and $\mathrm{Mo}$ tend to increase the melting point of Au-based braze, while $\mathrm{Ni}$ decreases the melting point. Consequently, a $\mathrm{Ni}$ interlayer was not used for the Inconel 718 . (Au-5Pd-2Ni)-Ti-PY6 system at $950^{\circ} \mathrm{C}$.

\subsection{FINAL, JOINT SYSTEMS}

\section{Material System}

Matcrial systems for braze joints were finalized as summarized in Table 4.4. The selections were based on the high-temperature performance and system compatibility. As a coating matcrial, $\mathrm{Ti}$ was chosen over $\mathrm{Zr}$ for all systems since $\mathrm{Zr}$ interacts with the current Pd-containing brazing alloys, crolving nitrogen gas. Also, Ti coating was found to have a minimal effect on the mechanical properties of PY6. $\mathrm{Ni}$ was selected as an interlayer material only for $65\left(0^{\circ} \mathrm{C}\right.$ application with PY 6 ceramic duc 10 limited temperature capability and severe interaction with SiC ceramic. Even though 30Au-34Pd$36 \mathrm{Ni}$ (Palniro 4) provides high joint strength at $500^{\circ} \mathrm{C}$, it was unable 10 consistently bond to $\mathrm{Si}_{3} \mathrm{~N}_{4}$. Therefore, $30 \mathrm{Au}-34 \mathrm{Pd}-36 \mathrm{Ni}$ was replaced with Au$5 \mathrm{Pd}-2 \mathrm{Ni}$ for the $950{ }^{\circ} \mathrm{C} \mathrm{Si}_{3} \mathrm{~N}_{4}$ application. 
Table 4.4. Final material systems for the brazed joints.

\begin{tabular}{|c|c|c|c|c|}
\hline Ceramic & Siructural & Alloy & Interlayer & Brazc \\
\hline $650^{\circ} \mathrm{C}$ Application & & & & \\
\hline PY6/Ti coating & Incoloy & 909 & $\mathrm{Ni}$ & $\mathrm{Au}-5 \mathrm{Pd}-2 \mathrm{Ni}$ \\
\hline $\mathrm{SiC} / \mathrm{Ti}$ coating & Incoloy & 909 & Mo & $A u-5 P d-2 N i$ \\
\hline $950^{\circ} \mathrm{C}$ Application & & & & \\
\hline PYб/Ti coating & Inconel & 718 & Mo & $A u-5 P d-2 N i$ \\
\hline SiC/Ti coating & Inconel & 718 & Mo & $30 \mathrm{Au}-34 \mathrm{Pd}-36 \mathrm{Ni}$ \\
\hline
\end{tabular}

The interactions between the biaze alloys and the structural and interlayer materials were studied with the three systems shown in Table 4.4: Incoloy 909-(Au-5Pd-2Ni)- Ni, Incoloy 909-(Au-5Pd-2Ni)-Mo, and Inconcl 718(30) $\mathrm{Au}-34 \mathrm{Pd}-36 \mathrm{Ni})-\mathrm{Mo}$.

The Incoloy 909-( $\mathrm{Au}-5 \mathrm{Pd}-2 \mathrm{Ni})-\mathrm{Ni}$ system did not form intermetallic compounds. However, the braze dissolved both the Incoloy 909 and the $\mathrm{Ni}$ to an appreciable extent. On the other hand, the Incoloy 909-( $\mathrm{Au}-5 \mathrm{Pd}-2 \mathrm{Ni})-\mathrm{Mo}$ system formed Mo-Ni intermetallic compounds at the brazc/Mo interface. The Au-5Pd-2Ni braze dissolved the Incoloy 909 and the Mo, as in the Incoloy 9()9$\mathrm{Ni}$ system. The Inconel 718-(30Au-34Pd-36Ni)-Mo system did not appear to react to any significant extent. No reaction zone was seen between the braze alloys and the Inconel 718 or the Mo. A limited amount of dissolution of the Inconel 718 and Mo was seen.

The $\mathrm{Ni}$ interlayer was uncracked in all of the joints made with a cylindrical joint, as shown in Figure 4.1. However, the Mo interlayer was cracked in all of the brazed joints with a Mo interlayer. Cracks from the Mo) interlayer had propagated into the ceramic member in the Inconel 718-(Au5Pd-2Ni)-Mo-Ti-PY6 brazed joint (Figure 4.2). 


\section{Inconel 718}

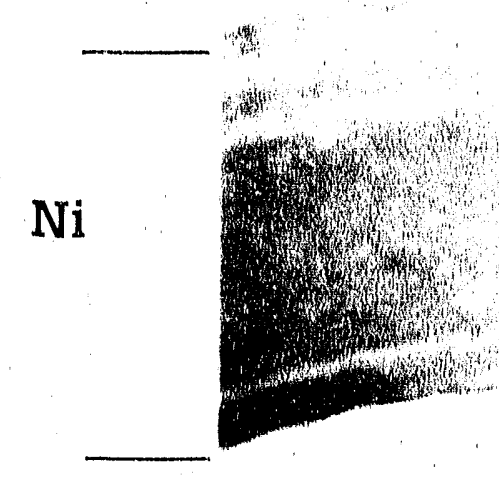

\section{PY6}

Figure 4.1. SEM micrograph of a brazed joint between lnconel 718 and $\mathrm{Ti}$ coated PYG Si3N4 with a $\mathrm{Ni}$ interlayer and the $\mathrm{Au}-5 \mathrm{Pd}-2 \mathrm{Ni}$ braze.

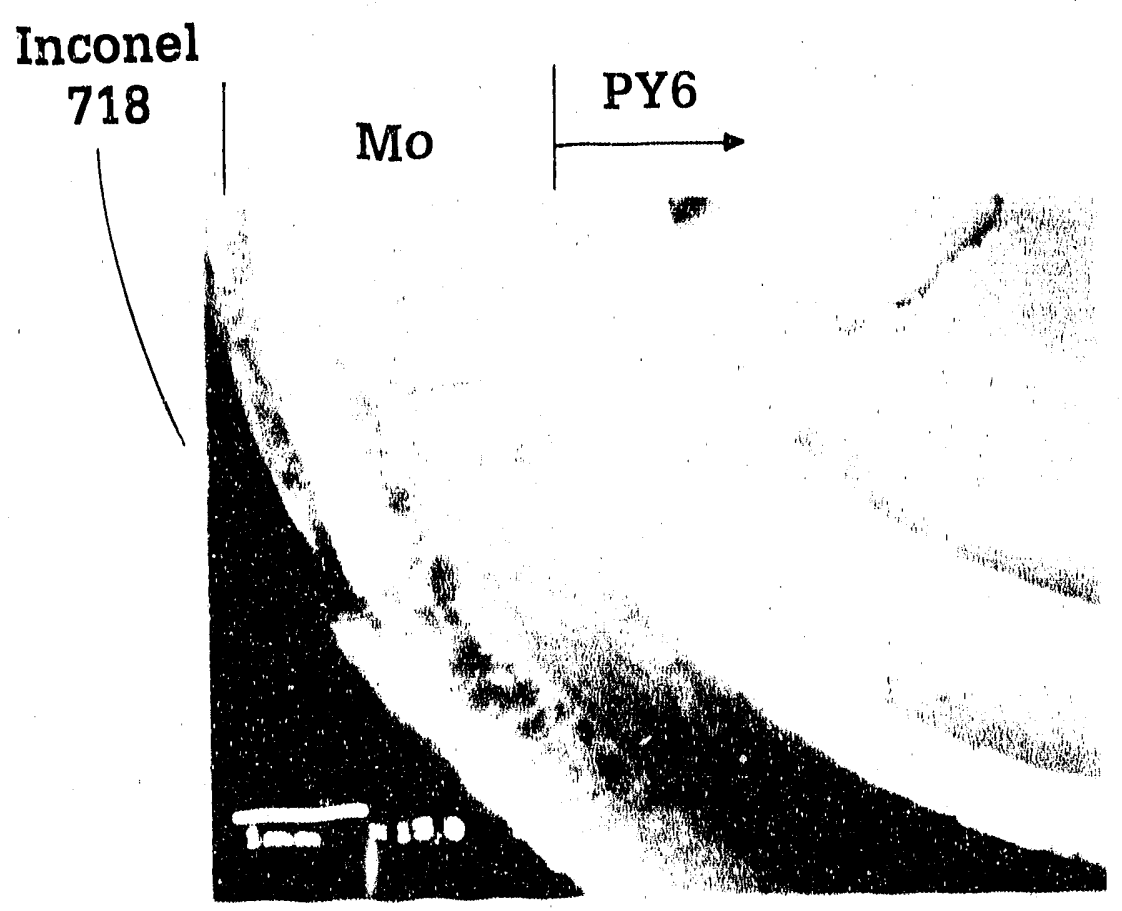

Figure 4.2. SEM micrograph of a brazed joint between Inconel 718 and Ti coated PYG with a Mo interlayer and $30 \mathrm{Au}-34 \mathrm{Pd}-36 \mathrm{Ni}$ braze. The top part of the PYG was removed. Note: cracks in the Mo interlayer propagated into the PYG. 


\section{Joint Geometry}

The final joint consists of a 0.5 " diameter rod of coramic brazed to a $0.766^{\prime \prime}$ outer diameter metal shaft. The end of the metal shaft is reduced to $0.5^{\prime \prime}$ diameter for gripping in the testing machine. The ceramic rod fits into a cup machined into the end of the metal shaft. The detalled geometry of the ceramic-metal joint is shown in Figure 4.3.

The upper ends of the metal piece have a $30^{\circ}$ taper. This taper helps to reduce the squecze of the ceramic by the metal. FEA"showed that this type of taper was very effectlve in reducing the residual stress in the ceramic (Section 2.3). The interlayer is placed in the $0.641^{\prime \prime}$ diameter section. It is held in place by resting on the $0.5785^{\prime \prime}$ diameter section below it. This $0.5785^{\prime \prime}$ diameter section is empty. space; however, occasionally it becomes partially filled with the braze alloy. The $0.500 "$ section provides an alignment hole for the ceramic piece. A $0.125^{\prime \prime}$ diameter hole is used to place a thermocouple inside the joint for temperature measurement. The three $0.063^{\prime \prime}$ diameter through holes act as gas vents. These holes allow any gas to escape instead of being trapped and causing unbonded areas in the brazed layer. The wall thickness of the structural alloy and interlayer werc $0.0525^{\prime \prime}$ and $0.0665^{\prime \prime}$, respectively, and have not yet been optimized.

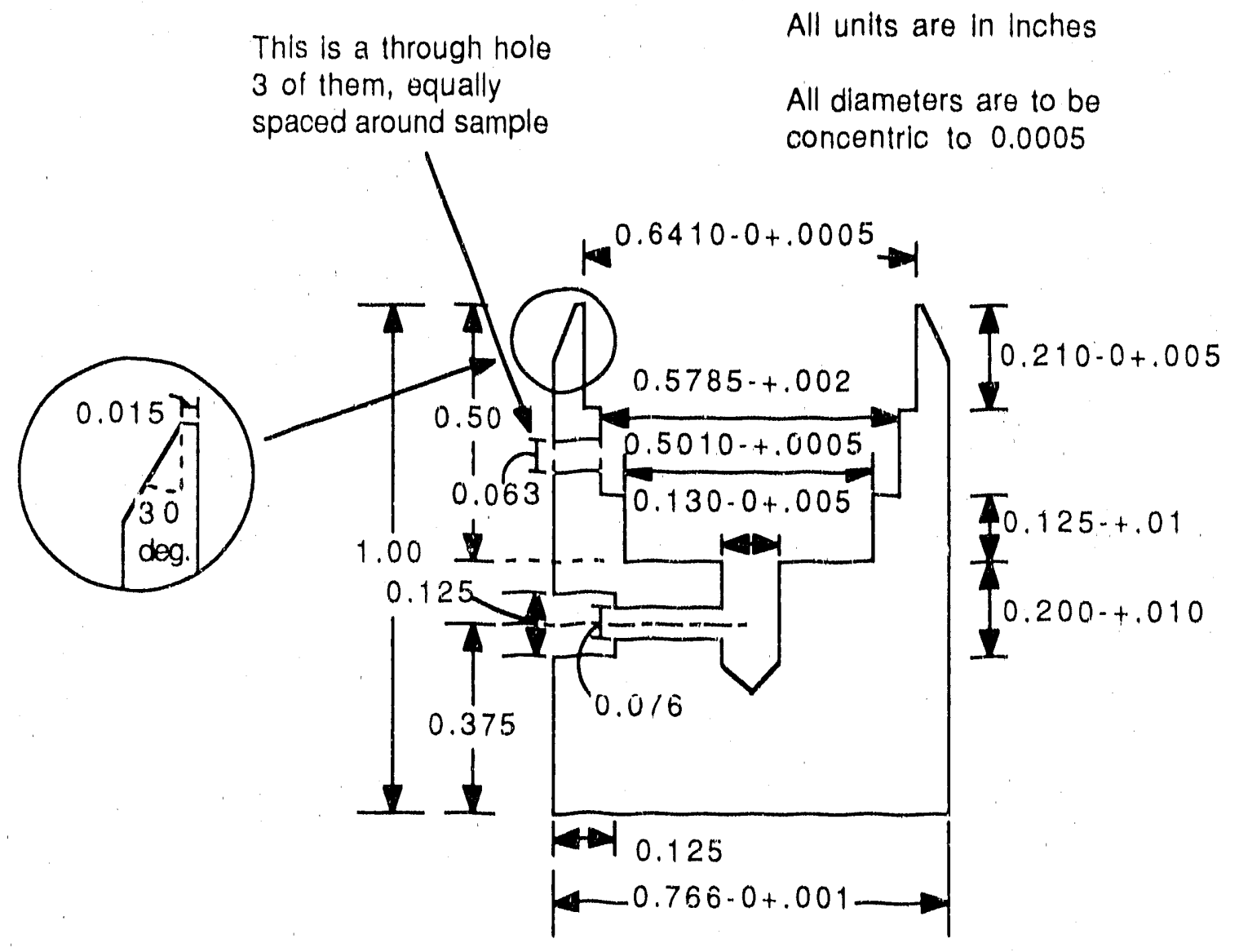

Figure 4.3. Detalts of metal-ceramic joint geometry. 


\section{PERFORMANCE TESTS AND FEA MODEL PREDIC'TIONS}

The ceramic-metal joints being developed are for use at 650 and 9.5()$^{\circ} \mathrm{C}$ in gas turbine heat engines. These jolnts will attach the ceramic lurbine rotor to a metal shaft for power transmission. The major type of loading these joints will sec is torsional, Therefore, the joint strength will be evaluated wilh torsion, torsion fatigue, and thermal fatigue tests.

The results from the torsion tests will be compared to the residual stress values predicted by FEA. The ability to compare the measured joint strength to the predicted residual stresses will allow the FEA model of the joints 10 be refined and will provide a tested method to ald in designing ceramic-metal joints in the future.

\subsection{LINKAGE BETWEEN FEA PREDICTIONS AND EXPERIMENTS}

Linkage between the FEA predictions and mechanical testing experiments was established based on the following assumptions:

- The brazing process provides ideal joints without defects, i.c., no unbonded area.

- Alloying effects are negliglble on the material properties.

- Each of the structural ceramic members has an equal probability for surface cracks.

While these assumptions may not be applicable to the brazed joints presently being studied, they represent a necessary assumption to make the problem tractable.

FEA predicts the location and level of the residual stresses buit up in the joint due to thermal mismatch between the ccramic and metal in terms of the maximum principal stress. The maximum principal stress controls the failure of the ceramic part in the joint at the temperatures presently being studied. FEA can also provide the same information in terms of Mises equivalent stress. Mises equivalent stress governs the failure of the braze and interlayer materials at the temperatures presently being studied, i.e., 650 and $950^{\circ} \mathrm{C}$.

The situations with and without residual stresses are represented by the properties of the brazed joint and of the unbrazed ceramic sample, respectively. The following relationships can be established in a tension test.

$$
\sigma_{\text {fracture }}=\sigma_{\text {residual }}+\sigma_{\text {applied }}
$$

Eq. 5,1

Expressing Equation 5.1 in terms of shear stresses: 
where $\tau$ fracture is the measured fracture shear stress of the unbrazed ccramic calculated using Equation 5.3, and $\tau_{\text {residual }}$ is calculated from FEA. $\tau_{\text {appliced }}$ is the measured fracture shear stress of the brazed joint calculated using Equation 5,3:

$$
\tau=\frac{16}{\pi \mathrm{D}^{3}}
$$

where $\mathrm{M}_{\mathrm{T}}$, and $\mathrm{D}$ are the applied torque at fallure and the diancter of the specimen gauge section, respectively. The maximum shear stress occurs at the surface of the specimen, which will eventually cause fracture of the material.

The residual stresses in the joint are determined by FEA. The stresses $\sigma_{z z}$ and $\sigma_{\theta \theta}$ are the maximum principal stresses taken from the frec surface in the vicinity of the ceramic-metal joint (i.c., $\sigma_{1}$ and $\sigma_{3}$ respectively). These stresses can be convirted into a maximum shearing stress for comparison with the measured joint sirength by a Mohr's circle analysis,

Substituting for the residual stress quantities in Equation 5.1, the relationship between the residual stress in the joint and the strength of the joint, $\tau_{\text {predicted, becomes }}$

$$
\sigma_{\max }=\frac{\sigma_{z z}+\sigma_{\theta \theta}}{2}+\sqrt{\left(\frac{\sigma_{z z}-\sigma_{\theta \theta}}{2}\right)^{2}+\left[\tau_{\text {predicted }}\right]^{2}}
$$

where $\sigma_{\max }$ is squals $\tau_{\max } . \tau_{\mathrm{max}}$ is the measured shear strength of the unbrazed ceramic from a torsion lest based on the following relationship:

$$
\tau_{11 \mathrm{ax}}=\frac{\sigma_{11}-\sigma_{33}}{2}=\frac{\sigma_{11}-\left(-\sigma_{11}\right)}{2}=\sigma_{11}=\sigma_{\max } .
$$

For real, nonideal samples, Equation 5.4 becomes

$$
\sigma_{\max }=\frac{\sigma_{Z Z}+\sigma_{\theta \theta}}{2}+\sqrt{\left(\frac{\sigma_{Z Z}-\sigma_{\theta \theta}}{2}\right)^{2}+\left|\tau_{\text {applicd }}+\Delta \tau\right|^{2}} \quad E_{l]} \text {.6.6 }
$$


where $\tau_{\text {applled }}$ is the shoar strength for fracture measured from brazod samples. $\Delta \tau$ is the change in the principal stress duc to processing, testing, and the probability factor for cracking in the coramic matcrial. $\tau_{\text {applice }}$ is calculated from Equation 5.3.

Therofore, a comparison can be made between the predicted values,

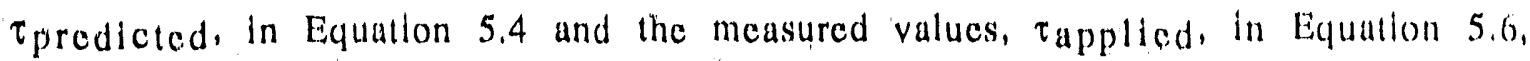
assuming that $\Delta \tau=0$. Setting $\Delta \tau=0$ is equivalent to assuming that the brazed joint is perfect, the ceramic has not becn damaged during the brazing process, and there is no unbonded area in the joint. Actual tests will be discussed in the following section.

\subsection{TORSION TESTING}

\section{Testing Procedure}

A brazed joint between Incoloy 909 and PY6 is shown in Figure 5.1. The PY6 is on the left side, and the Incoloy 909 is on the right side. This type of joint was used for the torsion and torsion fatigue tests.

All of the mechanical testing of the brazed joints was carried out on a MTS model $646.25 \mathrm{~S}$ hydraulic Axial/Torsion machinc. The maximum torque of the machine is 20,000 in-lbs, and the maximum axial load is 55,000 lbs. The machine is equipped with hydraulic grips that can accommodate (0.5" diameter samples. The gripping pressure was adjusted to $1,500 \mathrm{psi}$, 10 protect the coramic from premature cracking in the gripned area during lesting

The torsion tests were run at a rate of $0.2^{\circ} \theta / \mathrm{sec}$. During the test, the axial load was controlled to within $\pm 1.0 \mathrm{lbs}$ of zero. An induction furnace was used to heat the joints to 650 and $950^{\circ} \mathrm{C}$ for the elevated temperature tests. A SiC susceptor was used for more even heating of the ceramic-metal joint. The joints were equilibrated at the test temperature before the tests. Five joints were tested at room-temperature for the 650 and $950^{\circ} \mathrm{C}$ systems. Large sealter in the torsion strengths of these joints made further torsion tests unnecessary until the source of the scalter can be addressed. The very low strengths at 6.5() and $950^{\circ} \mathrm{C}$ made further high-temperature tests futle until stronger joints can be designed.

The mechanical fatigue tests were run under iorque control with the axial load controlled to within $\pm 1.0 \mathrm{lbs}$ of zero throughout the lesting. The tests were run between 35 and 185 in-lbs, with a mean torque level of 110 in-lbs. A $1.5 \mathrm{~Hz}$ loading frequency was used. Only five joints from the 650 and 95()$^{\circ} \mathrm{C}$ systems were fatigue tested. All of these joints easily met the test requirements and any further testing was felt to be unnecessary. The low high-temperature strengths of the joints made high-emperature fatigue testing impossible. 

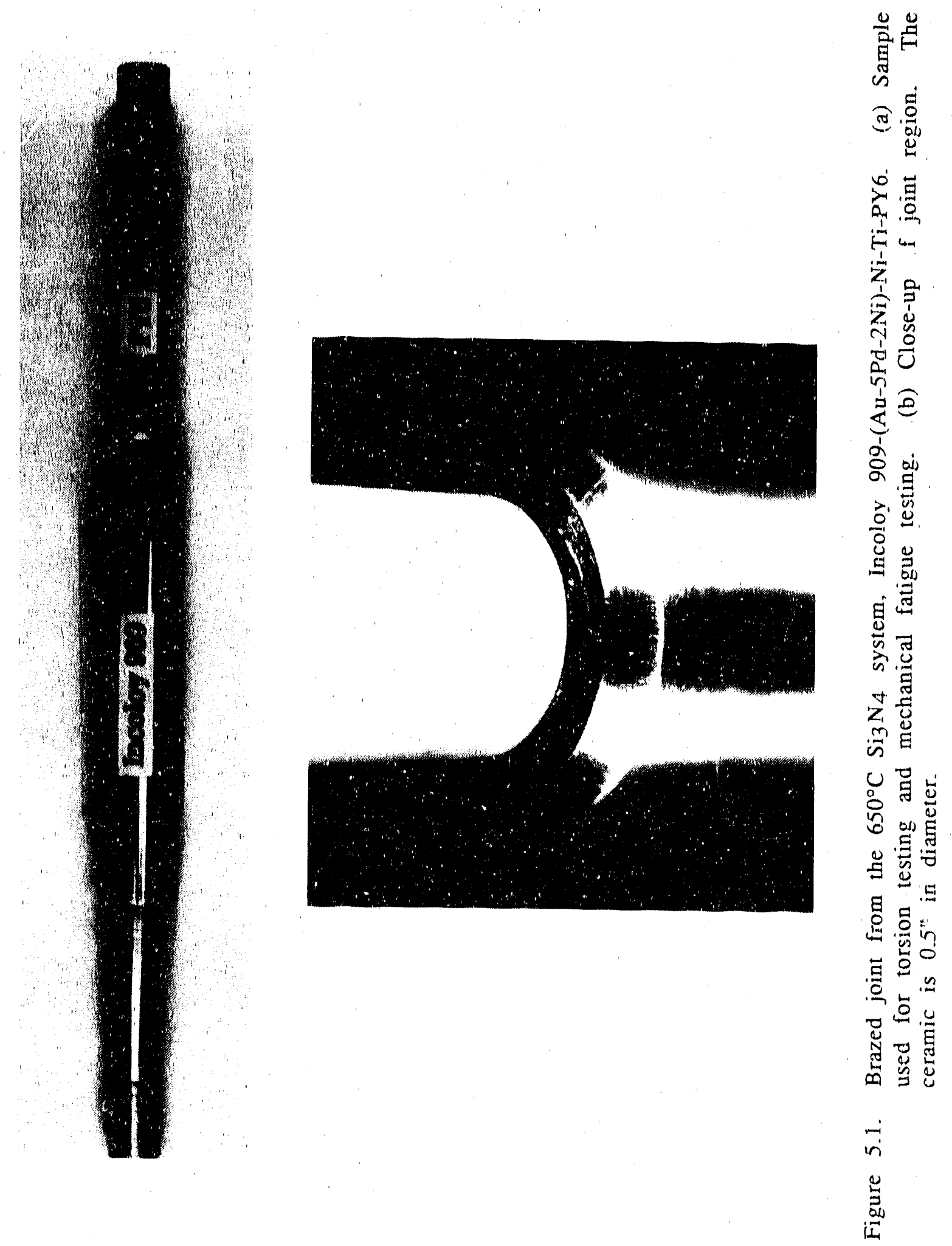


\section{Testing of Base Materials}

Torsion tests were performed at room-temperature and $650^{\circ} \mathrm{C}$ with Incoloy 909, Inconcl 718, and PY6. These tests measured the baseline propertics of each matcrial. The $650^{\circ} \mathrm{C}$ fracture strength of PY6 was the same as the room-temperature fracture strength; the twisting moment at failure vas 2,110 in-lb $(85,970 \mathrm{psi})$ and 0.4 degrees of rotation, as shown in Table 5.1 .

Table 5.1. Torsional strength of the PY6 material.

\begin{tabular}{|c|c|c|c|c|c|}
\hline Material & $\begin{array}{c}\text { Test } \\
\text { Conditions }\end{array}$ & $\begin{array}{l}\text { Torque } \\
\text { (in-lbs) }\end{array}$ & $\begin{array}{l}\text { Shear } \\
\text { Strength } \\
\quad(p s i)\end{array}$ & Rotation & $\begin{array}{l}\text { Diameter of } \\
\text { gauge section }\end{array}$ \\
\hline $\mathrm{Si}_{3} \mathrm{~N}_{4}$ & $\begin{array}{c}\mathrm{RT} \text { torsion } \\
650^{\circ} \mathrm{C} \text { torsion }\end{array}$ & $\begin{array}{r}530 \\
2,110 \\
525\end{array}$ & $\begin{array}{r}172,753 \\
85,970 \\
171,123\end{array}$ & $\begin{array}{l}1.83^{\circ} \\
0.40^{\circ} \\
1.84^{\circ}\end{array}$ & $\begin{array}{l}0.25^{\prime \prime} \\
0.50^{\prime \prime} \\
0.25^{\prime \prime}\end{array}$ \\
\hline
\end{tabular}

Samples with a gauge section diameter of $0.25^{\prime \prime}$ and $0.5^{\prime \prime}$ were used to measure the torsional strength of PY6. These samples had the same surface finish $(6 \mu$-inch) as the PY6 used to make the brazed joints. The sample with the $0.5^{\prime \prime}$ diameter had $50 \%$ of the strength of the 0.25 " diameter sample. This is related to the difference in the circumference between the two samples. The fracture of PY6 samples occurred at the outer surface. The strength of the 0.5" diameter sample should be one-half of the $0.25^{\prime \prime}$ diameter sample since the $0.5^{\prime \prime}$ diameter sample had twice the circumference of the $0.25^{\prime \prime}$ diameter sample.

The torsional yield strength of Inconel 909 and Inconel 718 at $650^{\circ} \mathrm{C}$ was lower than at room-temperature, while the rotational yield angle was unchanged at 2 - 3 degrees (Table 5.2). A 1-inch long gauge section was used in all of the tests.

Table 5.2. Torsional strength of Incoloy 909 and Inconel 718 materials.

\begin{tabular}{l|ccccc}
\hline Matcrial & $\begin{array}{c}\text { Test } \\
\text { Conditions }\end{array}$ & $\begin{array}{c}\text { Torque } \\
\text { (in-lbs) }\end{array}$ & $\begin{array}{c}\text { Shear Yield } \\
\text { Strength } \\
\text { (psi) }\end{array}$ & $\begin{array}{c}\text { Rotation } \\
\text { at yield }\end{array}$ & $\begin{array}{c}\text { Diameter of } \\
\text { gauge section }\end{array}$ \\
\hline \hline & & & & & \\
Incoloy 909 & RT torsion & 580 & 56,015 & $2.0^{\circ}$ & $0.375^{\prime \prime}$ \\
Inconcl 718 & " & 550 & 53,118 & $2.5^{\circ}$ & $" 1$ \\
Incoloy 909 & $650^{\circ} \mathrm{C}$ torsion & 400 & 38,631 & $2.3^{\circ}$ & $"$ \\
Inconel 718 & & 480 & 46,437 & $2.3^{\circ}$ & $"$ \\
\hline
\end{tabular}


Inserting the corresponding values into the equation and solving for the bending moment at the joint, we get, Mjoint, for the Incoloy 909-PY6 brazed joints:

$$
\begin{aligned}
& M_{\text {joint }}=2.5 \mathrm{P} \quad(\text { in }-\mathrm{lbs}) \\
& \mathrm{M}_{\text {joint }}=17,985 \mathrm{y} \quad(\text { in }-\mathrm{lbs})
\end{aligned}
$$

The deflection was measured by clamping the metal end of the brazed joint and spinning the joint while the deviation of the ccramic end was measured, where the deflection is one-half the deviation. The magnitude of the bending moment is important because any misalignment between the metal and ccramic introduces a bending moment in the joint; when the sample is gripped in the testing machine, the testing machine was aligned within $0.001 \mathrm{l}$. A bending moment of approximately 150 in-lbs, a deviation of $0.016^{\prime \prime}$, did not seem to affect the joint strength. There was not a strong correlation between the bending moment and the shear stress of a joint for bending. moments below 150 in-lbs. This suggests that other factors, such as residual stress, unbonded arca, or pre-existing cracks, are the controlling factors of the joint strength.

In the samples shown in Figure 5.2 the fracture started in the ceramic near the top of the inierlayer. Away from the interlayer, the fracture surface formed an approximately $45^{\circ}$ angle, reflecting that the fracture was caused by the principal tensile stress in torsion loading. Near the top of the interlayer, the angle of the fracture surface varied from $45^{\circ}$. This deviation from a $45^{\circ}$ angle near the interlayer reflects the fact that the stress pattern near the interlayer was significantly different than in the bulk $\mathrm{Si}_{3} \mathrm{~N}_{4}$ away from the interlayer. The residual stress caused by the metal components of the joint was predicted by FEA to be concentrated to within approximately $5 \mathrm{~mm}$ from the top of the interlayer (Figure 2.10). The localization of the maximum residual stresses in the ceramic to the top of the interlayer was reflected by the fracture surfaces shown in Figure 5.2.

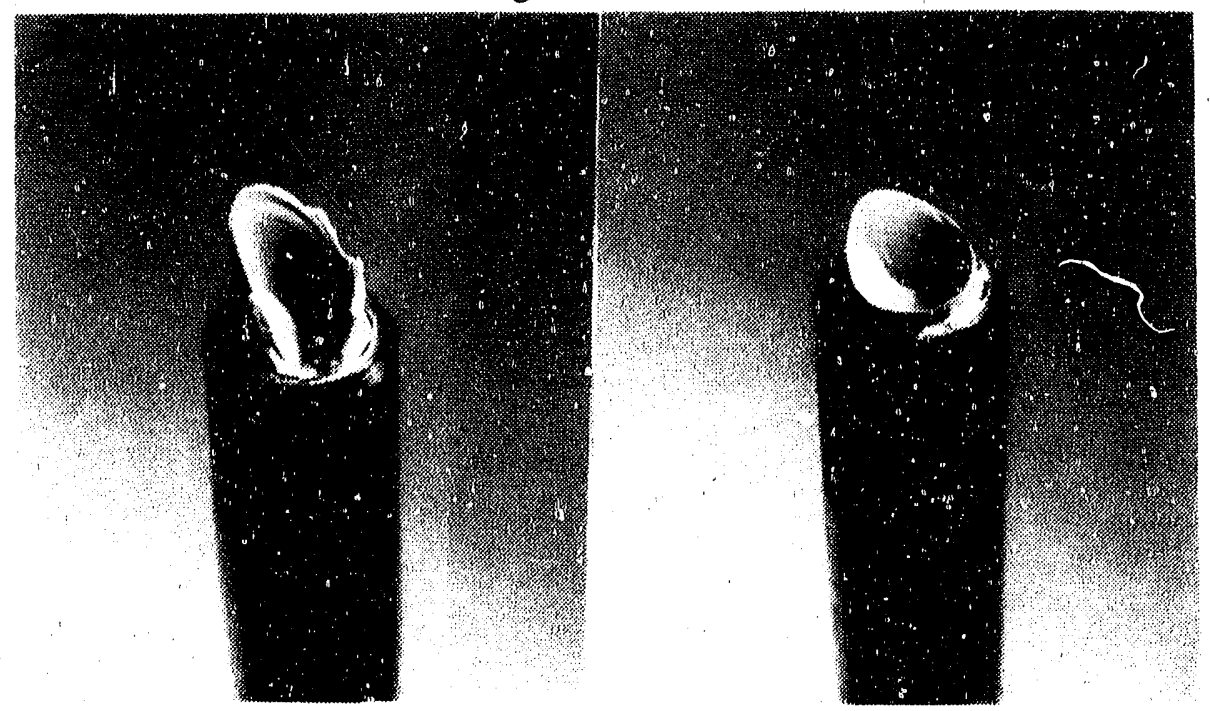

Figure 5.2. Fracture surface of the $650^{\circ} \mathrm{C} \mathrm{Si}_{3} \mathrm{~N}_{4}$ system fractured in a roomtemperature torsion test. 
Results from the $650^{\circ} \mathrm{C}$ torsion tests are shown in Table 5.4. In general, the strengths of these joints were very low. During the torsion test the ceramic would slip without fracturing. One sample was pulled apart in tension so that the fracture surface could be examined after such slippage occurred. Auger analysis of the fracture surface indicated that the fracture path was complex and oc surred in the $\mathrm{Si}_{3} \mathrm{~N}_{4}$, in the TiN reaction layer, and in the braze alloy. A schemilic of the fracture path is shown in Figure 5.3.

Table 5.4. Results of the $650^{\circ} \mathrm{C}$ torsion tests of the $650^{\circ} \mathrm{C} \mathrm{SizN_{4 }}$ brazed joints.

\begin{tabular}{|c|c|c|c|c|c|c|}
\hline $\begin{array}{l}\text { Material } \\
\text { System }\end{array}$ & $\begin{array}{c}\text { Test } \\
\text { Conditions }\end{array}$ & $\begin{array}{l}\text { Torque } \\
\text { (in-lbs) }\end{array}$ & $\begin{array}{l}\text { Shear } \\
\text { Strength } \\
\text { (psi) }\end{array}$ & Rotation. & Fracture & mode \\
\hline $650^{\circ} \mathrm{C} \mathrm{Si}_{3} \mathrm{~N}_{4}$ & $650^{\circ} \mathrm{C}$ torsion & 41 & 1,670 & $\cdots$ & $\begin{array}{l}\text { Slippage } \\
\text { ceramic }\end{array}$ & $\begin{array}{l}\text { at brazel } \\
\text { interface }\end{array}$ \\
\hline$"$ & $"$ & 14 & 570 & $0.10^{\circ}$ & & " \\
\hline$"$ & " & 62 & 2,526 & $\ldots$ & & $"$ \\
\hline$"$ & $"$ & 43 & 1,752 & $0.21^{\circ}$ & & $"$ \\
\hline
\end{tabular}

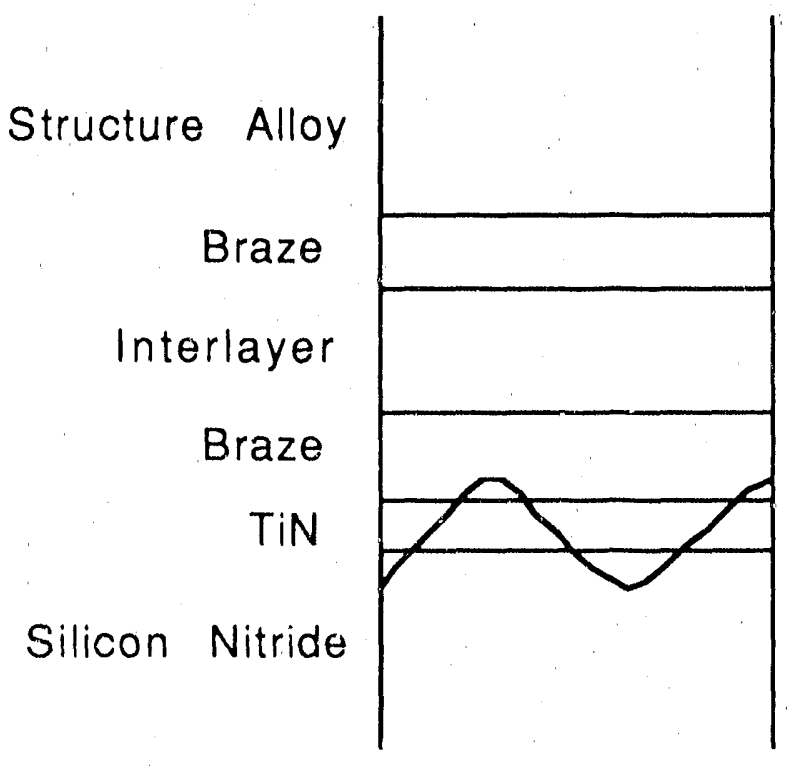

Figure 5.3. Schematic of the fracture path for the $650^{\circ} \mathrm{C} \mathrm{Si}_{3} \mathrm{~N}_{4}$ brazed joints tested at $650^{\circ} \mathrm{C}$. Crack passed through all 3 regions at the interface: the $\mathrm{Si}_{3} \mathrm{~N}_{4}$, the TiN reaction layer, and the braze layer. 
Si3 $\mathrm{N}_{4}$-Inconel 718 System. Results from the room-temperature torsion tests of the $9500^{\circ} \mathrm{C} \mathrm{SizN} 4$ system are showed in Table 5.5. In general, the fracture behavior of these joints was similar to those in the $650^{\circ} \mathrm{C}$ system, Figure 5.4. However, the $950^{\circ} \mathrm{C} \mathrm{Si} 3 \mathrm{~N}_{4}$ joints were significantly weaker than the $650^{\circ} \mathrm{C} \mathrm{Si3N} 4$ joints. This difference in room-temperature joint strength is attributed to the higher residual stresses in the $950^{\circ} \mathrm{C} \mathrm{Si} 3 \mathrm{~N}_{4}$ joints. The higher residual stresses are caused by the higher CTE of the Inconel $718\left(18 \times 10^{-6} /{ }^{\circ} \mathrm{C}\right)$ compared to the Incoloy $909\left(12 \times 10^{-6} /{ }^{\circ} \mathrm{C}\right)$

Table 5.5. Results of the room-temperature torsion tests of the $950^{\circ} \mathrm{C} \mathrm{Si}_{3} \mathrm{~N}_{4}$ brazed joints.

\begin{tabular}{|c|c|c|c|c|c|c|c|}
\hline $\begin{array}{c}\text { Material } \\
\text { System }\end{array}$ & $\begin{array}{c}\text { Test } \\
\text { Conditions }\end{array}$ & $\begin{array}{l}\text { Torque } \\
\text { (in-ibs) }\end{array}$ & $\begin{array}{l}\text { Shear } \\
\text { Strength } \\
\quad(p s i)\end{array}$ & $\begin{array}{l}\text { Bending } \\
\text { Moment } \\
\text { (in-lbs) }\end{array}$ & Rotation & Fracture & mode \\
\hline $\begin{array}{c}950^{\circ} \mathrm{C} \mathrm{Si3} \mathrm{N}_{4} \\
" \\
" \\
"\end{array}$ & $\begin{array}{c}\text { RT torsion } \\
" . \\
" \\
" . \\
"\end{array}$ & $\begin{array}{l}108 \\
350 \\
200 \\
453 \\
360\end{array}$ & $\begin{array}{c}4,400 \\
14,260 \\
8,148 \\
18,457 \\
14,667\end{array}$ & $\begin{array}{l}225 \\
117 \\
153 \\
144 \\
144\end{array}$ & $\begin{array}{l}0.38^{\circ} \\
1.19^{\circ} \\
0.70^{\circ} \\
0.80^{\circ} \\
0.64^{\circ}\end{array}$ & $\begin{array}{r}\text { Broke in } \\
" \\
" \\
"\end{array}$ & ceramic \\
\hline
\end{tabular}

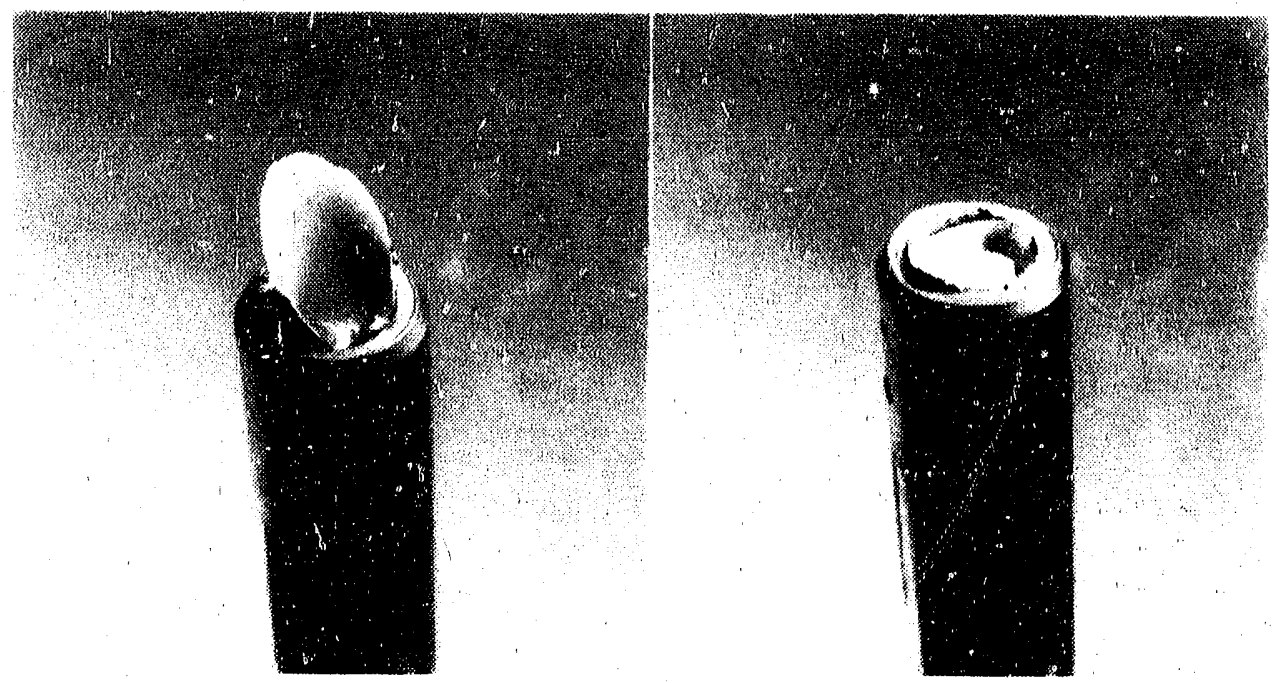

Figure 5.4. Fracture surface of the $950^{\circ} \mathrm{C} \mathrm{SizN} 4$ system fractured in a room-temperature torsion test.

Results from the $950^{\circ} \mathrm{C}$ torsion tests are shown in Table 5.6. In general, the strengths of these joints were very low. During the torsion test the ceramic would slip without fracturing. Several samples were tested at $950^{\circ} \mathrm{C}$. However, all but one of the samples was cracked. The cracked samples did not 
give meaningful results and are not reported. It was not known if the cracks formed on cooling from the brazing cycle or formed on heated to $950^{\circ} \mathrm{C}$ for the torsion tesi.

The joint tested at $950^{\circ} \mathrm{C}$ had a lower shear strength than did the joint tested at $650^{\circ} \mathrm{C}, 122 \mathrm{psi}$ at $950^{\circ} \mathrm{C}$ versus over $1,000 \mathrm{psi}$ at $650^{\circ} \mathrm{C}$. This difference in strength is probably related to a reduction in strength of the brazc alloy.

Table 5.6. Results of the $950^{\circ} \mathrm{C}$ torsion tests of the $950^{\circ} \mathrm{C} \mathrm{Si} 3 \mathrm{~N}_{4}$ brazed joints.

\begin{tabular}{|c|c|c|c|c|c|c|}
\hline $\begin{array}{c}\text { Material } \\
\text { System }\end{array}$ & $\begin{array}{c}\text { Test } \\
\text { Conditions }\end{array}$ & $\begin{array}{l}\text { Torque } \\
\text { (in-lbs) }\end{array}$ & $\begin{array}{l}\text { Shear } \\
\text { Strength } \\
\quad(\mathrm{psi})\end{array}$ & Rotation & Fracture & mode \\
\hline $950^{\circ} \mathrm{C} \mathrm{Si} 3 \mathrm{~N}_{4}$ & $950^{\circ} \mathrm{C}$ torsion & 3 & 122 & $\cdots$ & $\begin{array}{l}\text { Slippage } \\
\text { ceramic }\end{array}$ & $\begin{array}{l}\text { at brazel } \\
\text { interface }\end{array}$ \\
\hline
\end{tabular}

SiC-Incoloy 909 System. Results from the room-temperaturc torsion tests of the $650^{\circ} \mathrm{C} \mathrm{SiC} \mathrm{system} \mathrm{are} \mathrm{showed} \mathrm{in} \mathrm{Table} \mathrm{5.7.} \mathrm{The} \mathrm{fracture} \mathrm{behavior} \mathrm{of}$ these joints was similar to the $\mathrm{Si}_{3} \mathrm{~N}_{4}$ joint systems. The $\mathrm{SiC}$ joints were appreciably weaker than the $\mathrm{Si}_{3} \mathrm{~N}_{4}$ joints. This was probably related to the $\mathrm{SiC}$ being damaged more from the residual stresses generated during the brazing process. Since $\mathrm{SiC}$ has a lower fracture toughness than the $\mathrm{Si}_{3} \mathrm{~N}_{4}$, the strength of $\mathrm{SiC}$ would show a greater drop in strength compared to the $\mathrm{Si}_{3} \mathrm{~N}_{4}$.

Table 5.7. Results of the room-temperature torsion tests of the $650^{\circ} \mathrm{C} \mathrm{SiC}$ brazed joints.

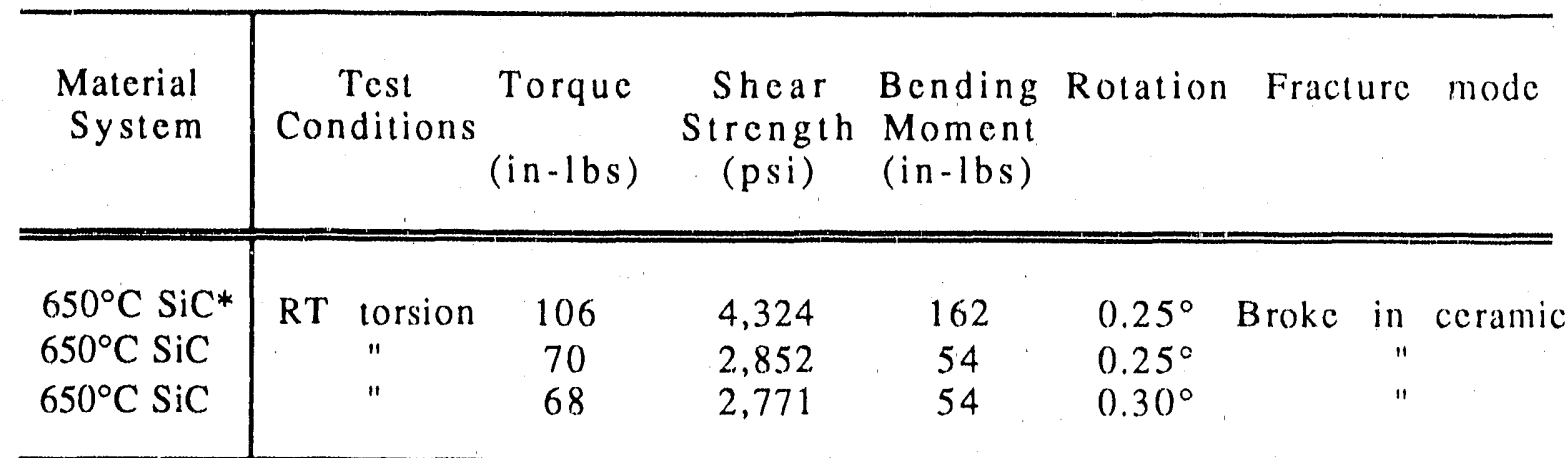

* This sample was heated to $650-700^{\circ} \mathrm{C}$, then gripped in MTS machine, and then cooled before testing to realign the sample for testing. 


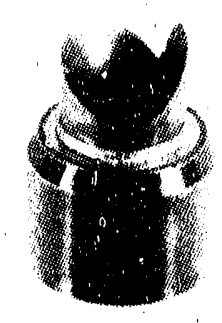

Figure 5.5. Fracture surface of the $650^{\circ} \mathrm{C}$ SiC system fractured in a room-temperature torsion test.

Results from the $650^{\circ} \mathrm{C}$ torsion tests are shown in Table 5:8. The strengths of these joints were approximately the same as the strength of the Incoloy $909 \mathrm{Si}_{3} \mathrm{~N}_{4}$ joints at $650^{\circ} \mathrm{C}$, Table 5.6. Both the $\mathrm{SiC}$ and $\mathrm{Si}_{3} \mathrm{~N}_{4}$ joints failed by slippage of the ceramic during the torsion test. The ceramic did not fracture in either the $\mathrm{SiC}$ or $\mathrm{Si}_{3} \mathrm{~N}_{4}$ joints.

Table 5.8. Results of the $650^{\circ} \mathrm{C}$ torsion tests of the $650^{\circ} \mathrm{C}$ SiC brazed joints.

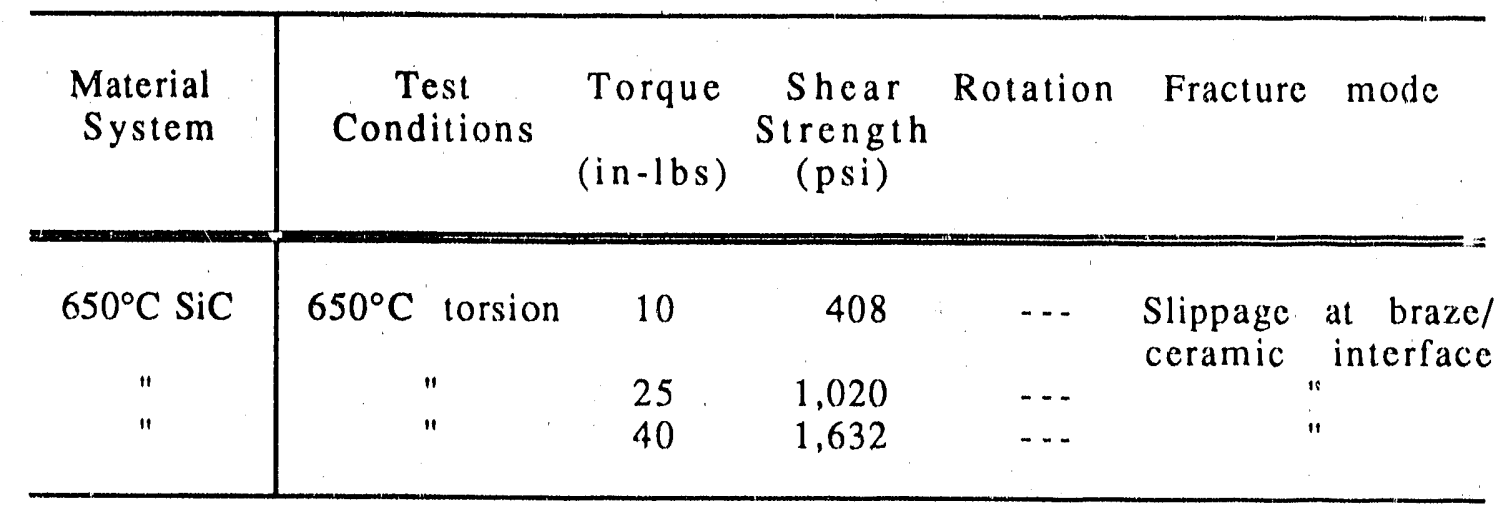

SiC-Inconel 718 System. No successful joints were made between SiC and Inconel 718. All of the samples brazed cracked in the SiC near the top of the interlayer during cool-down from the brazing temperature. This type of failure results from a residual stress level in the ceramic that is too high. New, low yield strength interlayer matcrials must be studied for successful joints to be made in this system. 


\subsection{VERIFICATION OF FEA PREDICTIONS}

Various constitutive equations were derived for the joint materials and used with FEA to predict the residual stress in the all the joint components in terms of maximum principal stress or Mises equivalent stress. Maximum principal stress determines the failure of the ceramic component, while Mises equivalent stress determines the deformation of the metal components. The joints were assumed to have no unbonded arca. Further, the influences of metallurgical reactions duc to processing was not accounted for in the analysis. Bulk properties were used for each material in the joint.

Comparisons betweon the predicted value and the measured values from torsion tests were made. The equations developed in Section 5.1 and testing results from the base materials and brazed joints were used in the comparison. In this analysis the strength of the base materials were treated as theoretical values and failure of the joint was assumed to occur at the maximum stress point. The residual stress state was expressed in terms of $\sigma_{z z}, \sigma_{\theta \theta}$, and $\sigma_{\mathrm{rr}}$.

The values of $\sigma_{z z}$ and $\sigma_{\theta \theta}$ at 20 and $650^{\circ} \mathrm{C}$ from the FEA study are listed in Table 5.9. These values were taken from the centroid of the FEA mesh element on the free surface of the ceramic. This element was immediately above the joint and did not represent the exact stress conditions, i.e., plane stress, on the surface. However, these values were taken as the principal stresses sinec the stress values of the third component, $\sigma_{\mathrm{rr}}$, were significantly smaller than those of $\sigma_{Z z}$ and $\sigma_{\theta \theta}$.

Table 5.9. Comparison between FEA predictions and experimental joint strengths.

\begin{tabular}{|c|c|c|c|c|c|}
\hline $\begin{array}{c}\text { Test } \\
\text { Temperalure }\end{array}$ & $\begin{array}{c}\text { FEA Prediction } \\
\sigma_{Z Z} \sigma_{\theta \theta}\end{array}$ & $\tau_{\text {predicted }}{ }^{*}$ & $\begin{array}{c}\tau_{\text {measured }} \\
(\mathrm{ksi})\end{array}$ & $\tau_{\text {corrected }}$ & $\begin{array}{c}\text { Testing Results } \\
\text { of } \\
\text { Brazed Joints }\end{array}$ \\
\hline $650^{\circ} \mathrm{C}$ & $\begin{array}{r}16.6 \\
-5.4\end{array}$ & $\begin{array}{r}64 \\
94.2\end{array}$ & $\begin{array}{c}10.8-35.2 \\
0.6-2.5\end{array}$ & $\begin{array}{c}18.4-59.8 \\
\ldots\end{array}$ & $\begin{array}{l}\text { Failed in } \\
\text { ceramic } \\
\text { Failed at } \\
\text { interface }\end{array}$ \\
\hline
\end{tabular}

* Calculation was based on $\tau_{\max }=86.0 \mathrm{ksi}$. 
Table 5.10. Comparison between FEA predictions and experimental joint failure strains. At $20^{\circ} \mathrm{C}$ the constant $k$ in Equation 2.24 was 13,694 in-lbs/rad.

\begin{tabular}{|c|c|c|c|c|c|}
\hline $\begin{array}{c}\text { Test } \\
\text { Temperature }\end{array}$ & 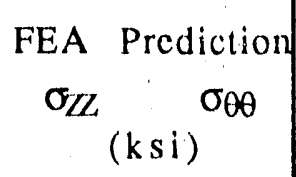 & $\gamma_{\text {predicled }}{ }^{*}$ & $\begin{array}{l}\gamma_{\text {measured }} \\
\text { (radians) }\end{array}$ & $\gamma_{\text {corrected }}$ & $\begin{array}{c}\text { Testing Results } \\
\text { of } \\
\text { Brazed Joints }\end{array}$ \\
\hline $\begin{array}{r}20^{\circ} \mathrm{C} \\
650^{\circ} \mathrm{C}\end{array}$ & $\begin{array}{rr}26.9 & 16.6 \\
-11.1 & -5.4\end{array}$ & $\begin{array}{c}3.4 \\
0.005\end{array}$ & $\begin{array}{c}0.6-1.8 \\
\ldots\end{array}$ & $\begin{array}{c}1.0-3.1 \\
\ldots\end{array}$ & $\begin{array}{l}\text { Failed in } \\
\text { ceramic } \\
\text { Failed at } \\
\text { interface }\end{array}$ \\
\hline
\end{tabular}

* Calculation was based on $\tau_{\max }=86.0 \mathrm{ksi}$.

Using Equation 5.4 and $\tau_{\max }$ from Table $5.1,86.0 \mathrm{ksi}$, the calculated value of $\tau_{\text {predicted }}$ at room temperature was $64.0 \mathrm{ksi}$ while the measured values from the torsion tests were in the range of $10.8-35.2 \mathrm{ksi}$. The measured values change to 18.4 - $59.8 \mathrm{ksi}$ when the stress concentration factor $\left(\mathrm{K}_{1}=1.7\right)$ associated with the change in diameter at the joint $\left(0.5^{\prime \prime}\right.$ ceramic to $0.75^{\prime \prime}$ metal) is accounted for. The failure strain in Table 5.10, $\gamma_{f}$, was predicted with Equation 2.24, where $k=13,694 \mathrm{in}-\mathrm{lbs} / \mathrm{rad}$. The constant $\mathrm{k}$ was measured from the torsion iests. The measured values are $30-90 \%$ of values predicted by FEA. The relatively large seatter in the strerigth values of the joints should be attributed to the handling of ceramic parts and to the difference in the ideal joints modelled and the real joints tested.

In FEA modelling, the statistical treatment of the surface flaw discussed in Section 2.3 was not preformed, and we assumed that the probability of ceramic survival or failure was a function of stress only. This implics that the failure of the joint should always coincide with the point of maximum residual stress. This was an over simplification.

From the fracture mechanics point of view, the crack initiation sitc will be determined based on the flaw size, residual stress, and applied stress. Since the ceramic part in the joint was subjected to various residual stress states, a weakest link statistical treatment should be used. The joint failure stress depends on the volume of the ceramic subjected to the stress. Subsequently the cracking probability should be determined as a function of the stress and the volume within the isostress regions. Therefore, the FEA predicted value for the joint failure stress would probably be smaller than the value presently predicted.

The joints usually had some unbonded regions. Nonuniform bonding results in the loss of the axial symmetry of the joint. This results in the loss of the plane stress condition at the point of maximum residual stress. 'The triaxial stress state at the surface, caused by the unbonded area in the joint, may reduce the effective stress for the failure of the ceramic. This will increase 
the difference between experimental values and FEA predicted values of the joint strength.

Also, during the brazing process, a change in the compositions and properties of the joint materials contributes to error in the FEA predictions. The presence of molten braze enhances the dissolution of other joint components. New phases form and the composition of the braze alloy changes. These will lead to changes in the mechanical properties of the joint. These property changes are thought to be one of the major factors causing disagreement between measured and predicted joint strengths.

Alignment of the ceramic part with respect to the metal component is another factor for the scatter. Misalignment in the range of $0.002-0.020$ " has been observed from the brazing practice with current test samples. This could induce large bending moments at the joint area, significantly lowering the measured strength values.

The FEA values of $\sigma_{Z Z}$ and $\sigma_{\theta \theta}$ at $650^{\circ} \mathrm{C}$, were obtained from the joint model which was cooled down to room temperature and heated back up to

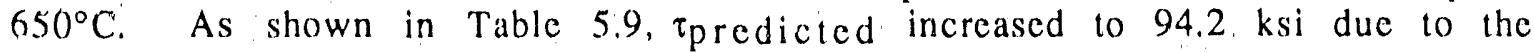
compressive principal stresses. This value exceeded the strength values of any components in the joint at $650^{\circ} \mathrm{C}$ and failure did not occur in the ceramic. The values of $\tau_{\text {measured }}(0.6-2.5 \mathrm{ksi})$ represents the strength of the weakest component, i.c., the interface region, at $650^{\circ} \mathrm{C}$. In this case, the stress concentration factor was not applicable.

Based on the discussions above, the following are recommendations for improving the analytical predictions of joint strengths and improving the consistency of the joint properties.

- Develop a statistical treatment of FEA results to determine the failure strength of the joints.

- FEA model should reflect changes occurring during the brazing process, such as; the formation of new layers, the change in mechanical properties of the layers, and the change in dimensions of the layers.

- Production of consist joints with no unbonded areas. Improvement in the alignment of the ceramic with respect to the metallic part is essential.

- Brazing alloys which have minimal interactions with other joint components at brazing temperature.

\subsection{FATIGUE TESTING}

Thermal and mechanical fatigue tests were used to evaluate the effects of temperature on the performance of the brazed joints. Thermal fatigue tests were used to access the the effects of repcated expansion and contract of the structural alloy and interlayer materials on the cracking behavior of the ceramic. Mechanical fatigue tests were used to determine if the brazed joints could withstand repeated loadings without loss of mechanical integrity. 


\section{Thermal Fatigue Testing}

The geometry and mass of a gas lurbine rolor play a large part in determining the internal temperatures of the rotor/shaft system; therefore, one system was chosen as a model. Thermal maps of the ceramic lurbine rotor and structural alloy shaft cross-section of the chosen model were based on work done at General Motors on their gas turbine engine.

A temperature of $650^{\circ} \mathrm{C}$ is the lower of the two braze joint service temperatures for both $\mathrm{Si}_{3} \mathrm{~N}_{4}$ and $\mathrm{SiC}$. The location of the $650^{\circ} \mathrm{C}$ isotherm was marked on the thermal map for steady state, maximum power conditions for both materials. This area was then examined on the thermal maps for steady state, idle conditions. The idle temperatures were found to be $335^{\circ} \mathrm{C}$ and $465^{\circ} \mathrm{C}$ for the $\mathrm{Si}_{3} \mathrm{~N}_{4}$ and $\mathrm{SiC}$, respectively. The $\mathrm{SiC}$ required approximately 66 seconds to reach $650^{\circ} \mathrm{C}$ from $465^{\circ} \mathrm{C}$ and return again, while the $\mathrm{Si}_{3} \mathrm{~N} 4$ cycle was approximately twice as long. Figure 5.6 is a graphical representation of the thermal cycle used for testing.

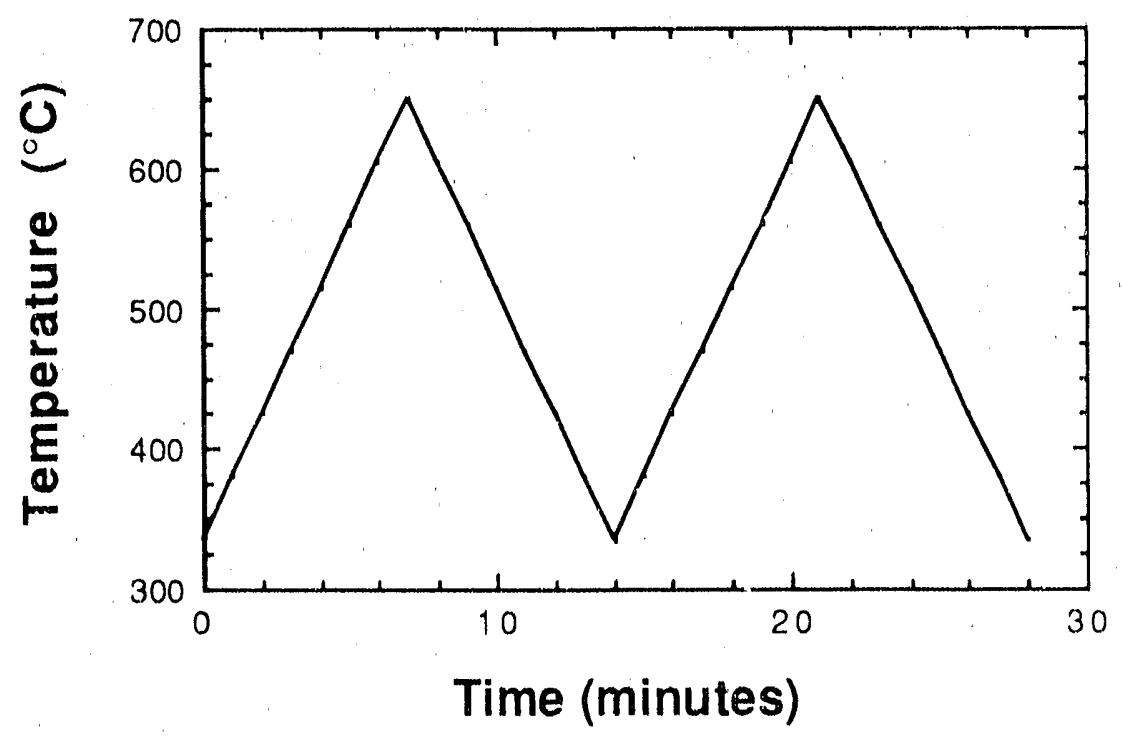

Figure 5.6. Thermal cycle used in thermal fatigue tests of brazed joints for a $650^{\circ} \mathrm{C}$ use temperalure.

The same method was used to develop the thermal cycle for the 95()$^{\circ} \mathrm{C}$ joint. The idle temperature is raised as the entire operating temperature of the hot section is raised in the gas turbine engine. This is the most efficient way of operating the engine because of the increased response lime when the temperature differences between maximum speed temperalure and idle speed temperature are small. Therefore, the cycle time was left the same as in the previous cycle, Figure 5.7 . 


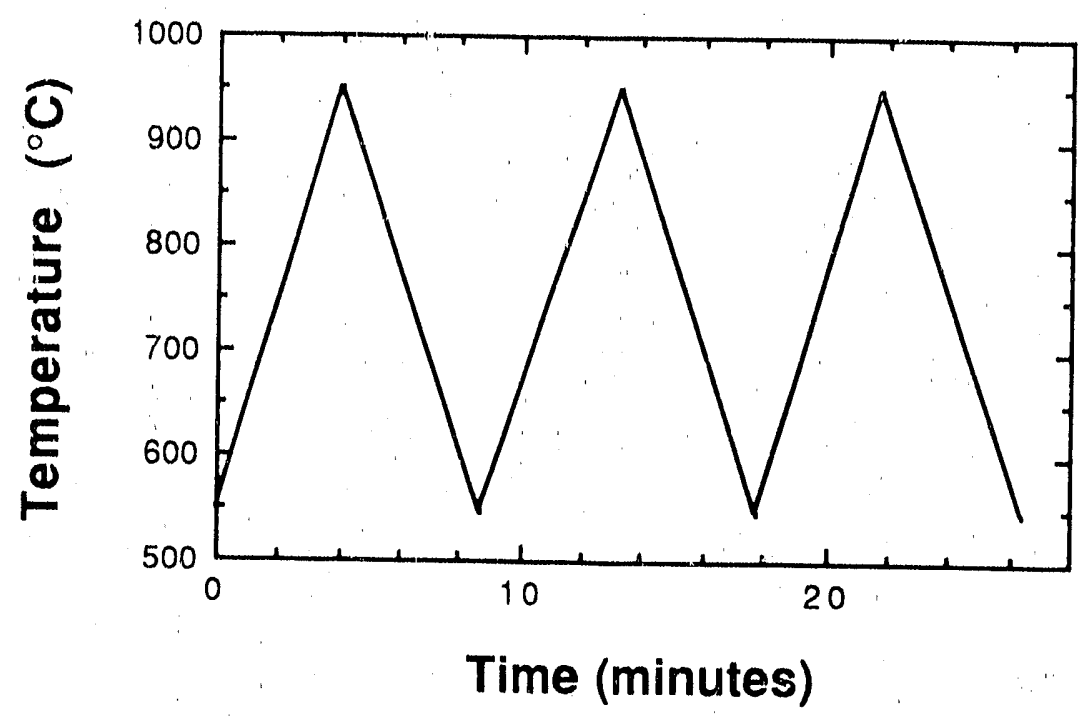

Figure 5.7. Thermal cycle used in thermal fatigue tests of brazed joints for a $950^{\circ} \mathrm{C}$ use temperature.

\section{Thermal Eatigue of Brazed Joints}

Braze joints were made for thermal fatigue tests at 650 and $950^{\circ} \mathrm{C}$. These joints were identical to the joints shown in Figures 4.3 and 5.1 except that the metal and ceramic sections were only 1" long. The initial crack distribution was checked with microfocus $x$-ray. Microfocus $x$-ray detected cracks in the 650 and $950^{\circ} \mathrm{C} \mathrm{SiC} \mathrm{systems} \mathrm{immediately} \mathrm{after} \mathrm{brazing} \mathrm{(Figure} \mathrm{5.8).} \mathrm{However,} \mathrm{no}$ cracks were detected in the $\mathrm{Si}_{3} \mathrm{~N}_{4}$ systems. The lack of cracks in the $\mathrm{Si}_{3} \mathrm{~N}_{4}$ systems could be due to either no cracking in $\mathrm{Si}_{3} \mathrm{~N}_{4}$ or to the cracks in the $\mathrm{Si}_{3} \mathrm{~N}_{4}$ being smaller than the detection limit of the $x$-ray equipment, which is $40 \mu \mathrm{m}$.

The samples were examined by microfocus $x$-ray after 10,100 , and 1,000 cycles. The $650^{\circ} \mathrm{C} \mathrm{Si} 3 \mathrm{~N}_{4}$ system survived all 1,000 cycles without evidence of cracking. Severe oxidation of the Mo interlayer in the $950^{\circ} \mathrm{C} \mathrm{Si} 3 \mathrm{~N} 4$ system prevented testing of these joints.

The $\mathrm{Si}_{3} \mathrm{~N}_{4}$ joints performed better than the SiC joints in the thermal fatigue tests. These results mirror the results observed in the torsion tests, where the $\mathrm{Si}_{3} \mathrm{~N}_{4}$ joints were stronger than the $\mathrm{SiC}$ joints. 


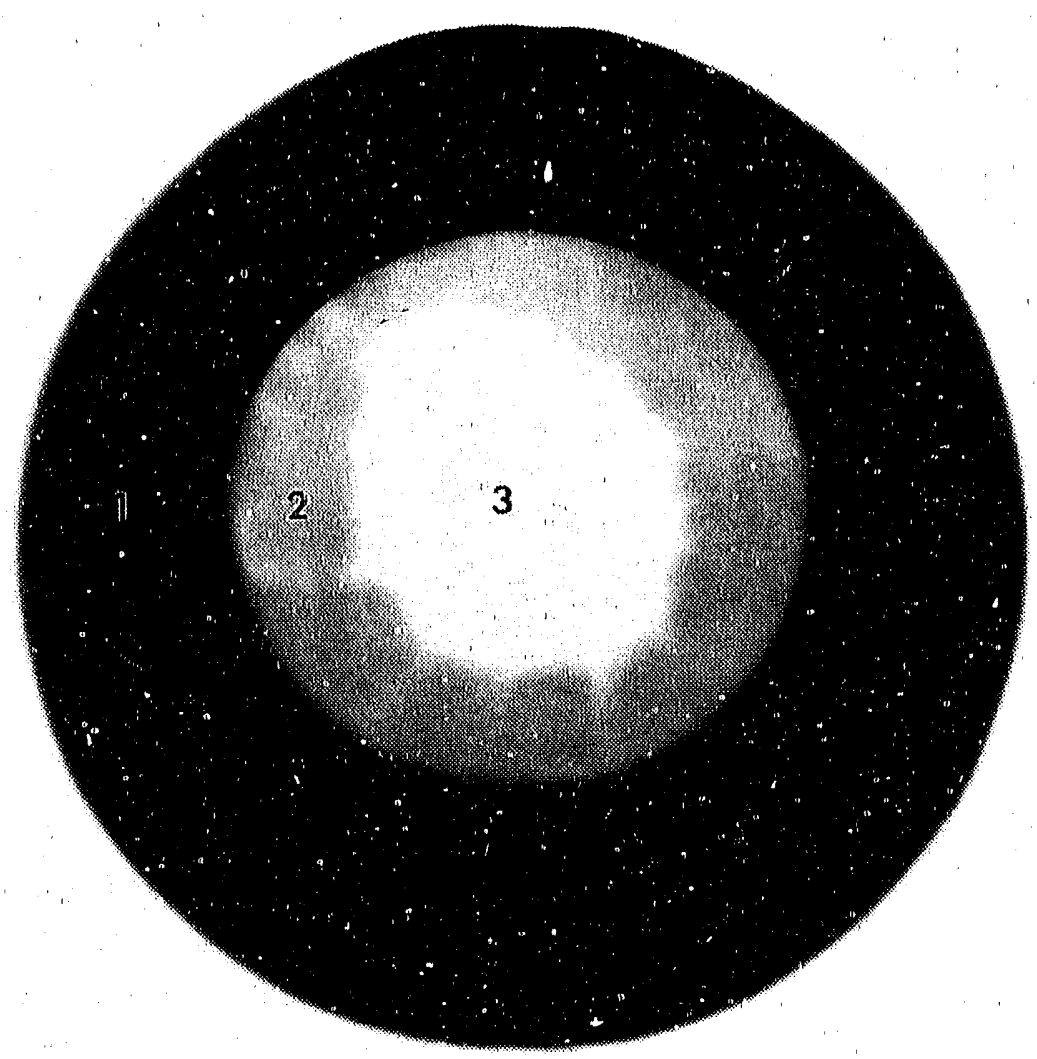

Figure 5.8. Microfocus $\mathrm{x}$-ray image of $650^{\circ} \mathrm{C}$ SiC brazed joint immediately after brazing. Lateral cracks extend from the ccramic-metal interface into the SiC. Structural alloy (1). Laterai cracks (2). Uncracked $\mathrm{SiC}(3)$. Taken at $90 \mathrm{kV}, 0.35 \mathrm{~mA}$.

\section{Mechanical Fatigue Testing}

The ceramic-metal joint was required to withstand 1,000 cycles of mechanical fatigue. As with the thermal fatigue evaluation, the mechanical cycle was developed with the idea of simulating the stresses developed in a gas turbine engine. The model used was the engine currently being tested by General Motors.

The braze joint area of a rotor/shaft assembly experiences many stresses. Torsional loading is the most severc. The torque experienced at minimum and maximum idle speeds is $35 \mathrm{in}-\mathrm{lb}$ and $185 \mathrm{in}-\mathrm{lb}$, respectively. The cycle time, from minimum to maximum, was $1 / 3$ seconds. A graph of the fatigue cycle is seen in Figure 5.9.

\section{Mechanical_Eatigue Testing of Brazed Joints}

Five joints from the $650^{\circ} \mathrm{C}$ and $950^{\circ} \mathrm{C} \mathrm{Si}_{3} \mathrm{~N}_{4}$ system were successfully tested at room-temperature, Table 5.11. The tests were not run at 650 or $950^{\circ} \mathrm{C}$ since the joints were not strong cnough to withstand the 185 in-lbs torque. 


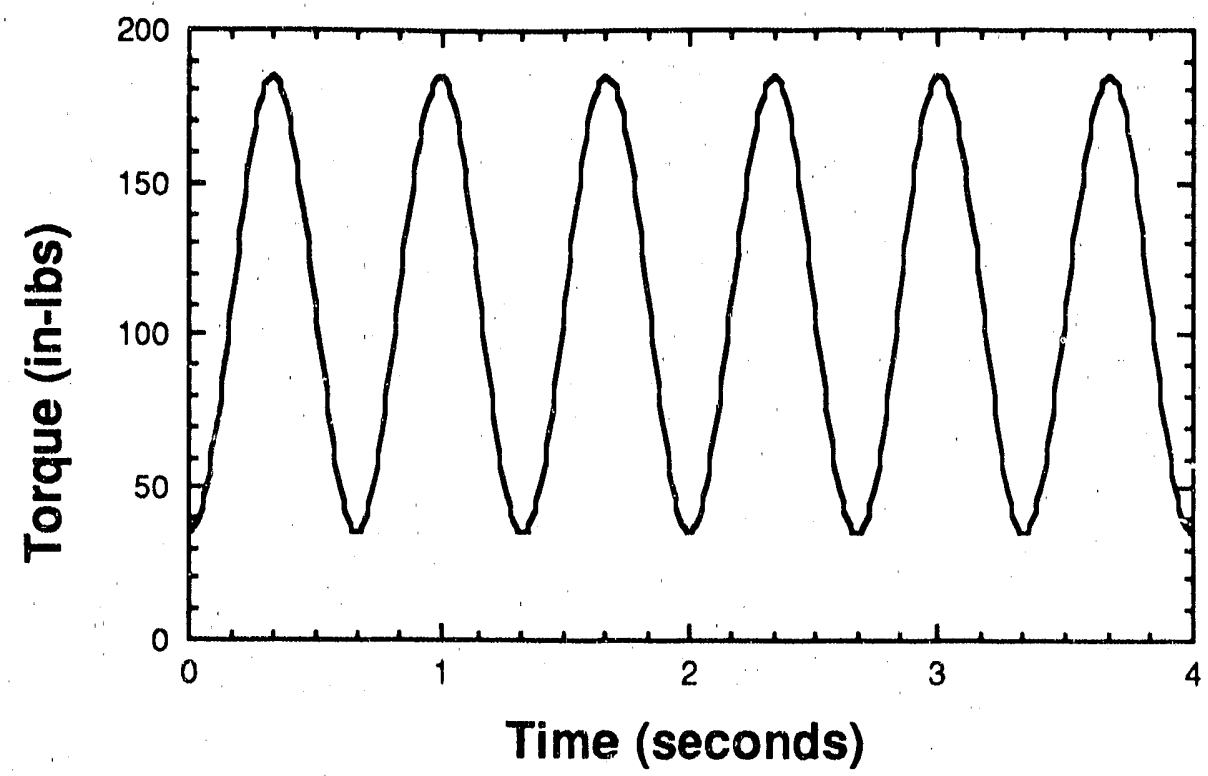

Figure 5.9. Mechanical cycle used for fatigue testing the brazed joints.

Table 5.11. Room-temperature fatigue tests of the $\mathrm{Si}_{3} \mathrm{~N}_{4}$ brazed joints.

\begin{tabular}{|c|c|c|c|c|c|}
\hline $\begin{array}{r}\text { Material } \\
\text { System }\end{array}$ & $\begin{array}{c}\text { Test } \\
\text { Conditions }\end{array}$ & $\begin{array}{l}\text { Torque } \\
\text { (in-lbs) }\end{array}$ & $\begin{array}{l}\text { Bending } \\
\text { Moment } \\
\text { (in-lbs) }\end{array}$ & Rotation & $\begin{array}{l}\text { Number of } \\
\text { cycles } \\
\text { for failure }\end{array}$ \\
\hline $\begin{array}{c}650^{\circ} \mathrm{C} \mathrm{Si} 3 \mathrm{~N}_{4} \\
" \\
" \\
"\end{array}$ & $\begin{array}{c}\text { RT fatigue } \\
" \\
" \\
" \\
"\end{array}$ & $\begin{array}{c}185-35 \\
\text { " } \\
" \\
" \\
"\end{array}$ & $\begin{array}{l}180 \\
171 \\
189 \\
234 \\
144\end{array}$ & $\begin{array}{l} \pm 0.31^{\circ} \\
\pm 0.32^{\circ} \\
\pm 0.31^{\circ} \\
\pm 0.32^{\circ} \\
\pm 0.32^{\circ}\end{array}$ & $\begin{array}{r}>1,000^{*} \\
>1,000^{*} \\
>1,000^{*} \\
>1,000^{*} \\
>1,00(0,000\end{array}$ \\
\hline $950^{\circ} \mathrm{C} \mathrm{Si} \mathrm{S}_{4}$ & RT fatigue & $\begin{array}{c}185-35 \\
\text { " }\end{array}$ & $\begin{array}{l}225 \\
162\end{array}$ & $\pm 0.26^{\circ}$ & $\begin{array}{l}>1,000^{*} \\
>1,000\end{array}$ \\
\hline
\end{tabular}

These samples were heated to $650-700^{\circ} \mathrm{C}$, then gripped in the MTS machine, and then cooled before testing to realign the sample.

A brazed joint from the $650^{\circ} \mathrm{C} \mathrm{Si}_{3} \mathrm{~N}_{4}$-Incoloy 909 system was first fatigued at room-temperature for 1,000 cycles. After this test was run, the joint was fatigued at room-temperature until failure. After $1,000,000$ cycles, the joint was still intact. The joint showed no signs of degradation; the rotation required for 35 and 185 in-lbs of torque was unchanged at $\pm 0.32^{\circ}$ from the start of the test. 


\section{SUMMARY AND CONCLUSIONS}

In this program, analytical mechanics was used to identify important concepts for the design of the joint geometry and to understand the roles of materials parameters in reducing residual stress in ceramic parts. Material systems were defined for 650 and $950^{\circ} \mathrm{C}$ applications to verify the validity of mechanics predictions via FEA in the magnitude and distribution of the residual stress. Torsion tests were performed to characterize the properties of the brazed joints and were related to the FEA results.

Failure criteria ( $\beta$ and $\gamma$ criteria) were developed with analytical mechanics for braze and ceramic failure. The $\beta$ criterion was expressed as a function of thermal expansion coefficients, temperature, rupture strain, and size of the braze assuming that the braze deforms in simple uniform shear through the braze thickness. However, it was found that the shear rupture of the braze was governed by strain localization rather than by the $\beta$ criterion.

Three concepts were examined in developing the $\gamma$ criterion for ccramic failure. These are the maximum principal stress, a crack growth criterion, and a stress concentration criterion. The crack growth criterion was derived in terms of the ceramic toughness and flaw size. It was assumed that the critical region for crack growth was for the case of cracking at the edge of the braze/ceramic interface. The stress concentration criterion was developed in terms of the principal shear stress near the critical area with consideration of stress relief due to the flow of the braze. Both crack growth and stress concentration criteria recommended high fracture toughness ceramics and low shear strength braze alloys. These two criteria also showed the importance of the geometrical factor of the possible cracks on the surface of the ccramics. The stress concentration criterion, in addition, showed the advantage of metals with low thermal expansion coefficients. These two criteria directed the selection of interlayer materials for the final material systems.

Constitutive equations were derived for the joint materials. These equations were used to select an optimum joint geometry using the ABAQUS finite element code. The joint geometries examined in this program were a butt joint, parabolic joints with different angles, conical joints, and cylindrical joints. The cylindrical joint was investigated with two different edge geometries, i.e., square and tapered edges. It was shown in the analysis that the cylindrical geometry was more advantageous in controlling the residual stress and in preventing premature failure than other geometrics duc to lower failure probability, although an exact 1:1 comparison was difficult among those geometries. Also, the cylindrical joint with tapered edge resulted in a lower stress state in the ceramic than that with the square edge.

Extensive FEA was done to screen the interlayer materials. This study showed that low yield strength materials like $\mathrm{Ni}$ outperformed low thermal expansion materials like Mo. The analysis was continued with final matcrial systems to verify the FEA predictions. FEA predicted the location and level of the residual stresses built up in the ceramic in terms of the maximum principal stress and Mises equivalent stress. 
For material systems development, a new methodology was developed to quantify the selection of materials for the brazed joint. Using a combination of thermodynamics, reaction kinetics, and FEA, it was possible to efficiently screen materials and to optimize the joint system. This screcning procedure included the following:

- FEA of the joint to optimize the geometry and interlayer thickness.

- Consideration of the oxidation properties, high-temperature strength, and CTE of the structural metal alloys.

- Consideration of the CTE, yield stress, and melting point of the interlayer materials.

- Evaluation of thermodynamic data to predict reactivity between the $\mathrm{Si}_{3} \mathrm{~N}_{4}$ and $\mathrm{SiC}$ and various coating materials.

- A study of the reaction kinetics between $\mathrm{Si}_{3} \mathrm{~N}_{4}$ and $\mathrm{SiC}$ and various coating materials.

- The wetting behavior of braze alloys on the various coating materials.

The high-temperature requirements and compatibility tests between material systems resulted in the following as final material systems used for the braze joints:

- Incoloy 909-(Au-5Pd-2Ni)-Ni-Ti-PY6 for $650^{\circ} \mathrm{C}$

- Incoloy 909-(Au-5Pd-2Ni)-Mo-Ti-SiC for $650^{\circ} \mathrm{C}$

- Inconel 718-(Au-5Pd-2Ni)-Mo-Ti-PY6 for $950^{\circ} \mathrm{C}$

- Inconel 718-(30Au-34Pd-36Ni)-Mo-Ti-SiC for $950^{\circ} \mathrm{C}$

PY6 was selected over SNW 1000 and AY6 $\mathrm{Si}_{3} \mathrm{~N}_{4}$ because of its excellent high-temperature strength and its compatibility with the coating matcrial selected. Hexaloy SA SiC was chosen as the SiC material. Incoloy 909 was the low-expansion, Fe-based superalloy and Inconel 718 was the Ni-based superalloy. Both of these metal alloys provide adequate high-temperature strength and oxidation resistance while being representative of the wider range of $\mathrm{Fe}$ - and $\mathrm{Ni}$-based superalloys.

The FEA study indicated that a material with a low CTE and a low yicld strength was the ideal interlayer material. In practice, it is not possible to have both of these properties simultaneously in one matcrial. Therefore, both types of interlayer materials were evaluated. Mo was selected for the $950^{\circ} \mathrm{C}$ application due to its low CTE, high stiffness, and high-temperature capability, while $\mathrm{Ni}$ was chosen for the $650^{\circ} \mathrm{C}$ application due to its low yield strength and low stiffness.

For most brazing systems, a reactive coating on the ceramic or a reactive component to the braze is needed to provide a driving force for wetting. The wetting experiments with the $\mathrm{Au}-5 \mathrm{Pd}-2 \mathrm{Ni}$ and the $\mathrm{Au}-5 \mathrm{Pd}-2 \mathrm{Ni}-$ $1.25 \mathrm{Ti}$ braze alloys indicated that the $\mathrm{Au}-5 \mathrm{Pd}-2 \mathrm{Ni}$ braze wet the Ti coated PY6 and the Ti coated Hexaloy $\mathrm{SA} \mathrm{SiC}$ with greater uniformity and consistency than 
the Au-5Pd-2Ni-1.25Ti braze wet uncoated PY6 and uncoated Hexaloy SA SiC. $\mathrm{Au}-5 \mathrm{Pd}-2 \mathrm{Ni}$ and $30 \mathrm{Au}-34 \mathrm{Pd}-36 \mathrm{Ni}$ were selected duc to their oxicution resistance, ductility, and relatively high melting points. The final braze alloys selected, $\mathrm{Au}-5 \mathrm{Pd}-2 \mathrm{Ni}$ and $30 \mathrm{Alt}-34 \mathrm{Pd}-36 \mathrm{Ni}$, did not contain $\mathrm{Ti}$.

$\mathrm{Ti}$ coating was chosen over the $\mathrm{Zr}$ coating since $\mathrm{Ti}$ provided good reactivity with the PY6 and Hexaloy SA SiC. Ti also caused minimal degradation of the properties of PY6 as did the $\mathrm{Zr}$ coating.

For the verification of the FEA predictions with experiments, linkage between' FEA and mechanical testing of brazed joints has been established under the assumptions that the effects of processing and the statistical factor for microcracking in the ceramic are not significant." However, large scatter in measured strengths and the difference between measured and predicted strengths indicate the importance of processing and statistical factors in the fracture. The measured strength values of the brazed joint were $30-90 \%$ of the joint strengths predicted by FEA.

The low high-temperature strength confirmed the need of new b.aze alloys and interlayer materials that can meet the high-temperature strength requirements. Nevertheless, the torsion strength of the joints at roomtemperature were encouraging.

Overall results clearly showed that FEA is an effective tool to design the geometrics for ccramic-metal joints and that joining by brazing is a suitable method for high-temperature heat engine applications. 


\section{PLANS FOR PHASE II AND III}

\section{Phase IL Material System and Design Optimization, and Joint Life Prediction}

The goal of Phase II is to optimize materials systems and joint designs building on the results of Phase 1. The work shall also include demonstration of the potential for scale-up of the joint size to interfacial arcas of commercial significance, applicability of the analytical joint modeling tools and the ability to use these tools to design and predict the mechanical and thermal stability of the larger joints. These joints, referred to as "scale-up" joints, shall have the ceramic shaft at least 0.8 inches in dianeter. The goal is to develop a system which can perform in an engine such as the ATTAP engine. The anticipated environment will be oxidizing and will have joint temperatures of up to 9.50$)^{\circ} \mathrm{C}$. Improved joint materials systems shall be developed to optimizc the combination of competing properties which include ductility, yicld strength, and creep resistance. The effect of cach of these propertics on joint performance shall be examined using the FEM model. Finally, a program of mechanical testing shall be carried out to confirm the effectiveness of the modeling program. This shalt include torsion tests, thermal and mechanical fatigue, and creep testing. In addition, an analytical and experimental program in service life prediction will be undertaken. The work in Phase II shall include five tasks (Tasks 5, 6, 7, 8 and 9):

\section{Task 5. Materials System Optimization}

\section{Subiasks}

In Phase I of this project, Inconel 718 and Incoloy 909 were selected as the structural alloys, nickel and molybdenum were selected as the interlayer materials, and "Y6 (silicon nitride - $6 \mathrm{wt}$. \% yttria) was shown to be the preferred ceramic. The continued program will be centered around these materials. Several braze alloys based on the Au-Pd-Ni and Au-Pd systems were studied. Because of the high-temperature strength of the structural materials and the joint geometry, the braze alloy is expected to be the weakest mechanical link in the joint system. Therefore, there is a need for the development of new braze alloys to provide the improved high-temperature properties required for the $650^{\circ} \mathrm{C}$ and $9500^{\circ} \mathrm{C}$ ceramic-to-metal joints.

\subsection{Braze Alloys}

The starting point for braze alloy development will center on defining the limiting properties of a successful braze alloy. The FEM model developed during Phase I of this project will be used to define the amount of plastic deformation carried by the interlayer and braze matcrials. FEM will be used 10 determine the minimum amount of deformation in the braze alloy that is required o obtain a crack-free joint. The sensitivity of a successful, crack-free joint on the plasticity and yield strength of the braze alloy will also be determined. Once the limiting mechanical requirements of the braze alloy are 
known, candidate material systems for the braze alloy will be identified and studied.

The first group of brazing alloys to be studied will be based on metal eutectic compositions with sufficient ductility and high temperature oxidation resistance. Compositions of this type will promote fluidity and minimize porosity due to shrinkage during solidification. High melting point, oxidationresistant metal systems will be evaluated with emphasis on metal cutectic systems (in contrast to non-cutectic $\mathrm{Au}-\mathrm{Ni}$ or $\mathrm{Pd}-\mathrm{Ni}$ ) and on Ni-based alloys. The principle of diffusion solidification will be taken into consideration in the design of braze alloys.

A second group of candidate brazing alloys will be evaluated concurrently with the above group. These will be based on superalloy compositions and turbine blade repair braze alloys. Their relatively high yield stress and low ductility (compared with precious metals) should make them less forgiving and require reliance on the interlayer to accommodate differential expansion. The FEM model will be used to establish whether such a set of properties is a viable approach.

Initial sereening of potential alloy systems will be based on published phase diagrams. Five samples will be required in each system to establish wetting. It will also be necessary to measure the mechanical properties of the braze with a minimum of three tensile specimens for each composition. The interactions between the brazc alloy and metals will be examined using coupon samples. About twenty per composition are anticipated.

\subsection{Interlayers}

Previous work conducted in Phase I demonstrated the relative, effectiveness of low yield strength materials and low CTE materials as interlayers in reducing the joint stress. Typical interlayer materials emphasized in Phase I were pure matcrials such as nickel, copper, molybdenum, tungsten and niobium. Imprevements in performance are possible by using alloys which could provide combinations of propertics unobtainable in pure materials. Service temperatures of the joints require combinations of high-temperature propertics which are possible through alloying. For example, a nickel alloy could provide adequately low yield stress to avoid cracking. the ceramic, while having improved creep resistance compared with pure nickel. Refractory metal alloys like Mo- and W-base could be acceptable with improved ductility, retaining their high-temperature properties and low CTE. Various alloys will be examined based on the working model developed in Phase I.

New interlayer ideas, such as multilayer matcrials, will also be examined in Phase II. An example of a multilayer material is an outer ring of Mo with an inner ring of $\mathrm{Ni}$. Preliminary FEM conducted in Phase 1 show promise for these types of interlayers. 'The planned work would screen three or four candidate interlayers based on yicld strength, CTE, creep strength, and oxidation resistance. Performance tests of room-temperature and crecp strength will be carried out. Published data will be used to verify oxidation resistance and CTE. 


\subsection{Coatings}

The study on new braze alloys and new interlayer matcrials will necessitate a review of the materials used to coat the ceramic component. Coatings on the ceramic are necessary in order to obtain wetting and adhesion between the chemically dissimilar braze and ceramic. The adhesion or wetling of a metal to a ceramic depends on the chemical compatibility between the metal and ceramic. Included in the concept of chemical compatibility is the nature of the wetting atmosphere, chemical bonds, chemical reactions, surface energy of the ceramic, and surface tension of the metal. The methodology for testing coatings developed in Phase I will be applied to the new study.

Task 6. Joint Design Optimization

\section{Subtasks}

6.1. Development of multiple interlayer joints (with Brown U.). Various multilayer systems shall be examined to minimize the stress generated from thermal expansion mismatch at the ccramic-metal interface. Analytical expressions shall be modified to account for the introduction of multiple interlayers in the structure. The modified expressions shall be used for the materials systems suggested by Task 5 with the use of finite element methodology.

6.2. Stress analysis of brazed joint and optimization (with Brown U.). Stress analysis shall be performed to take into account the dimensional change and composition change caused by the brazing process. FEM analysis of the joint system shall be done using the geometry of the joint and the properties of the braze alloy after brazing. Numerical stress analysis using the commercially available code, ABAQUS, shall be performed. The cylindrical joint shall be the basic joint design for consideration.

6.3. Stress analysis of structural alloy and optimization (with Brown U.). The effect of the overall macroscopic joint shape on the residual stress in the ceramic-metal brazed joint shall be studied by examining axisymmetric joints other than simple cylinders. The effects of tapers and reduced wall thickness are two of the geometrical factors that shall be addressed. The geometry of the structural alloy shaft shall be changed to reflect the findings.

Task 7. Joint Life Prediction Methodology and Testing

\section{Subtasks}

7.1. The gamma-criterion developed in Phase I shall be improved (with Brown University). Material data on the damage assessment and the crack growih, particularly for the ceramic components, shall be collected. Modeling of the crack growth failure mechanism shall be developed as a part of the ABAQUSsupported finite element braze joint model.

7.2. Mechanical fatigue. Mechanical fatigue tests shall be performed on the MTS machine purchased during Phase I. These tests shall cycle between 35 
and $185 \mathrm{in}-\mathrm{lbs}$ with a frequency of $1.5 \mathrm{~Hz}$. Ten samples $\left(2 \mathrm{~cm}^{2}\right.$ joint area) shall be tested at each of two temperatures, $650^{\circ} \mathrm{C}$ and up to $950^{\circ} \mathrm{C}$, for a total of twenty samples. Mechanical fatigue tests shall be run at constant temperature. The superimposed effects of mechanical and thermat cyclical loading may be investigated if time permits.

7.3. Creep characteristics of brazed joints. The srecp characteristics of the final brazed joint shall be characterized. A brazed sample $\left(2 \mathrm{~cm}^{2}\right.$ joint area) shall be loaded at a constant torque of 185 in be measured as a function of time. These tests shall be carried out at $650^{\circ} \mathrm{C}$ and another temperature, up to $950^{\circ} \mathrm{C}$. Ten samples shall be tested at each temperature, for a total of 20 samples.

Task 8. Fabrication and Evaluation of Scale-Up Size Ceramic-to-Metal Joints

\subsection{Scalc-Up Brazed Joint Production}

Brazed samples shall be produced for performance testing. Joint design shall be based on analytical and experimental results from earlier portions of the program. These joints shall be prototypical of rotor-to-shaft joints in the ATTAP program. The ceramic shaft end in this engine has a diameter of about 0.8 inches. The length of the brazed ring around this shall be determined using FEM to evaluate the relationship between two competing effects. If the brazed length is excessively long, the likelihood of cracking the ceramic is high, resulting in weak joints. If the joint is 100 short, the stress in the braze would probably exceed its capacity. The FEM model shall be used to yield a workable solution and minimize the number of experimental samples necded. A minimum of 3 test joints shall be fabricated and tested, each at roomiemperaturc, $650^{\circ} \mathrm{C}$ and $950^{\circ} \mathrm{C}$.

Task 9. Reporting and Quality Assurance Requirements

Reporting and quality assurance requirements will be identical to those used for Phase 1 .

Phase 1II. Ficld Engine Testing and Development of Production Methodologics.

Phase III will involve engine testing to confirm the life cycle predictions of Phase 1I. Also, the issues associated with volume manufacturing and the development of realistic production yields of acceptable joints will be addressed. 


\section{ACKNOWLEDGMENTS}

This research was sponsored, in part, by the U.S. Department of Energy, Assist nt Secretary for Conservation and Renewable Encrgy, Office of Transportation Systems, as part of the Ceramic Technology for Advanced Heat Engines Project of the Advanced Materials Development Program, under contract DE-AC05-840R21400 with Martin Marietta Energy Systems, Inc. Special thanks go to M. Santella and D. R. Johnson at ORNL for their thoughtful insights into the many problems involved in ceramic-metal brazing. Their suggestions and technical discussions were decply appreciated. The support of $R$. Schulz at the DOE is also appreciated.

Howard Mizuhara's (GTE Wesgo) research of new braze alloys, resulting in the $\mathrm{Au}-5 \mathrm{Pd}-2 \mathrm{Ni}$ braze, was a significant contribution to the project.

Edmund Dunn, formerly the principal investigator of the project at GTEL, is acknowledged for his leadership and scientific roles in this project.

The participation in the experimental program by Danicl Bazinet and Glenn McCloud is gratefully acknowledged. Assistance from Stove Wayne, Milton Downey, Jody Harris, Jesse Hefter, George Werber, Hida Scarles, and Kathy Bailey is much appreciated. 


\section{REFERENCES}

1) R.T.Shield, "The Plastic Indentation of a Plastic Layer by a Flat Punch," Quarterly of Applied Mathematics", XIII [1], p. 27-46, (1955).

2) A.P.Green, "The Plastic Yiclding of Mctal Junctions due to Combined Shear and Pressure," J. Mech. Phys. Solids, 2, p.197-211, (1954).

3) J. Dundurs, "Discussion of Bogy's 1968 paper,"J. Applied Mechanics, 36, p. 650-651, (1969).

4) K. Suganuma, T, Okamoto, and K. Kamachi, "Influence of shape and size on residual stress in ceramic/metal joining", J. Materials Science, 22 , p. $2702-2706$ (1987).

5) B.J. Dalgleish, M.C. Lu, and A.G. Evans, "The Strength of Ceramics Bonded with Metals", Acta Mctall., 36 [8], p. 2029-2035 (1988)

6) H.P. Kirchner, J. C. Conway, Jr., and A.E. Segall, "Effect of Joint Thickness and Residual Stresses on the Properties of Ceramic Adhesive Joints: I, Finite Element Analysis of Stresses in Joints", J. American Ceramic Society, 70 [2], p. $104-109$ (1987).

7) W.A. Zdaniewski, J. C. Conway, Jr, and H.P. Kirchner "Effect of Joint Thickness and Residual Stresses on the Properties of Ceramic Adhesive Joints: I, Experimental Results", J. American Ceramic Society, 70 [2], p. $110-118$ (1987).

8) F. Delannay, L. Froyen, and A. Deruyttere, "Review: The wetting of solids by molted metals and its relation to the preparation of metal-matrix composites", J. Matcrials Science, 22, p. 1-16 (1987).

9) R.E. Lochman and A. P. Tomsia, "Joining of Ceramics", American Ceramic Socicty Bulletin, 67 [2], p. 375-380 (1989).

10) $H$. John and $H$. Hausner, "Influence of oxygen partial pressure on the

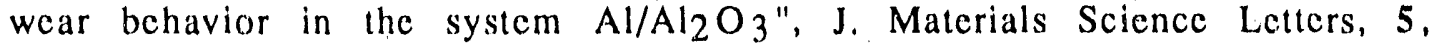
p. 549-551 (1986).

11) F.G. Yost and A.D. Romig, Jr., "Thermodynamics of Wetting by Liquid Mctals," Matcrials Research Society Proceedings, 108, p. 385-390, (1988).

12) J. Ferrante, J.R. Smith, and J. Rose, "Universal Binding Energy Relations in Mctallic Adhesion," Materials Research Society Proccedings, 40, p. 351358, (1985).

13) R.E. Lochman, "Joining and Bonding Mechanisms in Nitrogen Ceramics", Matcrials Rescarch Socicty Procecdings, Editor I. Iwmoto and T. Suga, to be published, conference held in Tokyo, Japan, June 1988. 
14) R. E. Lochman, Ceramic Bulletin, "Interfacial Reaclions in Coramic-Motal Syslems," 68 14], p. $891-896$ (1989).

15) Y. Ikuhara, M. Kobayashi and H, Yoshinaga, "Ioining of Roaction Bonded $\mathrm{Si}_{3} \mathrm{~N}_{4}$ Using Al," Yogyo-Kyokai-Shi, 95 191, p, 921-28 (1987).

16) K. Suganuma, T, Okamoto, M, Koizumi, and M. Shimada, "Effect of Thickness on Direct Bonding of Silicon Nitride (o) Stecl," J. American Ceramic Socicty, 68, p. C-334 - C335, (1985).

17) K. Suganuma, T, Okamoto, M. Koimumi, and M, Shimada, "Efrects of Interlayers in Ceramic-Metal Joinls wilh Thermal Expansion Mismatches," J. American Ceramic Socicly, 67, p. C-256 - C257, (1984),

18) K. Suganuma, T, Okamoto, M. Koizumi, and M. Shimada, "Effect of Thickness on Direct, Bonding of Silicon Nilride (o) Slcel", J. American Ceramic Socicty, 68, p. C-334-C335 (198.5)

19) K. Suganuma, T. Okamoto, M. Koizumi and M. Shimada. "Now Mothod for Solid-State Bonding between Ceramics and Metals,"J. American Ceramic Socicty, 66 17.], p. C-117-C-118 (1983).

20) M. G. Nicholas and R. M. Crispin. "Diffusion Bonding Stainless Stecl to Alumina Using Aluminum Interlayers,"J, Malcrials Science, 17, p. 33473360 (1982).

21) K. Suganuma, T, Okamoto, M. Koizumi and M. Shimada. "Joining of silicon Nitride 10 Silicon Nitride and to lnvar Alloy Using an Aluminum Interlayer," J. Materials Science, 22, p. 1359)-1364 (1987).

22) M. Ito, N. lshida and N. Kato, "Development of Brazing Technology for Ceramic Turbocharger Rotors," Proce of International Congress and Exposition, Detroit, Michigan, p. 55-63, Feb. 29 (1988)

2.3) H.P. Kirchner, J. C. Conway, Jr., and A.E. Segall, "Elfect of Joint Thickness and Residual Stresses on the Properlies of Ceramic Adhesive Joints: I, Finite Element Analysis of Stresses in Joints", J. American Ceramic Socicty, 70 121, p. 104-109 (1987).

24) H.C. Cao, M.D. Thouless, and A.G. Evans, "Residual Stresses and Cracking in Britle Solids Bonded with a Thin Ductile Layer". Acta Melall., 36 |8|, p. $2037-2046$ (1988).

25) M. Ito, N. Ishida, and N. Kato, "Development of Brazing Technology for Ceramic Turbocharger Rotors, "SAE International Congress and Exp., Automotive Ceramics(P-207), p. 55-63 Delroit, Mi March (1988).

26) M. Sakai and K. Watanabe, "Effect of Pre-Trealmont and Annealing Temperature on the strength of SiC-Ni Monolilament Composites", J. Materials Science, 19, p. 3430-3436 (1984). 
27) A.J. Moorhead, H.M. Henson, and T.J. Henson, "The Role of Interfacial Reactions on the Mechanical Properties of Ceramics Brazements", in Ceramic Microstructures 86 Role of Interfaces, Edited by J.A. Pask and A.G. Evans, Plenum Press, p. $949-958$ (1986).

28) R.R. Kapoor and T.W. Eagar, "Oxidation Bchavior of Silver- and CopperBased Brazing Filler Metals for Silicon Nitride/Metal Joints", J. American Ceramic Society, 72 [3], p. 448-454 (1989).

29) M. Naka, I. Okamoto, and Y. Arata, "Joining Mechanism of Ceramics to Metals Using an Amorphous T:tanium-based Filler Metal", Materials Science and Enginecring, 98, p. 407-410 (1988).

30) M. Santella, "Brazing of Titanium-Vapor-Coated Silicon Nitride", Advanced Ceramic Materials, 3 [5], p. 457-462 (1988).

31) J. K. Boadi, T, Yano, and T. Iscki, "Brazing of pressureless-sintered SiC using Ag-Cu-Ti alloy", J. Materials Science, 22 2431-2434 (1987).

32) A. J. Moorhead, "Direct Brazing of Alumina Ceramics", Advanced Ceramic Maicrials, 2 [21, p. 159-166 (1987).

33) R.R. Kapoor and T.W. Eagar, "Oxidation Bchavior of Silver- and CopperBased Brazing Filler Metals for Silicon Nitride/Metal Joints," J. American Ceramic Socicty, 72 [3], p. 448-454, (1989). 


\section{PUBLICATIONS}

1) "Issues in Ceramic-to-Metal Joining: An Investigation of Brazing a Silicon Nitride-Based Ceramic to a Low-Expansion Supcralloy," American Ceramic Society Bulletin, 68 [9] p. 1608-1617 (1989).

2) "An Investigation of Brazing Lanthana-Strenghthened Yltria Infrared Dome and Window Material to Mctal," Proc, of SPIE Conference on Window and Dome Technologies and Materials, Orlando, FL, March 27-31, p. 47-57 (1989).

3) "Analytical and Experimental Evaluation of Joining Silicon Nitride to Metal and Silicon Carbide to Metal," Procecdings of the 26th Automotive Technology Development Contract Coordination Mecting, Dearborn, MI, October 24-27, p. ${ }^{1} 65$ (1988).

\section{PATENTS}

1) "Method of Bonding a Ceramic Article to a Mctal Article," U. S. Patent $4,883,217$, November 28, 1989.

2) "Method of Brazing a Ceramic Article to a Metal Article," U. S. Patent $4,883,218$, November 28, 1989.

3) "Active Element Coatings for Silicon Nitride-Metal Joints," Four disclosures filed to U, S. Patent Office, 1989.

\section{PRESENTATIONS}

1) "Analytical and Experimental Evaluation of Joining Silicon Nitride to Metal and Silicon Carbide to Metal," at the 26 th Automotive Tech. Development Contract Coordination Mecting, Dearborn, MI, October 24-27, 1988.

2) "An Investigation of Brazing Lanthana-Strengthened Yttria Infrared Dome and Window Material to Metal," at SPIE Conference on Window and Dome Technologies and Materials, Orlando, FL, March 27-31, 1989.

3) "Reactive Coatings for Silicon Nitride-Incoloy 909 System Braze Joints," at the $91 \mathrm{st}$ Annual Mecting of the Amcrican Ceramic Socicly, Indianapolis, IN, April 24-27, 1989.

4) "Reactive Coatings for Silicon Carbide-Incoloy 909 System Braze Joints," at the $91 \mathrm{st}$ Annual Amcrican Ccramic Socicty Mecting, Indianapolis, IN, April 24-27, 1989. 
5) "The Effect of Titanium Coating on the Mechanical Propertics of Polycrystalline Alumina and Sapphire," at the 92 nd Annual American Ceramic Socicty Mecting, Dallas, TX, April 22-26, 1990.

6) "Microstructural Examination of Ccramic-Mctal Joints Brazed With Alloys Containing Palladium," at the $21 \mathrm{st}$ Amcrican Wolding Socicty International Brazing and Soldering Conference, Anaheim, CA, April 2326, 1990 . 

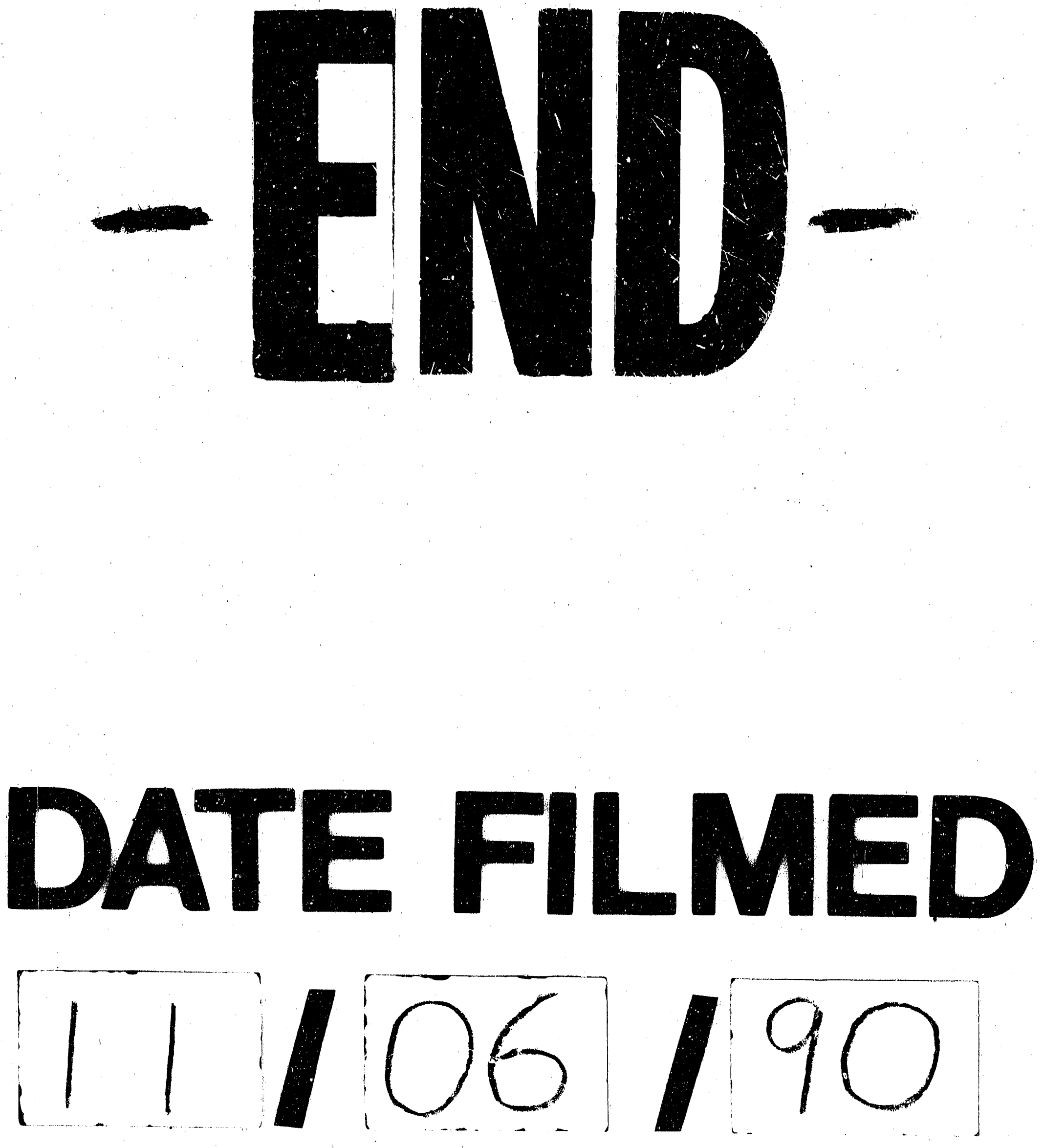
銅| 11 